\title{
Hydration and dehydration cycles in polymer electrolyte fuel cells operated with wet anode and dry cathode feed:
}

\section{A neutron imaging and modeling study}

\author{
P. A. García-Salaberri, ${ }^{1,2}$, D. G. Sánchez ${ }^{1,{ }^{*}}$, P. Boillat ${ }^{3,4}$, M. Vera ${ }^{2}$, K. A. Friedrich ${ }^{1}$ \\ 1 Institute of Engineering Thermodynamics, Deutsches Zentrum für Luft und Raumfahrt (DLR), 70569 \\ Stuttgart, Germany \\ 2 Departamento de Ingeniería Térmica y de Fluidos, Universidad Carlos III de Madrid, Leganés 28911, \\ Spain \\ 3 Electrochemistry Laboratory (LEC), Paul Scherrer Institut (PSI), 5232 Villigen, Switzerland \\ 4 Neutron Imaging and Activation Group (NIAG), Paul Scherrer Institut (PSI), 5232 Villigen, Switzerland \\ *Corresponding author: Tel.: +49 71168628071 ; fax: +49 7116862322 \\ E-mail: Daniel.GarciaSanchez@dlr.de (D. G. Sánchez)
}




\section{Abstract}

Proper water management plays an essential role in the performance and durability of Polymer Electrolyte Fuel Cells (PEFCs), but it is challenged by the variety of water transport phenomena that take place in these devices. Previous experimental work has shown the existence of fluctuations between low and high current density levels in PEFCs operated with wet hydrogen and dry air feed. The alternation between both performance states is accompanied by strong changes in the high frequency resistance suggesting a cyclic hydration and dehydration of the membrane. This peculiar scenario is examined here considering liquid water distributions from neutron imaging and predictions from a 3D two-phase nonisothermal model. The results show that the hydration-dehydration cycles are triggered by the periodic condensation and shedding of liquid water at the anode inlet. The liquid water input humidifies the anode channel and offsets the membrane dry-out induced by the dry cathode stream, thus leading to the high-performance state. When liquid water is flushed out of the anode channel, the dehydration process takes over, and the cell comes back to the lowperformance state. The predicted amplitude of the current oscillations grows with decreasing hydrogen and increasing air flow rates, in agreement with previous experimental data.

KEYWORDS: PEFC; water management; membrane; ionic resistance; hydration-dehydration; alternating performance states 


\section{Introduction}

Adequate water and thermal management is of vital importance to achieving improved performance and extended durability in Polymer Electrolyte Fuel Cells (PEFCs) [1-10]. Two opposite effects of the presence of water on PEFC operation can be distinguished. On one hand, a good hydration of the Proton Exchange Membrane (PEM) is necessary to maintain a low ionic resistance, and therefore a high cell performance [11,12]. A strong increase of the ionic conductivity of Perfluorosulfonic Acid (PFSA) membranes, such as Nafion ${ }^{\circledR}$, with water content has been widely reported in the literature (see, e.g., [11-14]). On the other hand, accumulation of liquid water should be avoided, because water flooding blocks reactant pathways towards the active catalyst sites, thus limiting the maximum power output [15-17]. Hence, a careful control of the Relative Humidity $(\mathrm{RH})$ of the feed streams and of the operating temperature of the cell is crucial to find an optimal balance [18-20]. This endeavor is further complicated by the wide variety of water transport phenomena that occur in PEFCs, including among others: i) diffusion, electro-osmotic drag, thermo-osmotic transport and convection of liquid water in the membrane $[12,21-23]$; ii) water production by the oxygen reduction reaction $[24,25]$; iii) water sorption and desorption in the Catalyst Layers (CLs) $[23,26,27]$; iv) two-phase flow in the mini-channels grooved on the Bipolar Plates (BPPs) [28]; v) capillary transport, and evaporation/condensation of liquid water in the Membrane Electrode Assembly (MEA) [29-31]; vi) two-phase interactions at the interface between the Gas Diffusion Layers (GDLs) and the flow channels [32-35]; and vii) convection and diffusion of water vapor under multiphase conditions, the latter governed by Fick's law or Maxwell-Stefan's equations and with a significant effect of Knudsen diffusion in the nanopores of the Microporous Layers (MPLs) and catalyst layers $[15,16,36-40]$.

A thorough understanding of the complex transport and electrochemical processes that occur in PEFCs from a combination of experimental and numerical research is therefore necessary to 
fully understand and optimize fuel cell performance [41]. Multiple diagnostic and visualization tools are currently available to explore cell operation [42,43], such as electrochemical impedance spectroscopy, cyclic voltammetry, segmented cells, neutron imaging and X-ray tomography (see, e.g., [15-19,31,44-47]). Significant advances have also been achieved in the characterization of the physicochemical properties of fuel cell components by both experimental and numerical methods $[15-17,35,48,49]$. As a complement to experimentation, numerical modeling is an essential tool to optimize cell design, and plays an important role for the study of multiphysics, multiphase and multiscale phenomena, which are difficult to explore experimentally due to the small characteristic dimensions of PEFCs $[15-17,50-56]$.

From a technical point of view, the operation of PEFCs with no external humidification is highly desirable in order to reduce the system complexity, weight, volume and cost, as well as to improve its efficiency and dynamical response [57-59]. Cells operated with low feed humidification rely on a delicate balance between water generated at the cathode and water removed by the gas streams to keep the membrane well hydrated. Multiple studies have addressed the operation of PEFCs with low humidification. One of the earliest works to consider the operation of a self-humidified PEFC was presented by Büchi and Srinivasan [57]. They showed stable operation of a dry-feed PEFC below $60^{\circ} \mathrm{C}$, with a $20-40 \%$ current density reduction at $0.6 \mathrm{~V}$ compared to a fully-humidified cell. Benziger et al. [59] studied the dynamics of an auto-humidified Stirred Tank Reactor (STR) PEFC, which was specially designed to ensure a uniform in-plane gas distribution. Different timescales were found in the cell dynamics due to sorption/desorption of water by the membrane, water transport through the membrane, and mechanical relaxation processes of the membrane. Kim et al. [60] reported an electrochemical analysis of a commercial PEFC operated at $60{ }^{\circ} \mathrm{C}$ with $80 \%$ anode relative humidity considering various humidification levels at the cathode. They observed that the electrochemical active area and double-layer capacitance were weakly dependent on the 
cathode $\mathrm{RH}$, and the catalyst layer and membrane ionic resistances were similar for dry-air feed. Adachi et al. [61] characterized ex-situ the water permeation flux through Nafion ${ }^{\circledR}$ NRE211 membranes exposed to either liquid and vapor phases of water, and examined in-situ the net water flux across the membrane in asymmetrically humidified cells. They found that the water flux in thin Nafion ${ }^{\circledR}$ membranes is larger when the membrane is exposed to liquid water on one side and water vapor on the other, and concluded that liquid-vapor permeation from cathode to anode can have a strong impact on the water balance of the MEA. Sánchez and García-Ybarra [62] studied the transients of a $25 \mathrm{~cm}^{2}$ cell equipped with single-serpentine channels after a sudden change from fully-humidified to non-humidified operating conditions. They observed the propagation of a drying front from the cathode inlet, which eventually led to the deactivation of the entire active area.

The literature cited so far serves to illustrate the complexities of PEFC operation, and, in particular, of water management under low humidification. On top of that, several works have also reported intricate nonlinear PEFC dynamics, including multiple steady states and oscillations. These works, which initially appeared to be atypical studies scattered in the literature, are nowadays the focus of several investigations, as is the case of this work. A deeper knowledge of the interplay between mass, charge and heat transport coupled to electrochemical kinetics in unusual scenarios will contribute to a better understanding of PEFC technology. According to Hanke-Rauschenbach et al. [63], three main phenomena leading to nonlinear PEFC dynamics can be distinguished: i) coupled water and proton transport in the membrane, ii) electrochemical surface kinetics, and iii) interaction between reactant mass transport and water two-phase flow $[18,19,64-75]$. Below we review some relevant contributions that have addressed PEFC dynamics induced by changes in membrane hydration under low feed humidification, i.e., belonging to point i) above. 
Focusing first on steady-state multiplicity, Moxley et al. [76] showed that various steady states may arise in auto-humidified STR PEFCs owing to the strong dependence of membrane ionic resistance on water content. In analogy to auto-thermal reactors [77], current ignitions and extinctions were found when the initial hydration of the membrane was, respectively, above and below a threshold value (water content per sulfonic acid group, $\lambda \approx 1.8 n_{\mathrm{H}_{2} \mathrm{O}} / \mathrm{SO}_{3}^{-}$). Current ignitions were caused by the good membrane hydration achieved from the positive (i.e., autocatalytic) feedback between water generation and membrane ionic conductivity. In contrast, current extinctions were caused by the dry-out of the membrane due to an insufficient initial water content. Hereafter, borrowing the terminology introduced by Benziger et al. [59] and Moxley et al. [76], the transitions from low to high and from high to low performance states will be referred to as ignition and extinction processes. In a second step, Benziger et al. [78] reported new findings on the bi-stable behavior found in [76] by examining the transients of the auto-humidified STR PEFC at different cell loads and temperatures. At temperatures above $70{ }^{\circ} \mathrm{C}$ and intermediate loads, they found the coexistence of two stable ignited states due to variations in the hydration level of the membrane, whereas a single steady state existed at either low or high loads. Chia et al. [79] presented a lumped isothermal single-phase steady-state model of an auto-humidified STR PEFC to study the effect of membrane ionic resistance, cell temperature, and hydrogen and air flow rates on the multiplicity of steady-state solutions. The bifurcation analysis showed the existence of up to five steady states for certain operating conditions. Nazarov and Promislow [80] developed a 2D isothermal single-phase transient model that captured the slow dynamics in an autohumidified STR PEFC. They showed that the bi-stability observed by Benziger et al. [78] at intermediate loads could be explained by the effect of lateral water diffusion in the membrane. 
Turning now the attention to oscillatory behavior, Benziger et al. $[59,78]$ reported autonomous current oscillations with an extremely long period of up to $3 \mathrm{~h}$ after continuous operation of an auto-humidified STR PEFC for over $5000 \mathrm{~h}$. They attributed this effect to the periodic relaxation of the membrane and the variation of the ohmic resistance at the membrane/electrode interface. Atkins et al. [64] also found spontaneous current oscillations in a PEFC operated with low anode and cathode humidification. They ascribed the oscillations to fluctuations of the membrane resistance due to the periodic hydration and dehydration of the anode side of the MEA. More recently, Sánchez et al. $[18,19]$ reported the existence of spontaneous current fluctuations in PEFCs operated with saturated anode $\left(\mathrm{RH}_{\mathrm{a}}^{\mathrm{in}} \geq 100 \%\right)$ and dry cathode $\left(\mathrm{RH}_{\mathrm{c}}^{\mathrm{in}} \approx 2-7 \%\right)$ feed. The current output oscillated between low- and high-performance levels accompanied by strong variations of the high-frequency resistance. The current distributions measured in a segmented cell revealed that the transition to the highperformance state was associated with the propagation of a hydration (or ignition) front along the anode channel. The ignition time remained almost constant, around $20-25 \mathrm{~s}$, regardless of the tested operating conditions. By contrast, the transition to the low-performance state was associated with the propagation of a dehydration (or extinction) front along the cathode channel; the extinction time was longer than the ignition time $(\sim 100 \mathrm{~s})$ and far more sensitive to the operating conditions. The authors attributed the cyclic membrane hydration and dehydration to the formation of an intermittent reservoir of liquid water in the anode, even though several aspects remained unclear. On one hand, the transient reservoir of liquid water was speculated to be located within the cell active area due to the strong variation of the membrane transport properties when it is in contact or not with liquid water, but this point was not confirmed in-situ [18]. On the other hand, forced convection of liquid water from the channel towards the membrane was assumed to be the main transport mechanism leading to membrane hydration [19]. However, such transport mechanism has been widely disregarded 
in the literature given the hydrophobic character and small pore structure of carbon paper GDLs compared to millimeter-sized flow channels $[3,6,24,33,81,82]$

This paper continues the research activity started by Sánchez et al. $[18,19]$ on hydrationdehydration cycles in PEFCs operated with asymmetric humidification. Specifically, the aim of the present work is two-fold:

1. To clarify the origin of the hydration-dehydration cycles that lead to spontaneous current oscillations. To this end, neutron imaging experiments were performed to visualize the liquid water distributions during the transitions between the low- and high-performance states.

2. To analyze the transport phenomena that take place in the cell during the hydrationdehydration cycles. To this end, a novel 3D non-isothermal two-phase steady-state macroscopic model was developed to examine the main features of the low- and highperformance states.

The structure of the paper is as follows. The cell fixture and the experimental setup are described in Section 2. The mathematical model is presented in Section 3. The experimental and numerical results are discussed in Section 4. And, finally, the concluding remarks are given in Section 5.

\section{Experimental}

Experiments were performed at PSI (Paul Scherrer Institut, Switzerland) using a cell designed at DLR (Deutsches Zentrum für Luft und Raumfahrt, Germany). Neutron radiograms were collected to visualize the liquid water distributions in the cell during the hydration-dehydration 
cycles $[18,19]$. Simultaneously, relevant operational parameters were monitored. The collected parameters included the cell current, voltage, High-Frequency Resistance (HFR), backpressures, flow rates, temperatures of the anode and cathode end plates, and dew point of the feed streams. In this work, we shall only report the current, HFR, and dew point temperature, since the remaining variables do not provide additional information.

\subsection{Cell hardware}

A cell with an active area of $5 \times 5 \mathrm{~cm}^{2}$ and single-serpentine flow fields was used for the experiments. The flow channels were grooved on gold-coated aluminum bipolar plates (Anticoroidal-112) including a total of 25 channel and 24 rib segments over the cell active area. Both the rib and square channel widths were equal to $1 \mathrm{~mm}$. The MEA featured MPL-coated SIGRACET $^{\circledR}$ 25BC GDLs with a 5\% PTFE by weight [83], and a commercial catalyst-coated membrane with $0.3 \mathrm{mg}_{\mathrm{Pt}} \mathrm{cm}^{-2}$ loading in both electrodes (Ion Power Inc., USA). Two membrane materials were tested, Nafion ${ }^{\circledR} 111\left(\delta_{\text {mem }} \approx 28 \mu \mathrm{m}\right)$ and Nafion ${ }^{\circledR} 117\left(\delta_{\text {mem }} \approx 175 \mu \mathrm{m}\right)$.

\subsection{Test bench and imaging setup}

Neutron imaging measurements were carried out in the ICON46 beamline at PSI [84]. The test bench was equipped with Programmable Logic Controllers (PLCS) and commercial electronic loads (Agilent Technologies, USA), which allowed automatic control of the cell operating conditions. The external humidification was supplied to the gases through Controlled Evaporator Mixers (CEM-Bronkhorst), while the cell temperature was controlled by a heater connected with a thermocouple in a closed-loop configuration. The electronic load could be operated in either galvanostatic (constant-current) or potentiostatic (constant-voltage) modes, although only potentiostatic operation was used here. In addition, ohmic losses were analyzed by measuring the cell HFR at $5 \mathrm{kHz}$. The HFR provides a direct indicator of the ionic resistance of the membrane and catalyst layers given the usually dominant role of ionic transport over electron transport on cell ohmic losses. 
Neutron radiograms were taken in two configurations, in-plane and through-plane directions, corresponding to side and top views of the cell water thickness. Nafion ${ }^{\circledR} 117$ was used for the in-plane experiments, and Nafion ${ }^{\circledR} 111$ for the through-plane experiments. The chosen setup used a detector in a tilted position, with an angle of $10^{\circ}$ between the detector surface and the beam axis $[85,86]$. This setup allowed a spatial resolution of approximately 55 pixels $/ \mathrm{mm}$. A scintillator screen made of ${ }^{6} \mathrm{LiF}$ and $\mathrm{ZnS}$ was employed to convert the neutrons into visible light, which was then acquired using a Charge Coupled Device (CCD) camera (Ikon-L, Andor, USA). The exposure time was 4 seconds per image, and the necessary read out time of the detector was 1 second, resulting in an acquisition rate of approximately 1 image every 5 seconds. The large size of the cell in the beam direction $\left(L_{\mathrm{ch}} \approx 5 \mathrm{~cm}\right)$ precluded the in-plane visualization of the water distribution inside the MEA, leading to completely noisy images in this region. Nevertheless, the images from the in-plane experiments enabled us to differentiate the liquid water present in the anode and cathode channels, and will be used in this section to illustrate the operating scenario at hand. The images from the through-plane experiments, which offered a good visualization of the cell water distribution, will be discussed in Section 4. The local water thickness was determined from the relative neutron transmission, $I / I_{0}$, by inverting the Lambert-Beer law [45]:

$$
\delta_{\mathrm{lw}}=\frac{-\log \left(I / I_{0}\right)}{\Sigma}
$$

where $I$ is the pixel intensity in the current image, $I_{0}$ is the pixel intensity in the reference image of the dry cell prior to the experiments, and $\Sigma$ is the attenuation coefficient of neutrons in liquid water with a value of $0.45 \mathrm{~mm}^{-1}$ for the given setup. 
Additional experiments were also conducted at DLR with a cell similar to the one tested at PSI in order to track the evolution of the outlet relative humidity in the anode channel. The measurements were carried out using a real-time relative humidity sensor (Landtec via laser sensor HS-1000, USA).

\subsection{Operating conditions}

The operating conditions used in the experiments and in the baseline case of the simulation campaign (Section 3) are listed in Table 1. The operating conditions were established at a cell voltage $V_{\text {cell }}=0.6 \mathrm{~V}$, operating temperature $T_{\text {cell }}=T_{\mathrm{a}}^{\text {in }}=T_{\mathrm{c}}^{\text {in }}=80^{\circ} \mathrm{C}$, and back-pressures $p_{\mathrm{a}}^{\text {out }}=p_{\mathrm{c}}^{\text {out }}=1.5$ bar. Hydrogen and air were supplied in counter-flow configuration at a flow rate $Q_{\mathrm{H}_{2}}=200 \mathrm{sccm}$ and $Q_{\text {air }}=1100 \mathrm{sccm}$ (ref. cond.: $T=0{ }^{\circ} \mathrm{C}, p=1 \mathrm{~atm}$ ), respectively. The corresponding stoichiometric ratios are equal to $\xi_{\mathrm{a}}=\rho_{\mathrm{H}_{2}}^{\mathrm{std}} Q_{\mathrm{H}_{2}} 2 F /\left(A_{\mathrm{cl}} I^{\text {ref }}\right)=1.4$ and $\xi_{\mathrm{c}}=\rho_{\mathrm{O}_{2}}^{\mathrm{std}} Q_{\mathrm{air}} X_{\mathrm{O}_{2, \text { air }}} 4 F /\left(A_{\mathrm{cl}} I^{\mathrm{ref}}\right)=3.3 \quad$ at $\quad I^{\mathrm{ref}}=0.8 \mathrm{~A} \mathrm{~cm}^{-2}, \quad$ where $\quad \rho_{\mathrm{H}_{2}}^{\mathrm{std}}=8.988 \times$ $10^{-2} \mathrm{~kg} \mathrm{~m}^{-3}, \rho_{\mathrm{O}_{2}}^{\text {std }}=1.429 \mathrm{~kg} \mathrm{~m}^{-3}$ and $X_{\mathrm{O}_{2, \text { air }}}=0.21$. Note that the flow rates of the humidified gases at the channel inlets are related to the hydrogen and air flow rates supplied to the test station by $Q_{\mathrm{a}}^{\mathrm{in}}=\rho_{\mathrm{H}_{2}}^{\mathrm{std}} Q_{\mathrm{H}_{2}} /\left(\rho_{\mathrm{g}, \mathrm{a}}^{\mathrm{in}} Y_{\mathrm{H}_{2}}^{\mathrm{in}}\right)$ and $Q_{\mathrm{c}}^{\mathrm{in}}=\rho_{\mathrm{O}_{2}}^{\mathrm{std}} Q_{\mathrm{air}} X_{\mathrm{O}_{2, \mathrm{air}}} /\left(\rho_{\mathrm{g}, \mathrm{c}}^{\mathrm{in}} Y_{\mathrm{O}_{2}}^{\mathrm{in}}\right)$; the mass flow rates of hydrogen and air remains unaltered during the humidification process. The above stoichiometries avoided a significant effect of mass-transport losses on cell performance, as in the previous experimental work of Sánchez et al. [18,19].

The inlet relative humidity was varied during the experiments as detailed below. First, the cell was pre-operated with fully-humidified gases $\left(\mathrm{RH}_{\mathrm{a}}^{\mathrm{in}}=\mathrm{RH}_{\mathrm{c}}^{\mathrm{in}} \approx 100 \%\right)$ by setting the dew point of the humidifiers at $80{ }^{\circ} \mathrm{C}$ until a stable current density was reached. Then, the external cathode humidification was switched off. Thereafter, the cell was operated with fullyhumidified anode $\left(\mathrm{RH}_{\mathrm{a}}^{\mathrm{in}} \approx 100 \%\right)$ and dry cathode $\left(\mathrm{RH}_{\mathrm{c}}^{\mathrm{in}} \approx 6 \%\right)$ feed, conditions which led to 
spontaneous current fluctuations in previous works $[18,19]$. The supplementary material includes videos showing the simultaneous evolution of the cell water distribution and current density recorded in different experiments. As seen in Figure 1, the cell response oscillated between low- and high-performance states, showing strong changes in the current density and high-frequency resistance. In particular, the neutron visualizations showed that the hydrationdehydration cycles were triggered by the periodic condensation of liquid water at the anode inlet and the subsequent shedding of water blobs into the anode channel. No liquid water was found, however, in the cathode channel. Specifically, water condensation took place in the anode inlet chamber, that is, the conical hollow machined in the bipolar plate that connects the hydrogen supply pipe with the anode flow field. Although the tubings connecting the humidifiers and the inlet of the cell were heated, water condensation was observed even at a specified feed dew point of $77{ }^{\circ} \mathrm{C}\left(3{ }^{\circ} \mathrm{C}\right.$ below the cell temperature). In principle, the condensation of water can be ascribed to an inadequate thermal insulation of the $90^{\circ}$ elbow located at the entrance of the anode inlet chamber and/or an improper design of the inlet chamber. Note that water condensation was also observed at both the anode and cathode inlets during the pre-operation of the cell at full humidification, but in this case the effect of water condensation on the current output was indiscernible due to the good hydration of the membrane.

\begin{tabular}{|c|c|c|}
\hline Parameter & Symbol & Value \\
\hline \multicolumn{3}{|l|}{ Geometrical parameters } \\
\hline Rib width & $w_{\text {rib }}$ & $1 \mathrm{~mm}$ \\
\hline Channel width & $w_{\mathrm{ch}}$ & $1 \mathrm{~mm}$ \\
\hline Outer frame width & $w_{\mathrm{fr}}$ & $1 \mathrm{~mm}$ \\
\hline Channel height & $H_{\mathrm{ch}}$ & $1 \mathrm{~mm}$ \\
\hline Bipolar plate height & $H_{\mathrm{bpp}}$ & $5 \mathrm{~mm}$ \\
\hline GDL thickness (SIGRACET ${ }^{\circledR}$ 25BC) & $\delta_{\mathrm{gdl}}$ & $200 \mu \mathrm{m}[83,87]$ \\
\hline MPL thickness (SIGRACET ${ }^{\circledR}$ 25BC) & $\delta_{\mathrm{mpl}}$ & $30 \mu \mathrm{m}[83,87,88]$ \\
\hline CL thickness (Ion Power Inc.) & $\delta_{\mathrm{cl}}$ & $10 \mu \mathrm{m}[89-91]$ \\
\hline PEM thickness & $\delta_{\text {mem }}$ & $28 \mu \mathrm{m}[90,92]$ \\
\hline Channel and rib length & $L_{\mathrm{ch}}$ & $4.8 \mathrm{~cm}$ \\
\hline Outer frame length & $L_{\mathrm{fr}}$ & $1 \mathrm{~mm}$ \\
\hline \multicolumn{3}{|l|}{ Operational parameters } \\
\hline Flow configuration & \multicolumn{2}{|c|}{ counterflow } \\
\hline Cell voltage & $V_{\text {cell }}$ & $0.6 \mathrm{~V}$ \\
\hline Cell temperature & $T_{\text {cell }}$ & $80^{\circ} \mathrm{C}$ \\
\hline Anode inlet temperature & $T_{\mathrm{a}}^{\mathrm{in}}$ & $80^{\circ} \mathrm{C}$ \\
\hline Cathode inlet temperature & $T_{\mathrm{C}}^{\text {in }}$ & $80^{\circ} \mathrm{C}$ \\
\hline
\end{tabular}




\begin{tabular}{|l|l|l|}
\hline Hydrogen feed flow rate & $Q_{\mathrm{H}_{2}}$ & $200 \mathrm{sccm}\left(\xi_{\mathrm{a}}=1.4 @ 0.8 \mathrm{~A} \mathrm{~cm}^{-2}\right)$ \\
\hline Air feed flow rate & $Q_{\mathrm{air}}$ & $1100 \mathrm{sccm}\left(\xi_{\mathrm{c}}=3.3 @ 0.8 \mathrm{~A} \mathrm{~cm}^{-2}\right)$ \\
\hline Anode back-pressure & $p_{\mathrm{a}}^{\text {out }}$ & $1.5 \mathrm{bar}$ \\
\hline Cathode back-pressure & $p_{\mathrm{c}}^{\text {out }}$ & $1.5 \mathrm{bar}$ \\
\hline Anode inlet $\mathrm{RH}$ & $\mathrm{RH}_{\mathrm{a}}^{\text {in }}$ & $1(100 \%)$ \\
\hline Cathode inlet $\mathrm{RH}$ & $\mathrm{RH}_{\mathrm{c}}^{\text {in }}$ & $0.06(6 \%)$ \\
\hline Anode inlet saturation & $\mathrm{s}_{\mathrm{ch}, \mathrm{a}}^{\text {in }}$ & $0 / 0.2($ low-/high-performance state) \\
\hline Cathode inlet saturation & $\mathrm{s}_{\mathrm{ch}, \mathrm{c}}^{\text {in }}$ & 0 \\
\hline
\end{tabular}

Table 1: Geometrical and baseline operational parameters. In the parametric study presented in Section 4.3,

the hydrogen and air feed flow rates vary between

$Q_{\mathrm{H}_{2}}=200-1600 \mathrm{sccm}\left(\xi_{a}=1.4-11.6 @ 0.8 \mathrm{~A} \mathrm{~cm}{ }^{-2}\right)$ and $Q_{\text {air }}=600-1200 \mathrm{sccm}\left(\xi_{\mathrm{c}}=1.8-3.6 @\right.$

$\left.0.8 \mathrm{~A} \mathrm{~cm}^{-2}\right)$

In-plane imaging (side view)

(a)

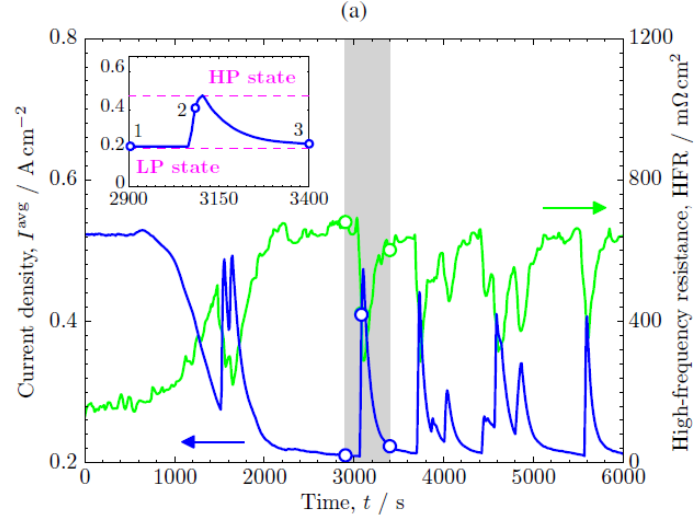

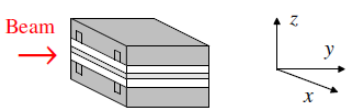

(b)
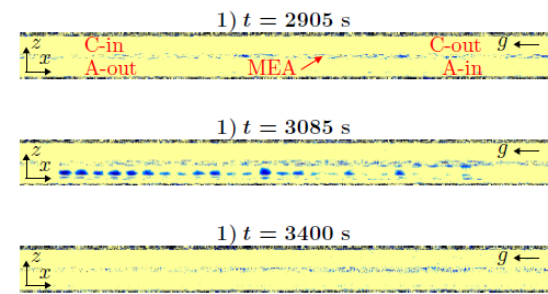

Liquid water thickness, $\delta_{\mathrm{lw}} / \mathrm{mm}$

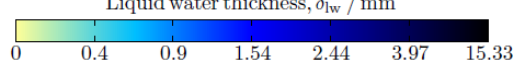

Figure 1: (a) Variation of the average current density, $I^{\text {avg }}$, and high-frequency resistance, HFR, as a function of time, $t$, after a change of the cathode stream from fully-humidified $\left(\mathrm{RH}_{\mathrm{c}}^{\mathrm{in}} \approx 100 \%\right)$ to non-humidified $\left(\mathrm{RH}_{\mathrm{c}}^{\mathrm{in}} \approx 6 \%\right)$ conditions, while keeping the anode stream fully humidified $\left(\mathrm{RH}_{\mathrm{a}}^{\mathrm{in}} \approx 100 \%\right)$. The initial decrease of the current density for $t<1200 \mathrm{~s}$ is caused by the decay of the water level in the cathode compartment. Current oscillations are then observed due to the periodic hydration and dehydration of the membrane. The data corresponding to the times shown in (b) are indicated by hollow dots. The inset shows a close-up view of the high- (HP) and lowperformance (LP) states achieved in the hydration-dehydration cycles. (b) Distributions of liquid water thickness, $\delta_{\mathrm{lw}}(x, z)$, from in-plane neutron imaging experiments (side view) at different times during a hydration-dehydration cycle, with indication of the MEA, channel inlets and outlets (C-in/out, A-in/out) and the direction of gravity $(g)$. The water thickness inside the MEA could not be visualize due to the large size of the cell in the beam direction, thus leading to noisy results in this region. Membrane material: Nafion ${ }^{\circledR} 117$.

\section{Macroscopic continuum modeling}


A 3D non-isothermal two-phase steady-state model was developed to investigate the low- and high-performance states observed in the hydration-dehydration cycles. The numerical model was implemented in the commercial finite-volume-based CFD code ANSYS ${ }^{\circledR}$ FLUENT, using its built-in parallel capabilities to reduce the computational time. Simulations were carried out on the supercomputing cluster of the Fluid Mechanics Research Group at University Carlos III of Madrid (Spain), varying the number of processors between 8 and 16 for the calculations. The model formulation can be found in Appendix A. As major features, the model accounts for non-equilibrium water sorption/desorption in the catalyst layers, as well as non-equilibrium water evaporation/condensation in the porous media of the MEA (GDLs, MPLs and CLs) and in the channels. The dominant transport mechanisms of dissolved water in the electrolyte are assumed to be diffusion and electro-osmotic drag; the effect of thermo-osmotic transport [22,93] and convection [21] is ignored. According to Bao and Bessler [94], the drop of the cathode reaction rate, $R R_{\mathrm{c}}$, when the activity of solvated protons is small [25] is modeled by introducing a multiplicative linear pre-factor equal to $a_{+}=\lambda / 2.5$ if $\lambda<2.5\left(a_{+}=1\right.$ if $\lambda \geq$ 2.5). In addition, the flow fields are treated as structured porous media following the work of Wang et al. [95] and Jiang and Wang [96]. This approach provides a more realistic description of the resistance exerted by liquid water on gas convection, and yields better results for the pressure drop along the channel. The model also considers the blockage of liquid water on Fickian diffusion and Darcian convection of the gas phase in the MEA, as well as the effect of effective anisotropic transport properties. Finally, the energy equation includes the reversible and irreversible heat generated by the electrochemical reactions, ohmic heating due to charge transport, and the latent heat released/absorbed by phase change of water (i.e., water sorption/desorption and condensation/evaporation).

\subsection{Geometry}


The geometry of the cell considered in the simulations is similar to that used in the experimental campaign. As depicted in Figure 2, the computational domain incorporated single-serpentine channels with straight U-turns (ach/cch) carved on the bipolar plates (abpp/cbpp), along with the seven layers comprising the MEA: anode and cathode catalyst layers (acl/ccl), MPLs (ampl/cmpl), GDL substrates (agdl/cgdl), and the central polymer membrane (mem). The geometrical dimensions are summarized in Table 1. The thicknesses of the GDL and MPL were equal to $\delta_{\mathrm{gdl}}=200 \mu \mathrm{m}$ and $\delta_{\mathrm{mpl}}=30 \mu \mathrm{m}$, respectively, so that the overall thickness of both porous media was similar to that of SIGRACET ${ }^{\circledast} 25 \mathrm{BC}\left(\delta_{\mathrm{gdl}+\mathrm{mpl}} \approx\right.$ $230 \mu \mathrm{m})[83,87,88]$. The catalyst layer thickness was set to $\delta_{\mathrm{cl}}=10 \mu \mathrm{m}$ as in previous works [89-91], while Nafion ${ }^{\circledR} 111$ with a swollen thickness $\delta_{\text {mem }}=28 \mu \mathrm{m}$ was used as membrane material $[90,92]$. The flow channels included a total of $49 \mathrm{rib} /$ channel segments with unit length $L_{\mathrm{ch}}=4.8 \mathrm{~cm}$; the channel and rib widths $\left(w_{\mathrm{ch}}, w_{\mathrm{rib}}\right)$ and the channel height $\left(H_{\mathrm{ch}}\right)$ were equal to $1 \mathrm{~mm}$. Finally, the flow channels were delimited with a solid frame of size $w_{\mathrm{fr}}=L_{\mathrm{fr}}=$ $1 \mathrm{~mm}$, and the height of the bipolar plates above the channels was fixed to $H_{\mathrm{bpp}}=5 \mathrm{~mm}$.

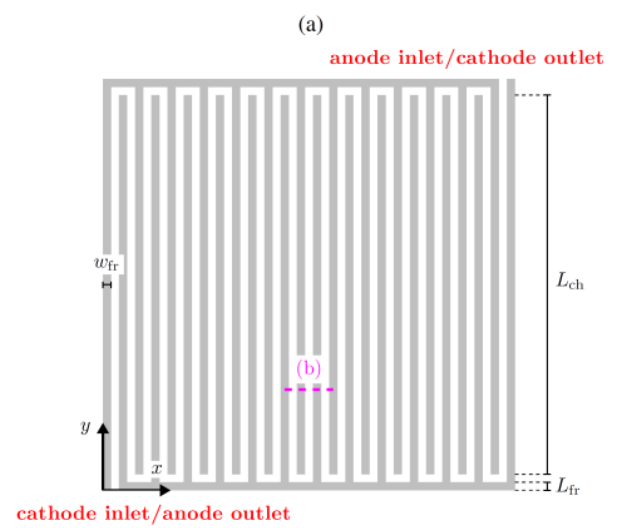

(b)

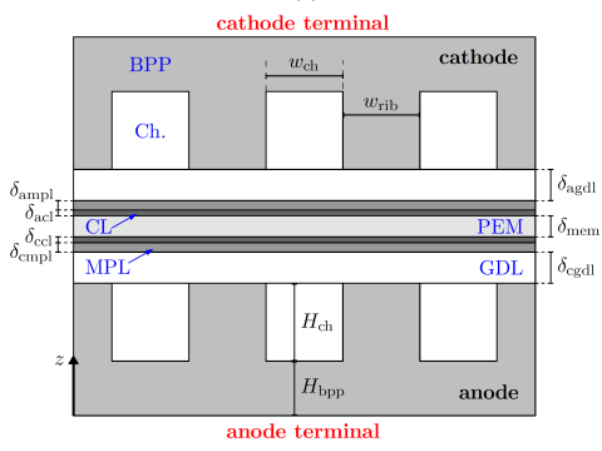


Figure 2: Schematic of the computational domain, showing the coordinate system, the anode and cathode terminals (see Section A.4), the channel inlets and outlets, the cell components (PEM, CLs, MPLs, GDLs, channels, and BPPs), and the notation used for the geometrical parameters (see Table 1): (a) top view of the single-serpentine flow field, and (b) detailed cross-sectional view of the MEA and the rib/channel pattern of the bipolar plates. Drawing dimensions in (b) are not to scale.

\subsection{Case studies: modeling of the low- and high-performance states}

The operating conditions of the baseline simulations were also similar to the experimental ones. These conditions, summarized in Table 1, will only be modified in Section 4.3, where a parametric study on the effect of the hydrogen and air flow rates is presented. In all the simulations, the two performance states of the hydration-dehydration cycles were reproduced by introducing or not introducing a steady flux of liquid water at the vapor-saturated anode inlet. As stated by Eq. (A.22), the mass flux of liquid water at the anode inlet is given by

$$
\left\|\boldsymbol{j}_{\mathrm{lw}, \mathbf{c h}, \mathbf{a}}^{\text {in }}\right\|=\rho_{\mathrm{lw}}^{\text {in }}\left\|\boldsymbol{u}_{\mathrm{lw}, \mathbf{c h}, \mathbf{a}}^{\mathrm{in}}\right\| s_{\mathrm{ch}, \mathrm{a}}^{\text {in }}
$$

where $\rho_{\mathrm{lw}}^{\mathrm{in}}$ and $\left\|\boldsymbol{u}_{\mathbf{l w}, \mathbf{c h}, \mathbf{a}}^{\mathrm{in}}\right\|$ are the density and velocity of liquid water, and $s_{\mathrm{ch}, \mathrm{a}}^{\mathrm{in}}$ is the inlet liquid saturation. Accordingly, when simulating the low-performance state $s_{\mathrm{ch}, \mathrm{a}}^{\mathrm{in}}$ was fixed to 0 , that is, the steady state if no liquid water would enter the anode channel $\left(\left\|\boldsymbol{j}_{\mathbf{l w}, \mathbf{c h}, \mathbf{a}}^{\text {in }}\right\|=0\right)$. On the contrary, $s_{\mathrm{ch}, \mathrm{a}}^{\mathrm{in}}$ was set larger than 0 in the simulations of the high-performance state $\left(\left\|\boldsymbol{j}_{\mathbf{l w}, \mathbf{c h}, \mathbf{a}}^{\mathrm{in}}\right\| \neq 0\right) ; s_{\mathrm{ch}, \mathrm{a}}^{\mathrm{in}}=0.2$ was assumed in the calculations. As seen in the supplementary videos, the residence time and dispersion of liquid water in the anode channel was found to vary with the amount of water introduced into the cell, so that high-amplitude oscillations were associated with cases in which the amount, dispersion and residence time of water in the anode channel were also higher. As a result, the quasi-steady-state approximation used here to model the high-performance state mimics the scenario found in high-amplitude oscillations, where high current densities prevail for a certain time $(\Delta t \approx 10 \mathrm{~s})$ before the dehydration 
process begins. This time may represent up to $25-30 \%$ of the residence time of water in the anode channel ( $\Delta t \approx 30-40 \mathrm{~s})$, thus showing that the cell approaches a quasi-steady state in which the amount of water sorbed by the membrane does not change appreciably by the presence of liquid water (see inset in Figure 3). The slowness of the dehydration process (compared to the hydration process) further supports the quasi-steady-state assumption as a reasonable first approximation to explore the main features of the high-performance state.

\section{Results and discussion}

\subsection{Experimental data (baseline case)}

We shall start the discussion by analyzing the results of the through-plane neutron imaging experiments. Figure 3(a) shows the time evolution of the current density and high-frequency resistance, while Figure $3(\mathrm{~b})$ shows the water distributions at specific times during a hydrationdehydration cycle. The subfigure in the frame displays the current density distributions during a hydration-dehydration cycle previously obtained in a segmented cell by Sánchez et al. [18]; see the figure caption for details concerning the operating conditions. As can be seen, the current fluctuations are perfectly correlated with the ups and downs of the high-frequency resistance, and with the shedding of liquid water at the anode inlet. The current oscillations occur with a period of about $400 \mathrm{~s}$, which is the time elapsed for the condensation and accumulation of liquid water in the anode inlet chamber $(\Delta t \approx 395 \mathrm{~s})$ and the eruption of water blobs into the anode channel ( $\Delta t \approx 5 \mathrm{~s})$. The amount of liquid water shed into the cell is equal to $m_{\mathrm{lw}}^{\mathrm{in}} \approx 40 \mathrm{mg}$, which is equivalent to the mass of water generated in $5 \mathrm{~s}$ by a $25 \mathrm{~cm}^{2}$ cell operated at a current density as high as $3.4 \mathrm{~A} \mathrm{~cm}^{-2}\left(I^{\text {avg }}=2 F m_{\mathrm{lw}}^{\mathrm{in}} /\left(M_{\mathrm{w}} A_{\mathrm{cl}} \Delta t\right)\right)$. Obviously, only a small portion of the water input is retained in the cell, whereas most of it leaves the cell flushed out by the hydrogen stream. The current raise (HFR drop) occurs with a delay of about 
$5 \mathrm{~s}$ from the entrance of liquid water owing to the time required by the membrane to absorb a noticeable amount of water and thus increase its ionic conductivity.

Two well-differentiated processes can be distinguished in the hydration-dehydration cycles. A fast autocatalytic increase of the current in 20-30 s that goes hand-in-hand with the transport of liquid water along the anode channel (i.e., current ignition). The dispersion of liquid water along the anode channel eventually leads to the high-performance state in which the entire anode channel is partially water-filled. As a result, a fairly homogeneous current density distribution is achieved in the cell, as shown by the results of Sánchez et al. [18] and the modeling results presented in forthcoming sections. Once the excess of liquid water, i.e., the amount of water introduced into the anode channel minus that accumulated in the cell, is flushed out of the channel, the current drops in $200-300$ s (i.e., current extinction). The membrane dehydration takes over from the dry cathode inlet and gradually propagates along the cathode channel, leading to a fairly inhomogeneous current density distribution in the lowperformance state [18]. The different time scales exhibited by the hydration and dehydration processes agree with those found in previous works (see, e.g., [97] and references therein). The slowness of the dehydration may be explained by the long time required by the membrane water content to fully stabilize with the local humidification of adjacent media. In contrast, the hydration is faster due to the autocatalytic rise of the water production rate after the membrane has sorbed a minimum amount of water [76]. 


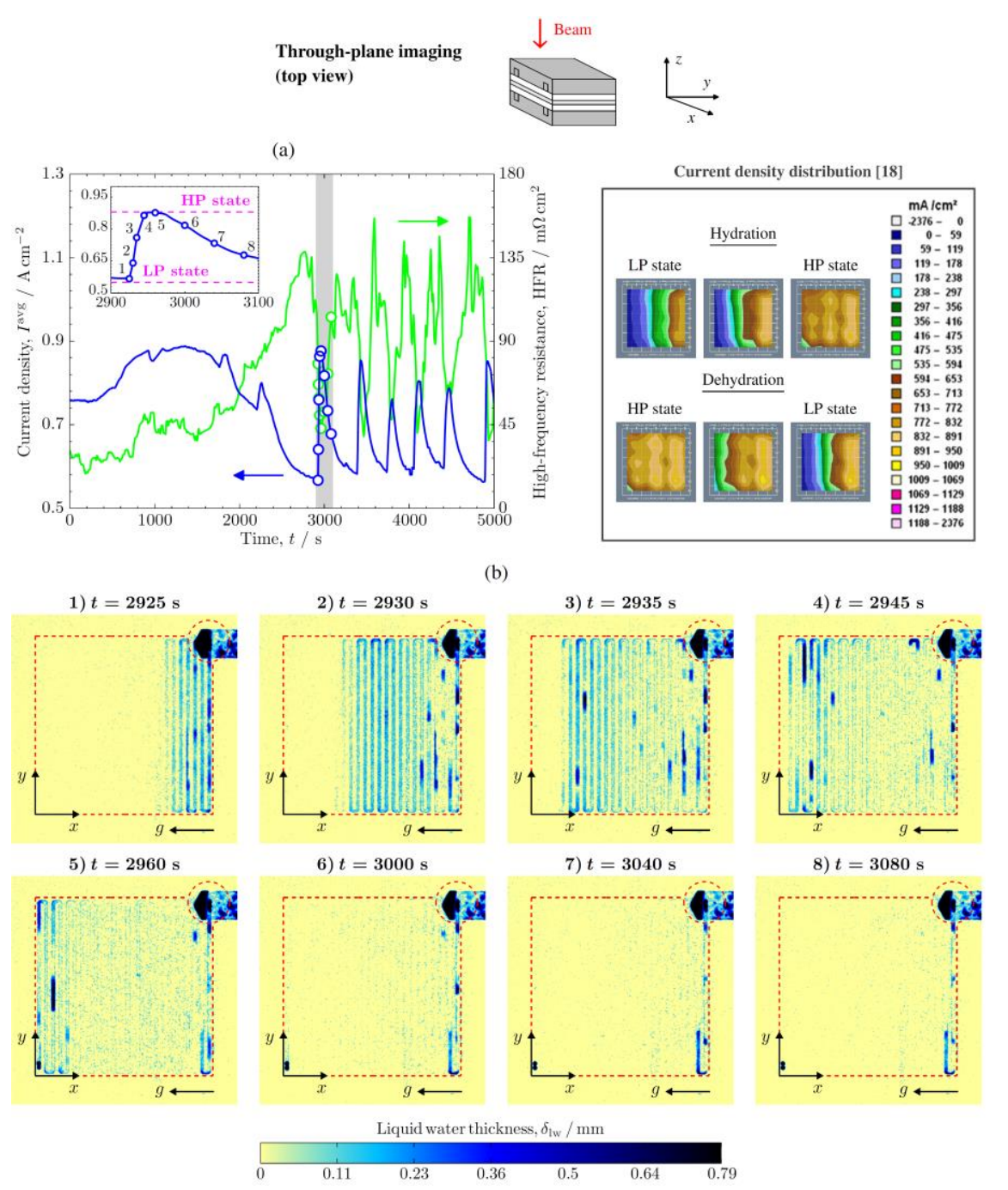

Figure 3: (a) Variation of the average current density, $I^{\text {avg }}$, and high-frequency resistance, HFR, as a function of time, $t$, after a change of the cathode stream from fully-humidified $\left(\mathrm{RH}_{\mathrm{c}}^{\mathrm{in}} \approx 100 \%\right)$ to non-humidified $\left(\mathrm{RH}_{\mathrm{c}}^{\mathrm{in}} \approx 6 \%\right)$ conditions, while keeping the anode stream fully humidified $\left(\mathrm{RH}_{\mathrm{a}}^{\mathrm{in}} \approx 100 \%\right)$. (b) Distributions of liquid water thickness, $\delta_{\mathrm{lw}}(x, y)$, from through-plane neutron imaging experiments (top view) at different times during a hydration-dehydration cycle, with indication of the direction of gravity $(g)$. The active area of the cell and the anode inlet chamber are indicated by red dashed lines; the cathode inlet is located at the diametrically opposite corner. Membrane material: Nafion ${ }^{\circledR} 111$. See caption to Figure 1 for further details. The subfigure in the frame shows the current density distributions during a hydration-dehydration cycle obtained in a segmented cell by Sánchez et al. [18] (op. conds. [18]: $V_{\text {cell }}=0.5 \mathrm{~V}, T_{\text {cell }}=70^{\circ} \mathrm{C}, Q_{\mathrm{H}_{2}}=200 \mathrm{sccm}\left(\xi_{\mathrm{a}} \approx 1.4\right), Q_{\mathrm{air}}=660 \mathrm{sccm}\left(\xi_{\mathrm{c}} \approx 2\right), p_{\mathrm{a}}^{\text {out }}=$ $p_{\mathrm{c}}^{\text {out }}=1.5$ bar, $\mathrm{RH}_{\mathrm{a}}^{\mathrm{in}} \approx 152 \%$ (condensing conditions), $\mathrm{RH}_{\mathrm{c}}^{\mathrm{in}} \approx 5 \%$ (dry air), $\mathrm{CL}$ with $0.3 \mathrm{mg}_{\mathrm{Pt}} \mathrm{cm}{ }^{-2}$ from lon Power Inc., Nafion ${ }^{\circledR}$ 111-IP, SIGRACET ${ }^{\circledR} 35$ BC).

\subsection{Numerical results (baseline case)}


The experimental results discussed above have shown that the hydration-dehydration cycles arise from the spontaneous condensation of liquid water at the anode inlet. However, no information has been provided about the transport processes that occur inside the cell. In this section, the effects of the input of liquid water are examined numerically by looking independently at the low- and high-performance states. Figure 4 shows from top to bottom the computed distributions of water saturation in the anode channel, $s_{\mathrm{ch}, \mathrm{a}}$, and of relative humidity in the anode and cathode channels and catalyst layers, $\mathrm{RH}_{\mathrm{ach} / \mathrm{acl}}$ and $\mathrm{RH}_{\mathrm{cch} / \mathrm{ccl}}$, corresponding to the low- and high-performance states. Figure 5 shows the distributions of current density, $I$, membrane ionic resistance and temperature, $R_{\text {mem }}$ and $T_{\mathrm{mem}}$, and water content in the anode and cathode catalyst layers, $\lambda_{\mathrm{acl} / \mathrm{ccl}}$. The 2D-distributions of variables $\Gamma_{\mathrm{i}}=s_{\mathrm{ch}, \mathrm{a}}, \mathrm{RH}_{\mathrm{ach} / \mathrm{acl}}, \mathrm{RH}_{\mathrm{cch} / \mathrm{ccl}}, T_{\mathrm{mem}}$ and $\lambda_{\mathrm{acl} / \mathrm{ccl}}$, as well as the 2D-distributions of current density and membrane ionic resistance, were calculated as:

$$
\begin{aligned}
& \Gamma_{\mathrm{i}}(x, y)=\frac{1}{\delta_{\mathrm{i}}} \int_{0}^{\delta_{\mathrm{i}}} \Gamma_{\mathrm{i}}(x, y, z) \mathrm{d} z, \quad I(x, y)=\int_{0}^{\delta_{\mathrm{icl}}} R R_{\mathrm{i}}(x, y, z) \mathrm{d} z, \\
& R_{\mathrm{mem}}(x, y)=\int_{0}^{\delta_{\mathrm{mem}}} \frac{\mathrm{d} z}{\sigma_{\mathrm{H}^{+}}^{\mathrm{eff}}(x, y, z)}
\end{aligned}
$$

where $\delta_{\mathrm{i}}$ is the thickness of the region of interest, $R R_{\mathrm{i}}(x, y, z)$ is the local reaction rate either at the anode $(\mathrm{i}=\mathrm{a})$ or cathode $(\mathrm{i}=\mathrm{c})$ catalyst layer, and $\sigma_{\mathrm{H}^{+}}^{\text {eff,tp }}(x, y, z)$ is the local throughplane ionic conductivity of the membrane. The mean value of each distribution is indicated in the different subplots.

As shown in the upper plot of Figure 4, in the low-performance state no liquid water is present in the anode channel, whereas in the high-performance state it partially fills the anode channel; the liquid saturation level is virtually equal to the inlet value $\left(\mathrm{s}_{\mathrm{ch}, \mathrm{a}, \mathrm{inps}}=0.2\right)$ due to the small amount of liquid water required to humidify the gas stream. In agreement with 
Sánchez et al. [19], the pressure drop along the anode channel, $\Delta p_{\mathrm{g}, \mathrm{ach}}$, increases from $0.96 \mathrm{kPa}$ to $1.44 \mathrm{kPa}$ during current ignitions due to the blockage exerted by liquid water on the hydrogen flow. In contrast, the cathode stream remains undersaturated in both performance states, as shown by the neutron visualizations (see, e.g., the absence of water in the cathode channel in Figure 1(b)). This result could have been anticipated by evaluating the water removal capacity of the air stream, $\dot{N}_{\mathrm{H}_{2} \mathrm{O}, \mathrm{c}}^{\mathrm{rc}} \approx Q_{\mathrm{c}}^{\mathrm{in}} C_{\mathrm{H}_{2} \mathrm{O}}^{\mathrm{sat}}\left(T_{\mathrm{c}}^{\mathrm{in}}\right) \approx 2.5 \times 10^{-4} \mathrm{~mol} \mathrm{~s}^{-1}$, which is $42 \%$ larger than the sum of the water vapor inflow at the anode, $\dot{N}_{\mathrm{H}_{2} \mathrm{O}, \mathrm{a}}^{\text {in }} \approx$ $Q_{\mathrm{a}}^{\mathrm{in}} C_{\mathrm{H}_{2} \mathrm{O}}^{\mathrm{sat}}\left(T_{\mathrm{a}}^{\mathrm{in}}\right) \approx 6.8 \times 10^{-5} \mathrm{~mol} \mathrm{~s}^{-1}$, plus the water production rate in the high-performance state, $\dot{N}_{\text {prod,hps }} \approx(I / 2 F) A_{\mathrm{cl}} \approx 1.1 \times 10^{-4} \mathrm{~mol} \mathrm{~s}^{-1}$ (i.e., $\dot{N}_{\mathrm{H}_{2} \mathrm{O}, \mathrm{c}}^{\mathrm{rc}} \approx 1.42\left(\dot{N}_{\mathrm{H}_{2} \mathrm{O}, \mathrm{a}}^{\mathrm{in}}+\dot{N}_{\text {prod,hps }}\right)$ ). Examining the RH distributions, shown in the middle and lower plots of Figure 4, it is seen that the evaporation of water fully humidifies the anode channel in the high-performance state $\left(\mathrm{RH}_{\text {ach,hps }}^{\text {avg }}=100 \%\right)$. The average relative humidity in the anode catalyst layer is somewhat lower $\left(\mathrm{RH}_{\mathrm{acl}, \mathrm{hps}}^{\mathrm{avg}}=89 \%\right)$ due to the higher temperature prevailing there and the net flux of water from anode to cathode. By contrast, in the low-performance state a decrease of the anode relative humidity is observed towards the cathode inlet due to the absence of the evaporation source term along the channel [98] $\left(\mathrm{RH}_{\mathrm{ach}, \mathrm{lps}}^{\mathrm{avg}}=75 \%, \mathrm{RH}_{\mathrm{acl}, \mathrm{lps}}^{\mathrm{avg}}=72 \%\right)$. The extra water supply during current ignitions, in turn, increases the relative humidity in the cathode channel from $\mathrm{RH}_{\mathrm{cch}, \mathrm{lps}}^{\mathrm{avg}}=23 \%$ to $\mathrm{RH}_{\mathrm{cch}, \mathrm{hps}}^{\mathrm{avg}}=40 \%$ (and in the cathode catalyst layer from $\mathrm{RH}_{\mathrm{ccl}, \mathrm{lps}}^{\mathrm{avg}}=32 \%$ to $\mathrm{RH}_{\mathrm{cch}, \mathrm{hps}}^{\mathrm{avg}}=53 \%$ ). It is worth noting that the full humidification of the anode channel was confirmed in experiments performed at DLR. As predicted by the model, the measurements showed a systematic saturation of the anode outflow during current ignitions. 

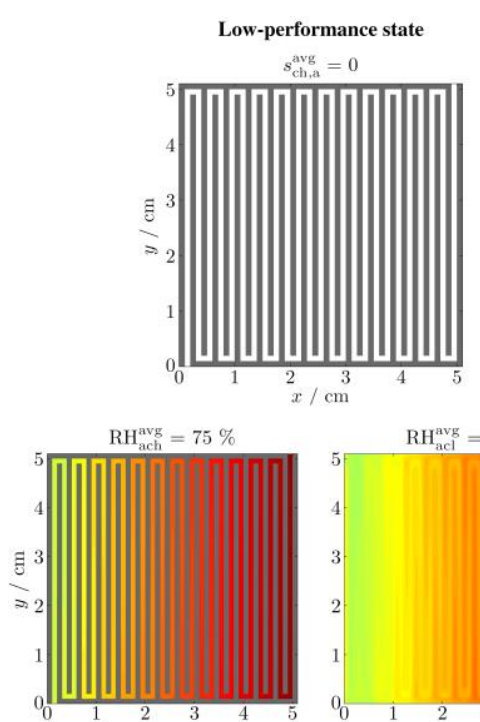

$\mathrm{RH}_{\mathrm{cch}}^{\mathrm{avg}}=23 \%$

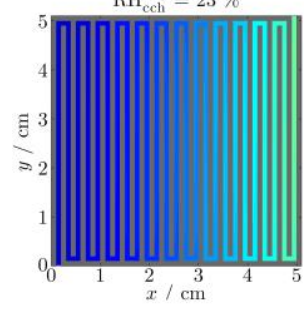

$\mathrm{RH}_{\mathrm{acl}}^{\mathrm{avg}}=72 \%$

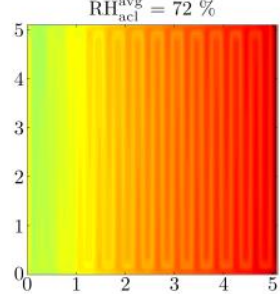

$\mathrm{RH}_{\mathrm{ccl}}^{\mathrm{avg}}=32 \%$

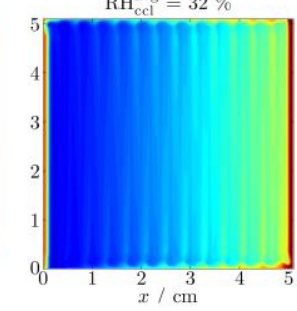

\begin{tabular}{llll}
\multicolumn{4}{c}{ Anode ch. sat., $s_{\mathrm{ch}, \mathrm{a}} /-$} \\
0.2 & 0.4 & 0.6 & 0.8
\end{tabular}
High-performance state

$s_{\mathrm{ch}, \mathrm{a}}^{\mathrm{avg}}=0.2$
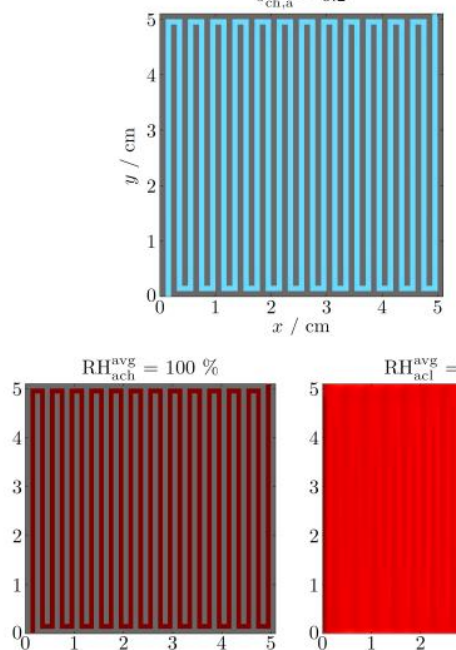

$\mathrm{RH}_{\mathrm{cch}}^{\mathrm{avg}}=40 \%$

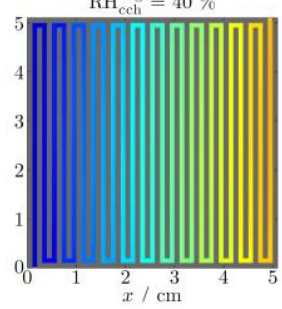

$\mathrm{RH} / \%$

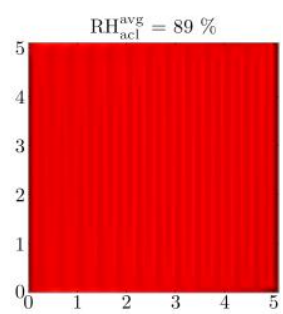

$\mathrm{RH}_{\mathrm{ccl}}^{\mathrm{avg}}=53 \%$

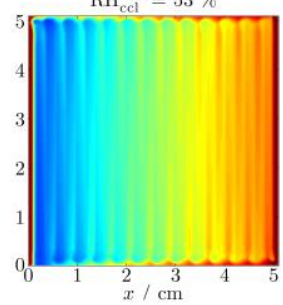

Figure 4: From top to bottom: computed distributions of liquid saturation in the anode channel, $s_{\text {ch,a }}(x, y)$, relative humidity in the anode channel and catalyst layer, $\operatorname{RH}_{\mathrm{ach}}(x, y)$ and $\mathrm{RH}_{\mathrm{acl}}(x, y)$, and relative humidity in the cathode channel and catalyst layer, $\mathrm{RH}_{\mathrm{cch}}(x, y)$ and $\mathrm{RH}_{\mathrm{ccl}}(x, y)$, corresponding to the low- (left) and high-performance (right) states of the hydration-dehydration cycles. The average value of the distributions is indicated at the top of each subplot. See Table 1 for details on the operating conditions.

Let us now focus on the results in terms of cell performance. As shown in the upper and middle plots of Figure 5, the membrane ionic resistance drops by a factor of 3.7 between the low- and high-performance states $\left(R_{\text {mem,lps }}^{\text {avg }}=211 \mathrm{~m} \Omega \mathrm{cm}^{2}\right.$ vs. $\left.R_{\text {mem,hps }}^{\text {avg }}=57 \mathrm{~m} \Omega \mathrm{cm}^{2}\right)$, resulting in an increase of the output current density from $I_{\mathrm{lps}}^{\mathrm{avg}}=0.55 \mathrm{~A} \mathrm{~cm}^{-2}$ to $I_{\mathrm{hps}}^{\mathrm{avg}}=$ $0.83 \mathrm{~A} \mathrm{~cm}^{-2}$; similar variations are found in the experimental data. These average results are accompanied by strong differences in the current density distributions. The low-performance state features a highly inhomogeneous current density distribution due to the sharp increase of the membrane ionic resistance towards the dry cathode inlet. By contrast, the highperformance state shows an almost homogeneous current density distribution due to the 
better humidification achieved throughout the cell, which offsets the dry-out induced by the air stream. The re-activation of the region near the cathode inlet also raises the local temperature there, so that the membrane temperature grows from $T_{\mathrm{mem}, \mathrm{lps}}^{\mathrm{avg}}=82.1^{\circ} \mathrm{C}$ to $T_{\text {mem,hps }}^{\text {avg }}=82.7^{\circ} \mathrm{C}$ [99]. At the rib-channel scale, higher current densities are found in the region under the rib due to the lower drying induced by the air stream [45]. Accordingly, as shown in the lower plot of Figure 5, higher membrane water contents prevail in the under-therib regions. This result agrees with the recent experimental data measured by Shrivastava and Tajiri [100] using a sub-millimeter segmented differential cell. Under dry operation (i.e., $\mathrm{RH}_{\mathrm{a}}^{\mathrm{in}}=50 \%, \mathrm{RH}_{\mathrm{c}}^{\mathrm{in}} \approx 0 \%$ ), they found that higher current densities are generated under the ribs due to the better membrane hydration achieved in this region [100].
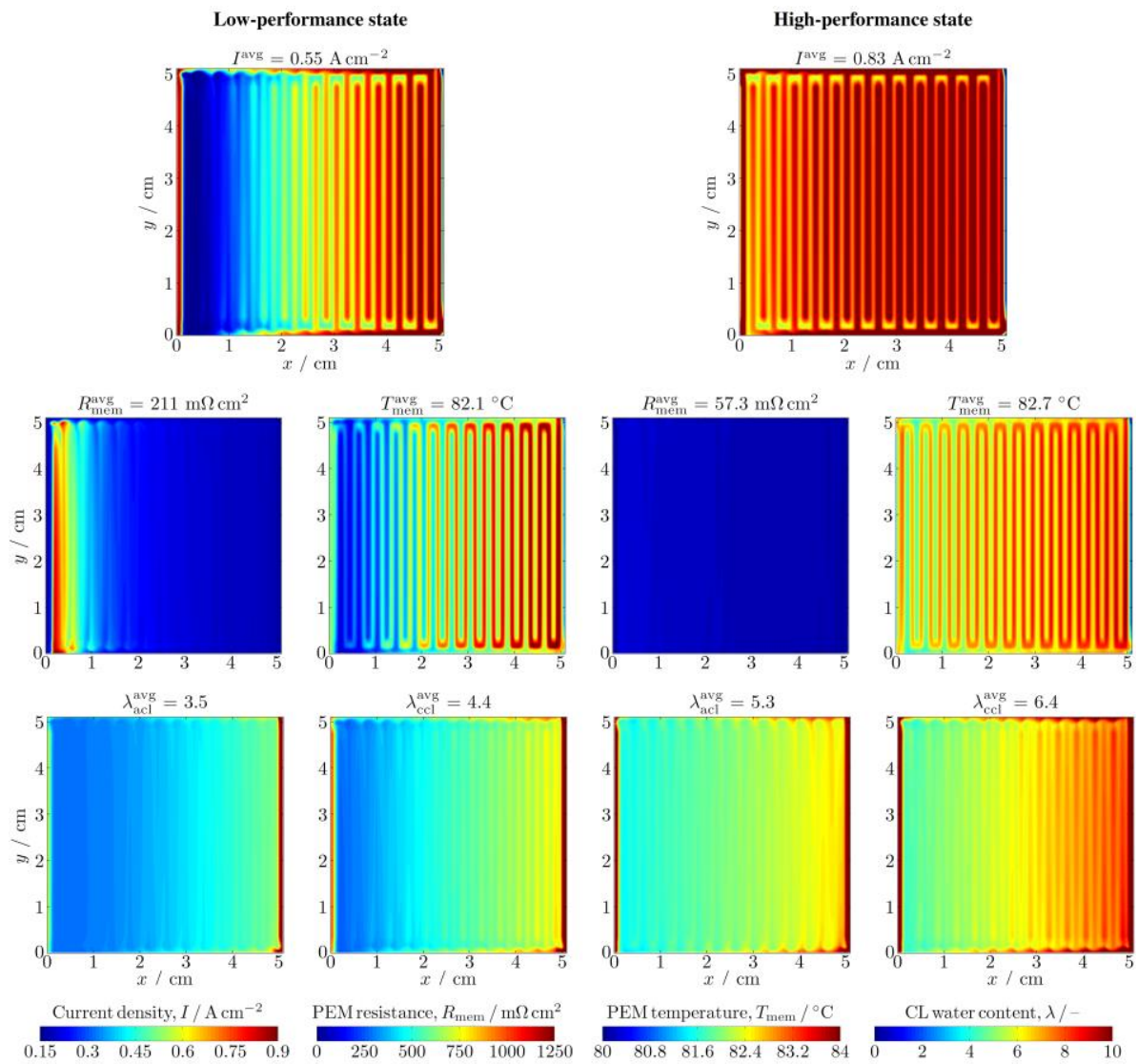

Figure 5: From top to bottom: computed distributions of current density, $I(x, y)$, ionic resistance and temperature in the membrane, $R_{\mathrm{mem}}(x, y)$ and $T_{\mathrm{mem}}(x, y)$, and water content in the anode and cathode catalyst layers, $\lambda_{\text {acl }}(x, y)$ and $\lambda_{\mathrm{ccl}}(x, y)$, corresponding to the low- (left) and high-performance (right) states. See caption to Figure 4 for further details. 
The differences in the hydration level of the membrane are further examined in Figure 6. Figure $6(a)$ shows the computed distributions of dissolved water in the membrane, $\lambda_{\text {mem }}$, while Figure 6(b) shows the Electro-osmotic Drag (EOD) and diffusive fluxes across the membrane, $N_{\text {mem,eod }}^{\mathrm{tp}}=\left(\mathrm{n}_{\mathrm{d}}^{\mathrm{w}} / F\right) j_{\mathrm{H}^{+}, \mathrm{z}}$ and $N_{\mathrm{mem}, \mathrm{diff}}^{\mathrm{tp}}=-\left(\rho_{\mathrm{e}} / E W_{\mathrm{e}}\right) D_{\mathrm{w}, \mathrm{e}}^{\mathrm{eff}} \partial \lambda / \partial z$, respectively. The variables, averaged over each rib/channel segment, are plotted as a function of the alongthe-cell distance ( $x$-coordinate). For comparative purposes, the distributions of liquid water thickness, $\delta_{\mathrm{lw}}$, obtained from the through-plane imaging experiments are also shown in Figure 6(a). The water thickness in the high-performance state corresponds to an instant close to the ignition current peak, after the liquid water in the anode channel had been flushed out of the cell. This was done to estimate the water level in the MEA, even though the inclusion of tiny droplets or films that may be present in the anode channel cannot be guaranteed. In addition, note that the amount of liquid water in the electrolyte was not distinguishable from that present in the void phase of the MEA.

As can be seen in Figure 6(a), the average water content in the membrane increases almost linearly from the dry cathode inlet $(x=0 \mathrm{~cm})$ towards the wet anode inlet $(x=5 \mathrm{~cm})$. A wavy pattern is superimposed on the global trend line due to the higher hydration level existing under the ribs. Similar results are observed in the experimental data, although the differences between rib and channel regions are more pronounced. The lower water content was found in the anode side of the membrane due to the effect of EOD, so that back diffusion from cathode to anode exists in the entire cell [98]. Note, however, that the net flux of dissolved water is directed from anode to cathode, since the EOD flux is higher than the diffusive flux. Accordingly, water is sorbed into the anode catalyst layer and desorbed to the cathode catalyst layer throughout the cell. The sorption rate at the anode catalyst layer equals the desorption rate minus the production rate at the cathode catalyst layer under steady-state conditions. This water transfer rate in the catalyst layers is, in turn, equal to the net transport rate of 
dissolved water (EOD + diffusion) through the membrane (i.e., $\dot{N}_{\text {acl,sor }}=\dot{N}_{\text {ccl,des }}-\dot{N}_{\text {ccl,prod }}=$ $\left.\dot{N}_{\text {mem }}\right)$. Figure 6 (b,bottom) also shows how the membrane dry-out in the low-performance state cuts down the flux of water, both under the rib and under the channel, near the cathode inlet. For reference, note that $N_{\text {mem }}^{\mathrm{tp}}$ should vanish under fully dry conditions, when both the EOD flux and the water content of the membrane are negligible. By contrast, Figure $6(b, t o p)$ shows that in the high-performance state the humidification of the cell and the increase of the current density lead to a more uniform water flux.

(a)

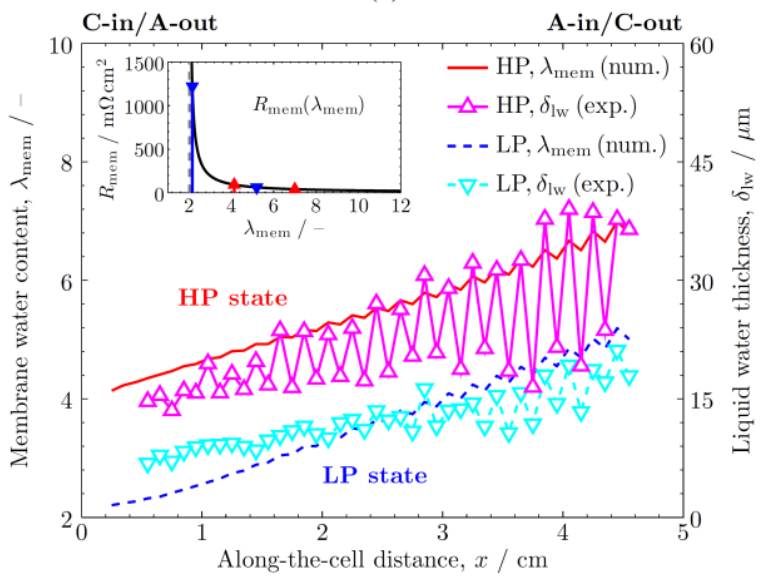

(b)

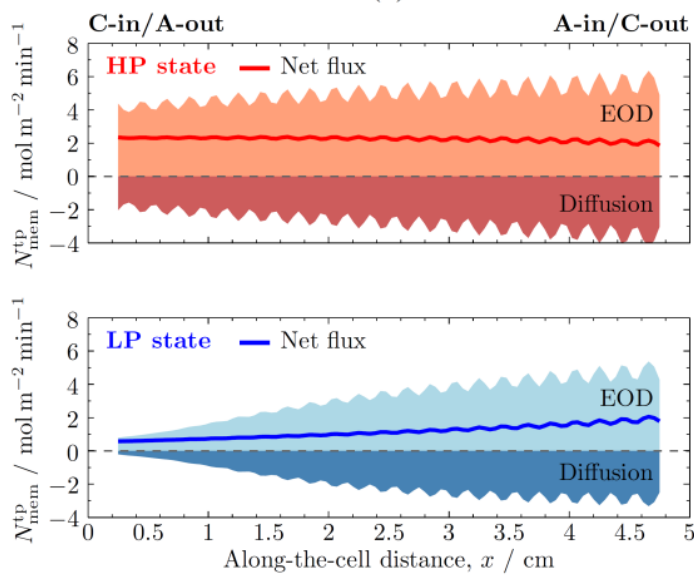

Figure 6: (a) Variation of the membrane water content, $\lambda_{\text {mem }}$, predicted by the model and the liquid water thickness, $\delta_{\mathrm{lw}}$, measured in the through-plane imaging experiments as a function of the along-the-cell direction $(x$ coordinate), corresponding to the low- and high-performance states. The variables are locally averaged over each rib/channel segment from the cathode inlet $(C$-in/A-out, $x=0 \mathrm{~cm})$ towards the anode inlet $(A$-in $/ \mathrm{C}$-out, $x=5 \mathrm{~cm})$. The inset shows the membrane ionic resistance, $R_{\mathrm{mem}}$, as a function of the membrane water content, $\lambda_{\text {mem }}$, with indication of the estimated range of variation of $R_{\mathrm{mem}}\left(\lambda_{\mathrm{mem}}\right)$ (low-performance state: downward triangles, highperformance state: upward triangles). The experimental data correspond to times $t=2900 \mathrm{~s}$ and $t=2990 \mathrm{~s}$ in Figure 3 (see also the supplementary videos). Membrane material: Nafion ${ }^{\circledR} 117$. (b) Variation of the flux of dissolved water across the membrane, $N_{\mathrm{mem}}^{\mathrm{tp}}$, corresponding to the low- and high-performance states, indicating the contribution of electro-osmotic drag and diffusion to the overall flux. Positive fluxes are directed from anode to cathode.

The enhanced water transfer rate to the cathode, along with the larger water production rate, increase the local membrane water content by a factor of 2-1.3 in the high-performance state 
$\left(\lambda_{\text {mem,lps }}=2.16-5.2\right.$ vs. $\left.\lambda_{\text {mem,hps }}=4.2-7\right)$. As shown in the inset of Figure $6(a)$, this difference is amplified in terms of cell performance by the inverse nonlinear relation between the membrane ionic resistance and the ionic conductivity

$$
R_{\mathrm{mem}} \sim \frac{\delta_{\mathrm{mem}}}{\sigma_{\mathrm{H}^{+}}^{\text {eff,tp }}\left(\lambda_{\mathrm{mem}}\right)}
$$

where $\sigma_{\mathrm{H}^{+}}^{\text {eff,tp }}=\left(-1 \times 10^{-2} \lambda_{\text {mem }}^{2}+1.05 \lambda_{\text {mem }}-2.06\right) \exp [751.5(1 / 303-1 / T)] \mathrm{S} \mathrm{m}^{-1}$ [101], $\delta_{\text {mem }} \approx 28 \mu \mathrm{m}$ and $T \approx 80^{\circ} \mathrm{C}$. With the computed values of $\lambda_{\mathrm{mem}}, R_{\mathrm{mem}}$ ranges from 1200 to $63 \mathrm{~m} \Omega \mathrm{cm}^{2}$ in the low-performance state, while it remains between 90 and $41 \mathrm{~m} \Omega \mathrm{cm}^{2}$ in the high-performance state. The divergence of $R_{\text {mem }}$ near the ionic conductivity threshold $\left(\sigma_{\mathrm{H}^{+}}^{\text {eff }} \approx 0\right.$ at $\left.\lambda_{\text {mem }}^{\text {th }} \approx 2[101]\right)$ dramatically reduces the cell performance near the cathode inlet, as shown in Figure 5. In contrast, the water content reached in the ignitions is high enough so as to make the range of variation of $R_{\text {mem }}$ comparable to that given by a membrane in equilibrium with saturated vapor $\left(R_{\mathrm{mem}} \approx 23 \mathrm{~m} \Omega \mathrm{cm}^{2}\right.$ at $\lambda_{\mathrm{eq}}\left(80{ }^{\circ} \mathrm{C}\right) \approx 12$ [102]). In other words, the input of liquid water during the ignitions shifts the minimum membrane water content away from the divergence region around $\lambda_{\mathrm{mem}}^{\text {th }}$, resulting in a far more homogenous current density distribution. As a final remark, it should be noted that the current density in the dry region facing the cathode inlet may be further reduced in the lowperformance state by the drop of the cathode reaction rate, $R R_{\mathrm{c}}$, when the electrochemical activity of solvated protons is small $[25,94]$.

An aspect that deserves further attention is whether liquid water is present or not in the porous media of the MEA (GDLs, MPLs and CLs). In the simulations, no water condensation was predicted in the MEA. In addition, no liquid water was assumed to enter from the anode channel into the MEA due to the micropore structure of PTFE-treated carbon paper GDLs (see Section A.1). However, the water thickness found in the experiments (up to $\delta_{\mathrm{lw}} \approx 40 \mu \mathrm{m}$ ) is 
significantly larger than that corresponding to the computed water contents $\left(\delta_{\mathrm{w}} \sim f_{\mathrm{V}}\left(\delta_{\text {mem }}+\right.\right.$ $\left.2 \omega_{\mathrm{e}} \delta_{\mathrm{cl}}\right)<10 \mu \mathrm{m}$, where $f_{\mathrm{V}}=\lambda V_{\mathrm{m}, \mathrm{lw}} /\left(V_{\mathrm{m}, \mathrm{e}}+\lambda V_{\mathrm{m}, \mathrm{lw}}\right)$ is the water volume fraction in the electrolyte [26]). This suggests that some liquid water may also be present in the porous media of the MEA. For instance, a water thickness $\delta_{\mathrm{lw}} \approx 7 \mu \mathrm{m}$ was measured near the cathode inlet in the low-performance state, which corresponds to a water content in the electrolyte $\lambda \sim 8$. Such a high water content does not agree with a dry membrane. Hence, it is possible that some liquid water resides in isolated pores that do not contribute significantly to membrane hydration. The uncertainty in the results precludes any firm conclusion. New in-plane imaging experiments should be performed in future work to clarify the existence and location of liquid water. The new light shed on the phenomenon may then be combined with a transient model for a detailed description of the process. For example, the potential entrance of small amounts of liquid water from the anode channel into the MEA is expected to increase even more the humidification level in the high-performance state and to lengthen the dehydration stage. Beyond these unknown aspects, the basic nature of the global process can be explained based on the steady-state results computed here for the low- and high-performance states.

According to previous discussions, the main transport processes that take place during the hydration-dehydration cycles are as follows [45]: i) the shedding of liquid water fully humidifies the anode channel; ii) water vapor is transported from the anode channel to the anode catalyst layer and sorbed into the membrane; iii) dissolved water is net transported through the membrane and desorbed to the cathode, iv) the current density increases and the dry-out induced by the air stream is temporarily offset, eventually reaching the high-performance state; and v) when the liquid water in the anode channel is flushed out of the cell, the dehydration process begins, eventually leading to the low-performance state. On top of that, during current ignitions some liquid water in the anode channel may enter by forced convection into the MEA and/or water condensation may be induced in the MEA, 
preferentially in the under-the-rib regions. It is worth noting that this explanation differs from that presented by Sánchez et al. [18], who attributed the hydration-dehydration cycles to the internal auto-regeneration of a liquid water reservoir at the anode side of the membrane. The internal regeneration of such reservoir was ascribed to the change of the membrane properties depending on whether it was in contact with liquid water or not. However, the present results clearly demonstrate that the hydration-dehydration cycles arise from the external input of liquid water at the anode inlet.

\subsection{Numerical parametric study: Effect of hydrogen and air feed flow rates}

To conclude the numerical analysis, in this section we investigate the effect of the hydrogen and air feed flow rates on the amplitude of the current oscillations. Figure 7(a) shows the variation of the current density of the two performance states $\left(I_{\mathrm{hps}}^{\mathrm{avg}}\right.$ and $\left.I_{\mathrm{lps}}^{\mathrm{avg}}\right)$ with the hydrogen flow rate $\left(Q_{\mathrm{H}_{2}}\right)$, while Figure $7(\mathrm{~b})$ shows the current density distributions corresponding to some specific values of $Q_{\mathrm{H}_{2}}$. The inset displays the amplitude of the current oscillations, $\Delta I^{\text {avg }}=I_{\mathrm{hps}}^{\mathrm{avg}}-I_{\mathrm{lps}}^{\mathrm{avg}}$. The results of the study of the air flow rate, $Q_{\mathrm{air}}$, are shown in Figure 8 using a similar representation. For reference purposes, the experimental data reported by Sánchez et al. [18] are also included in both figures; see the figure captions for details concerning the operating conditions. Note that the present analysis is only aimed to compare the results qualitatively, since the cell and operating conditions used by Sánchez et al. [18] are different from those considered here. Moreover, some parameters such as the inlet humidification of the dry air or the assembly pressure in [18] are not known in detail. Therefore, a recalibration of the model may be necessary to quantitatively match the experimental data presented in [18]. 
As shown in Figure $7(a)$, the low-performance state displays a strong sensitivity to the hydrogen flow rate, showing a relative increase in the current density of up to $50 \%$. In contrast, the current density of the high-performance state remains unchanged due to the full humidification reached in the anode channel regardless of the flow rate (and the negligible effect of increasing hydrogen stoichiometry). Hence, the amplitude of the oscillations decreases from $\Delta I^{\mathrm{avg}}=0.29 \mathrm{~A} \mathrm{~cm}^{-2}$ to $\Delta I^{\mathrm{avg}}=0.04 \mathrm{~A} \mathrm{~cm}^{-2}$ when increasing the hydrogen flow rate from $Q_{\mathrm{H}_{2}}=200 \mathrm{sccm}$ to $Q_{\mathrm{H}_{2}}=1600 \mathrm{sccm}$. Looking at the current density distributions in Figure $7(b)$, it can be seen that the better humidification reached at higher hydrogen flow rates gradually offsets the dry-out induced by the air stream [18]. Indeed, for a sufficiently high hydrogen flow rate (compared to the air flow rate), the additional humidification provided by the input of liquid water would have virtually no effect. As a result, both performances states tend to collapse onto a single state and the current oscillations disappear, as previously reported by Sánchez et al. [19].

As shown in Figure 8(a), the effect of the air flow rate is the opposite. The minimum air flow rate examined was restricted to $Q_{\mathrm{air}}=600 \mathrm{sccm}\left(\xi_{\mathrm{c}}=1.8\right)$ in order to avoid a significant loss of potential related to oxygen transport [18]. The sensitivity of the high-performance state to the air flow rate is again lower due to the better membrane hydration achieved in that case. Quantitatively, the current densities of the low- and high-performance states show a relative decrease of $25 \%$ and $8 \%$, respectively, when increasing the air flow rate from $Q_{\text {air }}=600 \mathrm{sccm}$ to $Q_{\text {air }}=1200 \mathrm{sccm}$. Consequently, the amplitude of the oscillations grows from $\Delta I^{\text {avg }}=$ $0.16 \mathrm{~A} \mathrm{~cm}^{-2}$ to $\Delta I^{\text {avg }}=0.3 \mathrm{~A} \mathrm{~cm}^{-2}$. The lower the flow rate (i.e., the lower the water removal capacity) of the air stream, the better the membrane hydration achieved throughout the cell. Hence, the current distributions of both performance states become more similar as the air flow rate is reduced. It is worth noting that water condensation was found at the cathode side of the MEA in an increasing portion near the anode inlet at moderate air flow rates. The 
numerical results are also in qualitative agreement with the current density data reported by Sánchez et al. [18].

(a)
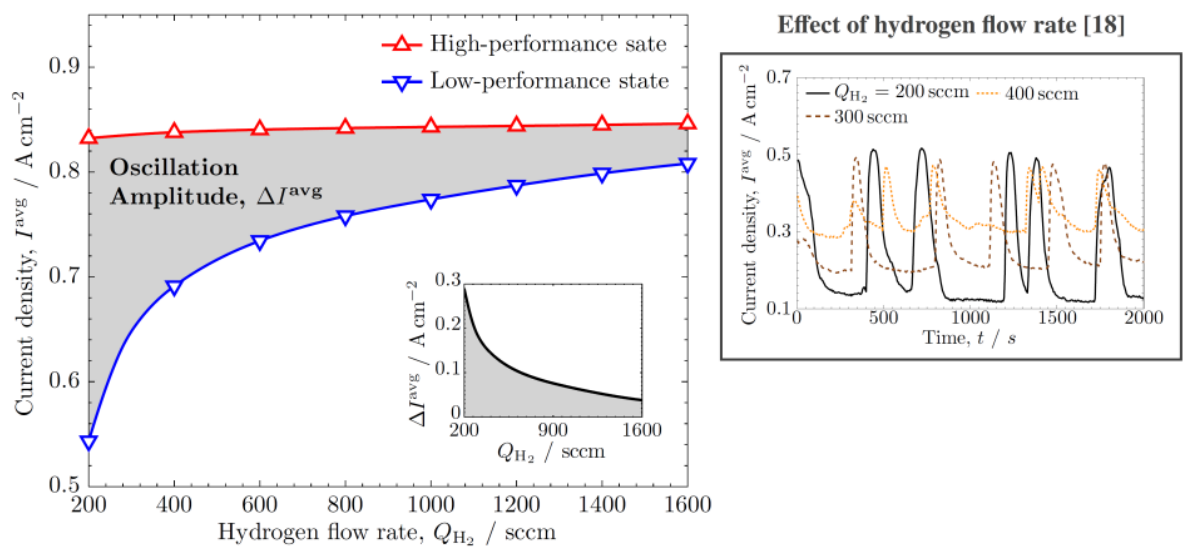

(b)

High-performance state

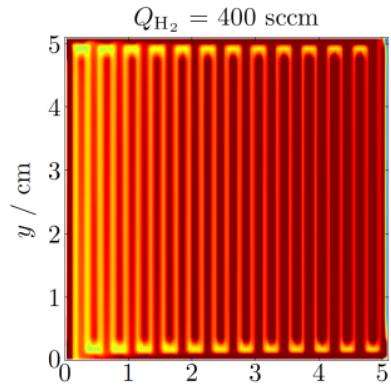

$Q_{\mathrm{H}_{2}}=800 \mathrm{sccm}$

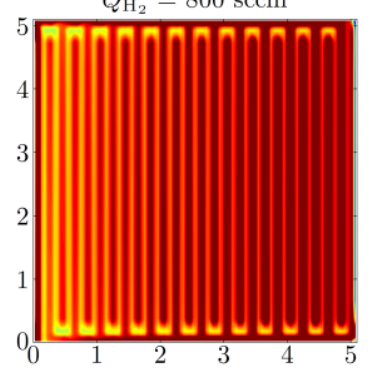

$Q_{\mathrm{H}_{2}}=1200 \mathrm{sccm}$

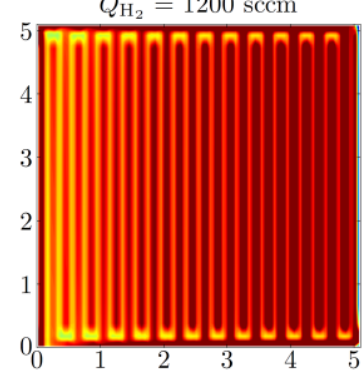

Low-performance state

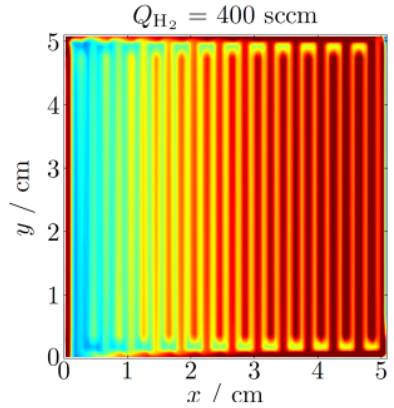

$Q_{\mathrm{H}_{2}}=800 \mathrm{sccm}$
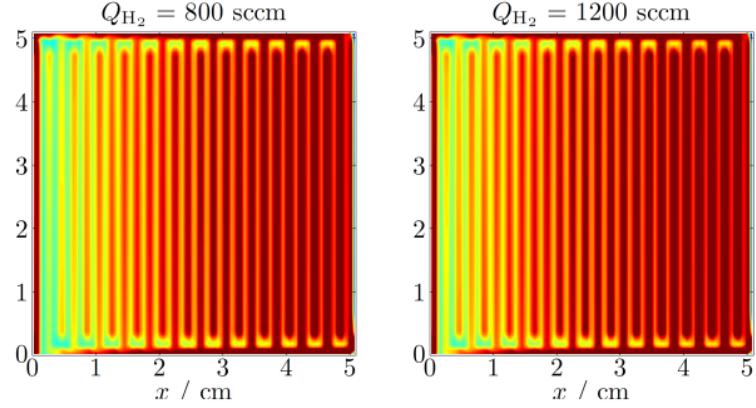

Current density / $\mathrm{A} \mathrm{cm}^{-2}$

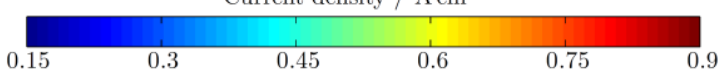

Figure 7: (a) Computed average current density, $I^{\text {avg }}$, as a function of the hydrogen feed flow rate, $Q_{\mathrm{H}_{2}}=200-$ $1600 \mathrm{sccm}\left(\xi_{\mathrm{a}}=1.4-11.6 @ 0.8 \mathrm{~A} \mathrm{~cm}^{-2}\right)$, corresponding to the low- and high-performance states. The inset shows the amplitude of the current oscillations, $\Delta I^{\text {avg }}=I_{\mathrm{hps}}^{\mathrm{avg}}-I_{\mathrm{lps}}^{\mathrm{avg}}$, as a function of $Q_{\mathrm{H}_{2}}$. (b) Computed current density distributions, $I(x, y)$, corresponding to different hydrogen flow rates $\left(Q_{\mathrm{H}_{2}}=400,800\right.$ and $1200 \mathrm{sccm}$; $\xi_{\mathrm{a}}=2.9,5.8$ and $8.7 @ 0.8 \mathrm{~A} \mathrm{~cm}^{-2}$ ). The subfigure in the frame shows the variation of the average current density with time for different hydrogen flow rates $\left(Q_{\mathrm{H}_{2}}=200,300\right.$ and $400 \mathrm{sccm} ; \xi_{\mathrm{a}} \approx 1.2,1.8$ and 2.4) reported by Sánchez et al. [18] (other op. conds. [18]: $V_{\text {cell }}=0.5 \mathrm{~V}, T_{\text {cell }}=70^{\circ} \mathrm{C}, Q_{\mathrm{air}}=660 \operatorname{sccm}\left(\xi_{\mathrm{c}} \approx 2\right), p_{\mathrm{a}}^{\text {out }}=p_{\mathrm{c}}^{\text {out }}=$ 
1.5 bar, $\mathrm{RH}_{\mathrm{a}}^{\mathrm{in}} \approx 152 \%$ (condensing conditions), $\mathrm{RH}_{\mathrm{c}}^{\mathrm{in}} \approx 5 \%$ (dry air), $\mathrm{CL}$ with $0.3 \mathrm{mg}_{\mathrm{Pt}} \mathrm{cm}^{-2}$ from lon Power Inc., Nafion ${ }^{\circledR} 111-I P$, SIGRACET $\left.^{\circledR} 35 \mathrm{BC}\right)$.

(a)

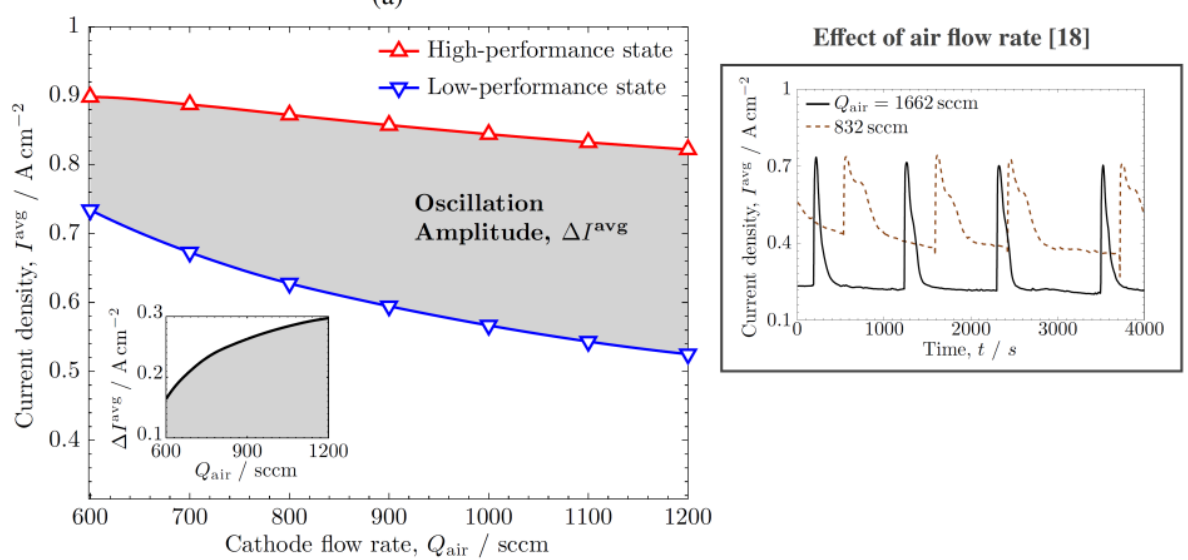

(b)

High-performance state

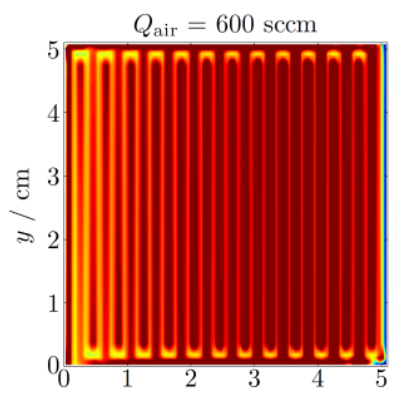

$Q_{\text {air }}=900 \mathrm{sccm}$

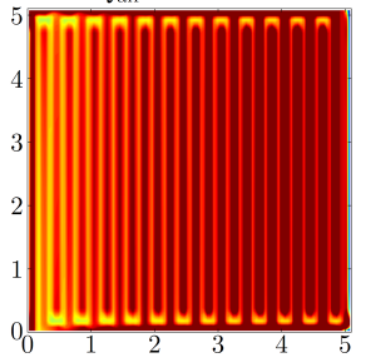

$Q_{\text {air }}=1200 \mathrm{sccm}$

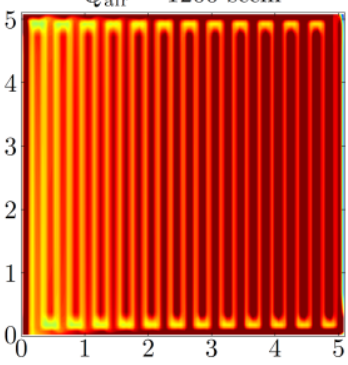

Low-performance state

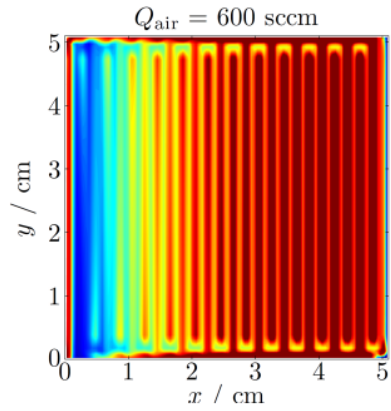

$Q_{\text {air }}=900 \mathrm{sccm}$
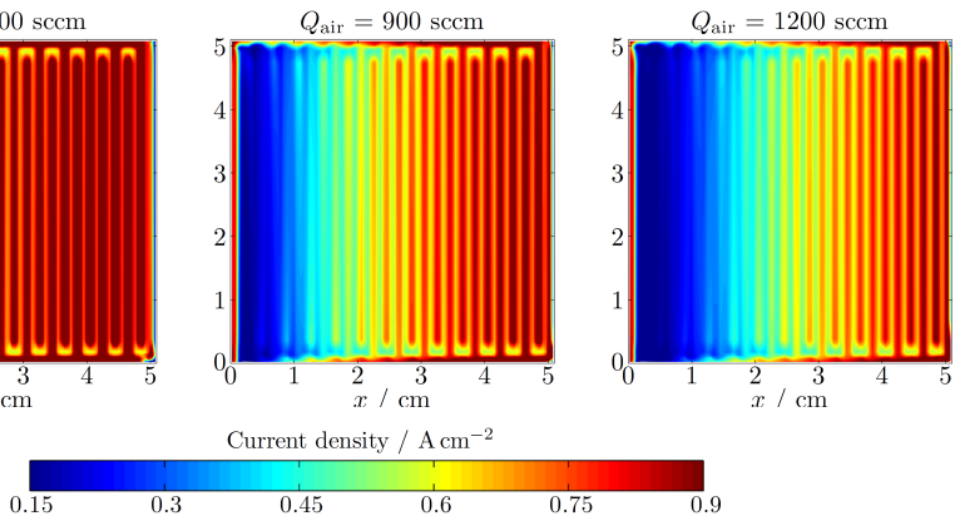

Figure 8: (a) Computed average current density, $I^{\text {avg }}$, as a function of the air feed flow rate, $Q_{\text {air }}=600-$ $1200 \mathrm{sccm}\left(\xi_{\mathrm{c}}=1.8-3.6 @ 0.8 \mathrm{~A} \mathrm{~cm}^{-2}\right)$, corresponding to the low- and high-performance states. The inset shows the amplitude of the current oscillations, $\Delta I^{\mathrm{avg}}=I_{\mathrm{hps}}^{\mathrm{avg}}-I_{\mathrm{lps}}^{\mathrm{avg}}$, as a function of $Q_{\mathrm{air}}$ (b) Computed current density distributions, $I(x, y)$, corresponding to different air flow rates $\left(Q_{\mathrm{air}}=600,900\right.$ and $1200 \mathrm{sccm} ; \xi_{\mathrm{c}}=1.8,2.7$ and $3.6 @ 0.8 \mathrm{~A} \mathrm{~cm}^{-2}$ ). The subfigure in the frame shows the variation of the average current density with time for different air flow rates $\left(Q_{\text {air }}=832\right.$ and $1662 \mathrm{sccm} ; \xi_{\mathrm{a}} \approx 2$ and 4$)$ reported by Sánchez et al. [18] (other op. conds. [18]:

$$
V_{\text {cell }}=0.6 \mathrm{~V}, T_{\text {cell }}=70^{\circ} \mathrm{C}, Q_{\mathrm{H}_{2}}=261 \mathrm{sccm}\left(\xi_{\mathrm{a}} \approx 1.8\right), p_{\mathrm{a}}^{\text {out }}=p_{\mathrm{c}}^{\text {out }}=1.5 \mathrm{bar}, \mathrm{RH}_{\mathrm{a}}^{\text {in }} \approx 152 \%
$$


(condensing conditions), $\mathrm{RH}_{\mathrm{C}}^{\mathrm{in}} \approx 5 \%$ (dry air), $\mathrm{CL}$ with $0.3 \mathrm{mg}_{\mathrm{Pt}} \mathrm{cm}^{-2}$ from lon Power Inc., Nafion ${ }^{\circledR}$ 111-IP, SIGRACET $\left.{ }^{\circledR} 35 \mathrm{BC}\right)$.

\section{Conclusions}

In this work, we have examined the low- and high-performance states arising in a Polymer Electrolyte Fuel Cell (PEFC) operated with wet anode and dry cathode feed $\left(\mathrm{RH}_{\mathrm{a}}^{\mathrm{in}} \approx 100 \%\right.$, $\mathrm{RH}_{\mathrm{c}}^{\mathrm{in}} \approx 6 \%$, due to the periodic hydration and dehydration of the membrane. The hydrationdehydration cycles are characterized by a fast current raise (ignition), followed by a slow current drop (extinction). This peculiar scenario has been investigated by analyzing water distributions from neutron imaging experiments and predictions from a 3D non-isothermal two-phase steady-state model. The main conclusions drawn from the experimental and numerical studies are, respectively, as follows:

- The imaging experiments have shown that the hydration-dehydration cycles are caused by the periodic condensation of water in the anode inlet chamber, and the subsequent shedding of water blobs into the anode flow field. The membrane hydration evolves hand-in-hand with the transport of liquid water along the anode channel, leading to a sharp decrease of the cell high-frequency resistance. The preference of the system for the high-performance state is lost once the liquid water leaves the anode channel. Then, the membrane dehydration occurs as the water stored in the cell (both in liquid and gas form) is removed away, eventually leading to the low-performance state.

- Based on the insight gained from the experiments, the main characteristics of the two extreme performance states were then studied using a steady-state model. The high- and low-performance states were respectively modeled by either introducing or not introducing a steady flux of liquid water at the vapor-saturated anode inlet. The results have shown that the evaporation of liquid water during ignitions fully humidifies the anode channel, so that 
the increase of the water transfer rate from anode to cathode and the water production rate offset the membrane dry-out induced by the cathode stream. As a result, a homogeneous current density distribution is achieved in the cell in the high-performance state, in contrast to the fairly inhomogeneous current density distribution characterizing the low-performance state. A parametric study has also been performed to qualitatively assess the effect of the hydrogen and air flow rates on the amplitude of the current oscillations. In agreement with previous experimental data, the amplitude of the current oscillations decreases for higher hydrogen and lower air flow rates. This result is explained by the better membrane hydration resulting under these conditions in the low-performance state, so that the output current density becomes more similar to that of the high-performance state.

Putting all together, the work clearly shows that liquid water injected into the anode channel of a PEFC is very efficient for membrane humidification, even in the presence of a dry cathode feed, and without incurring in significant mass-transport losses. Thus, the engineered injection or spraying of liquid water at the anode inlet without the need of cathode humidification is worth exploring in new cell designs. Furthermore, operation in the oscillatory hydrationdehydration regime was found to be useful to study membrane resistance in durability tests.

Several aspects of the investigation warrant further work. A new cell fixture suitable for inplane neutron imaging should be tested to clarify the existence and location of liquid water in the porous media of the MEA (catalyst layers, microporous layers and gas diffusion layers). Moreover, the transient modeling of the hydration-dehydration cycles should be considered to analyze the different timescales associated with both processes. Finally, the study of the thermal-fluid problem governing the temperature and humidity fields in the anode inlet chamber should also be addressed to explain the exact origin of water condensation. 


\section{Acknowledgments}

This work has been partially supported by the European Union's Seventh Framework Programme (FP7/2007-20013) for Fuel Cell and Hydrogen Joint Technology Initiative under grant No. 325239 (NanoCat project), and by project ENE2015-68703-C2-1-R of the Spanish Ministerio de Economía y Competitividad. The neutron imaging measurements were conducted with the support of the EU within the European Research Infrastructure H2FC (funded under the FP7 specific program capacities, grant agreement No. 284522). The authors thank Mr. Sander at Deutsches Zentrum für Luft und Raumfahrt (DLR) for helpful discussions, Dr. Forner-Cuenca and Dr. Cochet at Paul Scherrer Institut (PSI) for their help in the imaging experiments, and Mr. Sánchez-Monreal at University Carlos III of Madrid for his assistance in the simulation campaign. The first author also thanks the postdoctoral fellowship awarded at DLR from the Deutsche Akademische Austausch Dienst (DAAD) program.

\section{Appendix A. Mathematical Model}

The model formulation is divided into five sections. The assumptions are presented in Section A.1, the governing equations in Section A.2, the source terms in Section A.3, the boundary conditions in Section A.4, and the model implementation in Section A.5. The physicochemical and effective transport properties and the kinetic parameters used in the model are listed in Tables 2 and 3. In the equations presented below, bold symbols denote 3D vectors, e.g., the superficial gas-phase velocity, $\boldsymbol{u}_{\mathrm{g}}=\left(u_{\mathrm{g}, \mathrm{x}}, u_{\mathrm{g}, \mathrm{y}}, u_{\mathrm{g}, \mathrm{z}}\right)$, and over-lined bold symbols denote second-order tensors, e.g., the absolute permeability tensor

$$
\overline{\overline{\boldsymbol{K}}}=\left[\begin{array}{ccc}
K_{\mathrm{xx}} & 0 & 0 \\
0 & K_{\mathrm{yy}} & 0 \\
0 & 0 & K_{\mathrm{zz}}
\end{array}\right]=\left[\begin{array}{ccc}
K^{\mathrm{ip}} & 0 & 0 \\
0 & K^{\mathrm{ip}} & 0 \\
0 & 0 & K^{\mathrm{tp}}
\end{array}\right]
$$


where the superscripts ip and tp are the in- and through-plane orthotropic tensor components, respectively. Here, only the anisotropy of GDL absolute permeability was taken into account, whereas other transport properties were assumed isotropic; this hypothesis could be easily relaxed in future work $[15,16,103]$. The symbols $\circ$ and : denote the elementwise (Hadamard) and double-dot products, respectively. The source terms, described in Section A.3, are denoted by $S$.

\section{A.1. Assumptions}

The main assumptions and simplifications adopted in the model are as follows: i) the flow is laminar and steady; ii) the components of the MEA are macroscopically homogeneous; iii) interfacial ohmic and thermal resistances are negligible; iv) the membrane is treated as a solid perfectly impermeable to gases and to liquid water saturation; v) liquid water produced in the cathode catalyst layer is dissolved in the electrolyte; vi) the flow-channels are modeled as structured and ordered porous media $[95,96]$; vii) thermo-osmotic transport $[22,93]$ and convection [21] of dissolved water are neglected; viii) Soret/Dufour effects, viscous heat dissipation, and heat transfer through the liquid phase are ignored (only the effect of liquid water on heat conduction in the channels is taken into account); ix) the Leverett J-function is used to model capillary transport of liquid water in the porous media of the MEA (CLs, MPLs and GDLs) [2,104-107], considering a continuous interfacial saturation; $\mathrm{x}$ ) water saturation in the porous media of the MEA, $s_{\text {mea, }}$ and in the channels, $s_{\mathrm{ch}}$, are implemented as two different variables. The remaining assumptions can be found elsewhere $[2,105,108-110]$. It should be noted that assumption $\mathrm{x}$ ) was used to avoid the transfer of liquid water from the channel into the GDL that was unavoidable when a single continuum variable was considered for both regions. Making use of these two variables, $s_{\text {mea }}$ was set to zero in the channels (i.e., $p_{\mathrm{c}}=0$ ), while $s_{\mathrm{ch}}$ was set equal to the actual saturation distribution inside the MEA (i.e., 
$\left.s_{\mathrm{ch}}=s_{\text {mea }}\right)$. This workaround enabled us to account for the flux of liquid water from the MEA

into the channel when $s_{\text {mea }}>s_{\mathrm{ch}}$, while preventing liquid water to enter the MEA when

$s_{\text {mea }}<s_{\text {ch }}$. Similar considerations were adopted in other modeling studies (see, e.g.,

$[24,81,82])$.

\begin{tabular}{|c|c|c|c|}
\hline Parameter & Symbol & Value & Reference \\
\hline Density of liquid water & $\rho_{\mathrm{lw}}$ & $1000-1.78 \times 10^{-2}(T-277.15)^{1.7} \mathrm{~kg} \mathrm{~m}^{-3}$ & [111] \\
\hline Density of electrolyte & $\rho_{\mathrm{e}}$ & $1980 \mathrm{~kg} \mathrm{~m}^{-3}$ & {$[104,110]$} \\
\hline $\begin{array}{l}\text { Bulk diffusivity of } \mathrm{H}_{2} \text { in } \mathrm{H}_{2} \mathrm{O} \\
\text { (equal to } \mathrm{H}_{2} \mathrm{O} \text { in } \mathrm{H}_{2} \text { ) }\end{array}$ & $D_{\mathrm{H}_{2}, \mathrm{H}_{2} \mathrm{O}}^{\text {bulk }}$ & $1.05 \times 10^{-4}\left(\frac{T}{333}\right)^{1.5}\left(\frac{10^{5}}{p_{\mathrm{g}}}\right) \mathrm{m}^{2} \mathrm{~s}^{-1}$ & {$[112]$} \\
\hline Bulk diffusivity of $\mathrm{O}_{2}$ in air & $D_{\mathrm{O}_{2}, \mathrm{air}}^{\text {bulk }}$ & $2.65 \times 10^{-5}\left(\frac{T}{333}\right)^{1.5}\left(\frac{10^{5}}{p_{\mathrm{g}}}\right) \mathrm{m}^{2} \mathrm{~s}^{-1}$ & [112] \\
\hline Bulk diffusivity of $\mathrm{H}_{2} \mathrm{O}$ in air & $D_{\mathrm{H}_{2} \mathrm{O}, \text { air }}^{\text {bulk }}$ & $2.98 \times 10^{-5}\left(\frac{T}{333}\right)^{1.5}\left(\frac{10^{5}}{p_{\mathrm{g}}}\right) \mathrm{m}^{2} \mathrm{~s}^{-1}$ & [112] \\
\hline Dynamic viscosity of $\mathrm{H}_{2}$ & $\mu_{\mathrm{H}_{2}}$ & $3.2 \times 10^{-3}\left(\frac{T}{293.85}\right)^{1.5}(T+72)^{-1} \mathrm{~kg} \mathrm{~m}^{-1} \mathrm{~s}^{-1}$ & {$[104,110]$} \\
\hline Dynamic viscosity of $\mathrm{O}_{2}$ & $\mu_{\mathrm{O}_{2}}$ & $8.46 \times 10^{-3}\left(\frac{T}{292.25}\right)^{1.5}(T+127)^{-1} \mathrm{~kg} \mathrm{~m}^{-1} \mathrm{~s}^{-1}$ & {$[104,110]$} \\
\hline Dynamic viscosity of $\mathrm{H}_{2} \mathrm{O}$ & $\mu_{\mathrm{H}_{2} \mathrm{O}}$ & $7.51 \times 10^{-3}\left(\frac{T}{291.15}\right)^{1.5}(T+120)^{-1} \mathrm{~kg} \mathrm{~m}^{-1} \mathrm{~s}^{-1}$ & {$[104,110]$} \\
\hline Dynamic viscosity of $\mathrm{N}_{2}$ & $\mu_{\mathrm{N}_{2}}$ & $7.33 \times 10^{-3}\left(\frac{T}{300.55}\right)^{1.5}(T+111)^{-1} \mathrm{~kg} \mathrm{~m}^{-1} \mathrm{~s}^{-1}$ & {$[104,110]$} \\
\hline Dynamic viscosity of liquid water & $\mu_{\mathrm{lw}}$ & $2.41 \times 10^{-5} 10^{247.8 /(T-140)} \mathrm{N} \mathrm{m}^{-1}$ & {$[104,110]$} \\
\hline Specific heat of $\mathrm{H}_{2} / \mathrm{O}_{2} / \mathrm{H}_{2} \mathrm{O} / \mathrm{N}_{2}$ & $\begin{array}{l}c_{\mathrm{p}, \mathrm{H}_{2}} / c_{\mathrm{p}, \mathrm{O}_{2}} / c_{\mathrm{p}, \mathrm{H}_{2} \mathrm{O}} \\
/ c_{\mathrm{p}, \mathrm{N}_{2}}\end{array}$ & $1.44 \times 10^{4} / 9.28 \times 10^{2} / 1.88 \times 10^{3} / 1.04 \times 10^{3} \mathrm{~J} \mathrm{~kg}^{-1} \mathrm{~K}^{-1}$ & [113] \\
\hline Thermal conductivity of $\mathrm{H}_{2} / \mathrm{O}_{2} / \mathrm{H}_{2} \mathrm{O} / \mathrm{N}_{2}$ & $k_{\mathrm{H}_{2}} / k_{\mathrm{O}_{2}} / k_{\mathrm{H}_{2} \mathrm{O}} / k_{\mathrm{N}_{2}}$ & $1.67 \times 10^{-2} / 2.46 \times 10^{-2} / 2.61 \times 10^{-2} / 2.4 \times 10^{-2} \mathrm{~W} \mathrm{~m}^{-1} \mathrm{~K}^{-1}$ & [113] \\
\hline $\begin{array}{l}\text { In- and through-plane effective thermal conductivity of } \\
\text { BPP/GDL/MPL/CL/PEM }\end{array}$ & $\begin{array}{l}k_{\mathrm{bpp} / \mathrm{tp}}^{\text {eff,ip }} / k_{\mathrm{gdl}}^{\text {eff,ip/tp }} \\
/ k_{\mathrm{mpl}}^{\text {eff,ip }} / k_{\mathrm{cl}, \mathrm{efp} / \mathrm{tp}}^{\text {eff }} \\
/ k_{\mathrm{mem}}^{\text {eff,ip/tp }}\end{array}$ & $120 / 0.5 / 0.1 / 0.27 / 0.13 \mathrm{~W} \mathrm{~m}^{-1} \mathrm{~K}^{-1}$ & {$[24,82,87,93,114,115]$} \\
\hline Thermal conductivity of liquid water & $k_{\mathrm{lw}}$ & $0.66 \mathrm{~W} \mathrm{~m}^{-1} \mathrm{~K}^{-1}$ & {$[116]$} \\
\hline Evaporation/condensation rate constant of water & $k_{\text {evp }} / k_{\text {con }}$ & $1 \times 10^{-4} \mathrm{~Pa}^{-1} \mathrm{~s}^{-1} / 1 \times 10^{4} \mathrm{~s}^{-1}$ & [117] \\
\hline Saturation vapor pressure of water & $\log _{10}\left(p_{\mathrm{H}_{2} \mathrm{O}}^{\text {sat }}\right)$ & $\begin{array}{c}-2.18+2.95 \times 10^{-2}(\mathrm{~T}-273.15)-9.18 \times 10^{-5}(\mathrm{~T}-273.15)^{2}+1.44 \\
\times 10^{-7}(\mathrm{~T}-273.15)^{3} \mathrm{~atm}\end{array}$ & {$[2,13]$} \\
\hline Equivalent weight of electrolyte & $E W_{\mathrm{e}}$ & $1.1 \mathrm{~kg} \mathrm{~mol}^{-1}$ & {$[104,110]$} \\
\hline Electrolyte volume fraction in $\mathrm{PEM} / \mathrm{CL}$ & $\omega_{\mathrm{e}}$ & $1 / 0.3$ & [106] \\
\hline In- and through-plane effective ionic conductivity & $\sigma_{\mathrm{H}^{+}}^{\text {effip/tp }}$ & $\omega_{\mathrm{e}}^{1.5}\left(-1 \times 10^{-2} \lambda^{2}+1.05 \lambda-2.06\right) \exp \left[751.5\left(\frac{1}{303}-\frac{1}{T}\right)\right] \mathrm{S} \mathrm{m}^{-1}$ & [101] \\
\hline $\begin{array}{l}\text { Effective diffusivity of dissolved water in the electrolyte } \\
\text { phase }\end{array}$ & $D_{\mathrm{w}, \mathrm{e}}^{\mathrm{eff}}$ & $8 \times 10^{-10} \omega^{1.5}\left(\frac{\lambda}{25}\right)^{0.15}\left[1+\tanh \left(\frac{\lambda-2.5}{1.4}\right)\right] \mathrm{m}^{2} \mathrm{~s}^{-1}$ & {$[23,118]$} \\
\hline $\begin{array}{l}\text { In- and through-plane effective } \\
\text { electrical conductivity of BPP/GDL/MPL/CL }\end{array}$ & $\sigma_{\mathrm{e}^{-}}^{\text {eff,ip/tp }}$ & $20 \times 10^{3} / 300 / 300 / 300 \mathrm{~S} \mathrm{~m}^{-1}$ & {$[104,106,110]$} \\
\hline Porosity of GDL/MPL/CL & $\varepsilon_{\mathrm{gdl}} / \varepsilon_{\mathrm{mpl}} / \varepsilon_{\mathrm{cl}}$ & $0.8 / 0.5 / 0.4$ & {$[50,106,119]$} \\
\hline $\begin{array}{l}\text { In- and through-plane gas-phase normalized dry } \\
\text { effective diffusivity of channel/GDL/MPL/CL }\end{array}$ & $f^{\text {ip/tp }}(\varepsilon)$ & $1 / 0.4 / 0.12 / 0.2$ & {$[36,40,120-124]$} \\
\hline $\begin{array}{l}\text { In- and through-plane gas-phase relative effective } \\
\text { diffusivity of channel, GDL, MPL and } \mathrm{CL}\end{array}$ & $g^{\mathrm{ip} / \mathrm{tp}}(s)$ & $(1-s)^{2.5}$ & {$[15,16]$} \\
\hline In-plane absolute permeability of channel/GDL/MPL/CL & $K_{\mathrm{ch}}^{\mathrm{ip}} / K_{\mathrm{gdl}}^{\mathrm{ip}} / K_{\mathrm{mpl}}^{\mathrm{ip}} / K_{\mathrm{cl}}^{\mathrm{ip}}$ & $3.52 \times 10^{-8} / 7 \times 10^{-11} / 1 \times 10^{-13} / 1 \times 10^{-12} \mathrm{~m}^{2}$ & {$[103,125,126]$} \\
\hline $\begin{array}{l}\text { Through-plane absolute permeability of } \\
\text { channel/GDL/MPL/CL }\end{array}$ & $K_{\mathrm{ch}}^{\mathrm{tp}} / K_{\mathrm{gdl}}^{\mathrm{tp}} / K_{\mathrm{mpl}}^{\mathrm{tp}} / K_{\mathrm{cl}}^{\mathrm{tp}}$ & $3.52 \times 10^{-8} / 4 \times 10^{-11} / 1 \times 10^{-13} / 1 \times 10^{-12} \mathrm{~m}^{2}$ & {$[103,125,126]$} \\
\hline $\begin{array}{l}\text { In- and through-plane gas-phase relative permeability of } \\
\text { channel/GDL/MPL/CL }\end{array}$ & $k_{\mathrm{rg}}^{\mathrm{ip} / \mathrm{tp}}$ & $(1-s)^{4} /(1-s)^{3} /(1-s)^{3} /(1-s)^{3}$ & {$[90,106,117]$} \\
\hline $\begin{array}{l}\text { In- and through-plane liquid-phase relative permeability } \\
\text { of GDL, MPL and CL }\end{array}$ & $k_{\mathrm{rl}}^{\mathrm{ip} / \mathrm{tp}}$ & $s^{3}$ & {$[90,106,117]$} \\
\hline $\begin{array}{l}\text { Latent heat of condensation/evaporation (same as for } \\
\text { sorption/desorption) }\end{array}$ & $h_{\mathrm{gl}}$ & $3.17 \times 10^{6}-2438.5 T \mathrm{~J} \mathrm{~kg}^{-1}$ & [127] \\
\hline $\begin{array}{l}\text { ORR entropy change } \\
\text { (liquid water production) }\end{array}$ & $\Delta S$ & $163.11 \mathrm{~J} \mathrm{~mol}^{-1} \mathrm{~K}^{-1}$ & {$[104,110]$} \\
\hline Contact angle of GDL/MPL/CL & $\theta_{\mathrm{gdl}} / \theta_{\mathrm{mpl}} / \theta_{\mathrm{cl}}$ & $110^{\circ} / 120^{\circ} / 95^{\circ}$ & {$[88,104,105,110]$} \\
\hline Surface tension coefficient & $\sigma$ & $0.12-1.67 \times 10^{-4} \mathrm{~T} \mathrm{~N} \mathrm{~m}^{-1}$ & {$[104,110]$} \\
\hline $\begin{array}{l}\text { In- and through-plane liquid-phase effective diffusivity } \\
\text { in the channel }\end{array}$ & $D_{\mathrm{lw}, \mathrm{ch}}^{\text {eff,ip/tp }}$ & $0.1 \mathrm{~m}^{2} \mathrm{~s}^{-1}$ & Assumed \\
\hline Liquid-phase velocity under fully-saturated conditions & $\left.u_{\mathrm{lw}, \mathrm{ch}}\right|_{s=1}$ & $1 \mathrm{~m} \mathrm{~s}^{-1}$ & Assumed \\
\hline
\end{tabular}

Table 2: Physicochemical and transport properties of the numerical model. See text in Appendix A for other properties not explicitly mentioned in the list. 


\begin{tabular}{|l|l|l|l|}
\hline Parameter & Symbol & Value & Reference \\
\hline Open-circuit voltage & OCV & $1.17 \mathrm{~V}$ & {$[2,90,110]$} \\
\hline $\begin{array}{l}\text { Exchange current density of } \\
\text { hydrogen oxidation reaction }\end{array}$ & $i_{0, \mathrm{a}}$ & $5 \times 10^{8} \mathrm{~A} \mathrm{~m}^{-3}$ & {$[89,90]$} \\
\hline $\begin{array}{l}\text { Reaction order of hydrogen } \\
\text { oxidation reaction }\end{array}$ & $\gamma_{\mathrm{a}}$ & 0.5 & {$[90,104,110,114]$} \\
\hline $\begin{array}{l}\text { Transfer coefficient of hydrogen } \\
\text { oxidation reaction }\end{array}$ & $\alpha_{\mathrm{a}}$ & 1 & {$[89,97,114]$} \\
\hline $\begin{array}{l}\text { Reference hydrogen } \\
\text { concentration }\end{array}$ & $C_{\mathrm{H}_{2}}^{\text {ref }}$ & $40 \mathrm{~mol} \mathrm{~m}^{-3}$ & {$[89]$} \\
\hline $\begin{array}{l}\text { Exchange current density of } \\
\text { oxygen reduction reaction }\end{array}$ & $i_{0, \mathrm{c}}$ & $1 \times 10^{4} \mathrm{~A} \mathrm{~m}^{-3}$ & {$[89,90]$} \\
\hline $\begin{array}{l}\text { Reaction order of oxygen } \\
\text { reduction reaction }\end{array}$ & $\gamma_{\mathrm{c}}$ & 1 & {$[90,104,110,114]$} \\
\hline $\begin{array}{l}\text { Transfer coefficient of oxygen } \\
\text { reduction reaction }\end{array}$ & $\alpha_{\mathrm{c}}$ & 1 & {$[89,97,114]$} \\
\hline $\begin{array}{l}\text { Reference oxygen } \\
\text { concentration }\end{array}$ & $C_{\mathrm{O}_{2}}^{\mathrm{ref}}$ & $40 \mathrm{~mol} \mathrm{~m}^{-3}$ & {$[89]$} \\
\hline
\end{tabular}

Table 3: Kinetic parameters of the numerical model.

\section{A.2. Governing equations}

The thirteen conservation equations of the model are presented below, indicating the region of interest and solution variable of each equation.

1-4) Gas-phase flow: CLs, MPLs, GDLs and channels $\left(\boldsymbol{p}_{\mathrm{g}}, \boldsymbol{u}_{\mathrm{g}, \mathrm{x}}, \boldsymbol{u}_{\mathrm{g}, \mathrm{y}}\right.$, and $\left.\boldsymbol{u}_{\mathrm{g}, \mathrm{z}}\right)$. The mass and momentum conservation equations governing the motion of the gas phase are written as:

$$
\boldsymbol{\nabla} \cdot\left(\rho_{\mathrm{g}} \boldsymbol{u}_{\mathrm{g}}\right)=S_{\mathrm{mg}}, \quad \boldsymbol{\nabla} \cdot\left(\frac{\rho_{\mathrm{g}}}{[\varepsilon(1-s)]^{2}} \boldsymbol{u}_{\mathrm{g}} \boldsymbol{u}_{\mathrm{g}}\right)=-\boldsymbol{\nabla} p_{\mathrm{g}}+\boldsymbol{\nabla} \cdot \overline{\overline{\mathbf{\tau}}}+S_{\mathrm{ug}}
$$

where $\rho_{\mathrm{g}}=p_{\mathrm{g}} M_{\mathrm{g}} / R T$ is the density of the ideal gas mixture (with $M_{\mathrm{g}}=\left(\sum_{\mathrm{i}} Y_{\mathrm{i}} / M_{\mathrm{i}}\right)^{-1}$ the molecular weight of the mixture), $\boldsymbol{u}_{\mathrm{g}}$ is the superficial gas-phase velocity, $s$ is the liquid saturation (defined as the ratio of water volume to void volume), and $\varepsilon$ is the dry porosity (with $\varepsilon=1$ in the channels). The viscous stress tensor is given by 


$$
\overline{\overline{\mathbf{\tau}}}=\mu_{\mathrm{g}}\left[\boldsymbol{\nabla}\left(\frac{\boldsymbol{u}_{\mathbf{g}}}{\varepsilon(1-s)}\right)+\left[\boldsymbol{\nabla}\left(\frac{\boldsymbol{u}_{\mathbf{g}}}{\varepsilon(1-s)}\right)\right]^{\mathbf{T}}-\frac{2}{3} \boldsymbol{\nabla} \cdot\left(\frac{\boldsymbol{u}_{\mathbf{g}}}{\varepsilon(1-s)}\right) \overline{\bar{I}}\right]
$$

where $\overline{\bar{I}}$ denotes the second-order unit tensor. According to the kinetic theory of gases, the dynamic viscosity of the mixture is equal to

$$
\mu_{\mathrm{g}}=\sum_{\mathrm{i}} \frac{X_{\mathrm{i}} \mu_{\mathrm{i}}}{\sum_{\mathrm{j}} X_{\mathrm{i}} \beta_{\mathrm{ij}}} ; \beta_{\mathrm{ij}}=\frac{\left[1+\left(\frac{\mu_{\mathrm{i}}}{\mu_{\mathrm{j}}}\right)^{1 / 2}\left(\frac{M_{\mathrm{j}}}{M_{\mathrm{i}}}\right)^{1 / 4}\right]^{2}}{\left[8\left(1+\frac{M_{\mathrm{i}}}{M_{\mathrm{j}}}\right)\right]^{1 / 2}}
$$

where $X_{\mathrm{i}}, \mu_{\mathrm{i}}$ and $M_{\mathrm{i}}$ are the mole fraction, dynamic viscosity and molecular weight of species $\mathrm{i}$, respectively.

5-7) Species: CLs, MPLs, GDLs and channels $\left(Y_{i}, \mathbf{i}=\mathbf{H}_{2}, \mathbf{O}_{2}\right.$ and $\left.\mathbf{H}_{2} \mathbf{0}\right)$. The species mass fractions are governed by the convection-diffusion equation:

$$
\boldsymbol{\nabla} \cdot\left(\rho_{\mathrm{g}} \boldsymbol{u}_{\mathrm{g}} Y_{\mathrm{i}}\right)-\boldsymbol{\nabla} \cdot\left(\rho_{\mathrm{g}} \overline{\overline{\boldsymbol{D}}}_{\mathbf{i}, \mathrm{j}}^{\mathrm{eff}} \nabla Y_{\mathrm{i}}\right)=S_{\mathrm{i}}
$$

where the effective diffusivity tensor of species $i$ in species $j$ is given by

$$
\overline{\overline{\boldsymbol{D}}}_{\mathrm{i}, \mathrm{j}}^{\text {eff }}=D_{\mathrm{i}, \mathrm{j}}^{\mathrm{bulk}}\left[\begin{array}{ccc}
f^{\mathrm{ip}}(\varepsilon) g^{\mathrm{ip}}(s) & 0 & 0 \\
0 & f^{\mathrm{ip}}(\varepsilon) g^{\mathrm{ip}}(s) & 0 \\
0 & 0 & f^{\mathrm{tp}}(\varepsilon) g^{\mathrm{tp}}(s)
\end{array}\right]
$$

Here, $f(\varepsilon)^{\mathrm{ip} / \mathrm{tp}}=D_{\mathrm{i}, \mathrm{j}}^{\text {eff,dry,ip/tp }} / D_{\mathrm{i}, \mathrm{j}}^{\text {bulk }}$ and $g^{\mathrm{ip} / \mathrm{tp}}(s)=D_{\mathrm{i}, \mathrm{j}}^{\text {eff,wet,ip/tp }} / D_{\mathrm{i}, \mathrm{j}}^{\text {eff,dry,ip/tp }}$ are the gasphase normalized dry and relative effective diffusivities, which account for the blockage of the unsaturated media and liquid water on gas diffusion, respectively. As shown in Table 2, $f^{\text {ip/tp }}(\varepsilon)<1$ for the porous layers of the MEA, while $f^{\text {ip/tp }}(\varepsilon)=1$ for the bulk channels. On the other hand, $g^{\mathrm{ip} / \mathrm{tp}}(s)$ is modeled both in the MEA and in the channels using a power law of 
the form $g^{\mathrm{ip} / \mathrm{tp}}=(1-\mathrm{s})^{2.5}$, according to the range of saturation exponents reported by García-Salaberri et al. [15,16].

8) Energy: PEM, CLs, MPLs, GDLs, channels and BPPs (T). The energy conservation equation determining the temperature field, $T$, is written as follows:

$$
\boldsymbol{\nabla} \cdot\left[\boldsymbol{u}_{\mathbf{g}}\left(\rho_{\mathrm{g}} E_{\mathrm{g}}+p_{\mathrm{g}}\right)\right]-\boldsymbol{\nabla} \cdot\left(\overline{\overline{\boldsymbol{k}}}^{\mathbf{e f f}} \boldsymbol{\nabla} T\right)=S_{\mathrm{T}}
$$

where $\overline{\overline{\boldsymbol{k}}}^{\text {eff }}$ is the effective thermal conductivity tensor, assumed constant for each MEA component (see Table 2), and variable with the gas mixture composition and the liquid saturation for the channels, $k_{\mathrm{ch}}^{\text {eff,ip/tp }}=\left(1-s_{\mathrm{ch}}\right) \sum_{\mathrm{i}} X_{\mathrm{i}} k_{\mathrm{i}} /\left(\sum_{\mathrm{j}} X_{\mathrm{j}} \beta_{\mathrm{ij}}\right)+s_{\mathrm{ch}} k_{\mathrm{lw}}$. Here, $k_{\mathrm{i}}$ and $k_{\mathrm{lw}}$ are the thermal conductivity of gas species $\mathrm{i}$ and of liquid water, respectively, and the parameter $\beta_{\mathrm{ij}}$ is given by Eq. (A.4). The total gas-phase energy is equal to $E_{\mathrm{g}}=h_{\mathrm{g}}-p_{\mathrm{g}} / \rho_{\mathrm{g}}+$ $\left\|\boldsymbol{u}_{\mathrm{g}}\right\|^{2} / 2$, where the sensible enthalpy, $h_{\mathrm{g}}$, is determined as the mass-weighted average of the enthalpy of each species, $h_{\mathrm{g}}=\sum_{\mathrm{i}} Y_{\mathrm{i}} h_{\mathrm{i}}, h_{\mathrm{i}}=\int_{T}^{T}{ }_{\mathrm{ref}} c_{\mathrm{p}, \mathrm{i}} \mathrm{d} T ; c_{\mathrm{p}, \mathrm{i}}$ is the specific heat capacity at constant pressure of species $\mathrm{i}$ and $T^{\mathrm{ref}}=298 \mathrm{~K}$ is the reference temperature.

9) Electronic transport: CLs, MPLs, GDLs and BPPs $\left(\phi_{\mathrm{e}^{-}}\right)$. Electron transport is governed by Poisson's equation:

$$
\boldsymbol{\nabla} \cdot\left(\overline{\overline{\boldsymbol{\sigma}}}_{\mathrm{e}^{-}}^{\text {eff }} \boldsymbol{\nabla} \phi_{\mathrm{e}^{-}}\right)=S_{\mathrm{e}^{-}}
$$

where $\phi_{\mathrm{e}^{-}}$is the electronic potential in the solid phase, and $\overline{\overline{\boldsymbol{\sigma}}}_{\mathrm{e}}^{\text {eff }}$ is the effective electrical conductivity tensor, which is assumed constant for all the cell components. As stated by Ohm's law, $\boldsymbol{j}_{\mathrm{e}^{-}}=\overline{\overline{\boldsymbol{\sigma}}}_{\mathrm{e}^{-}}^{\text {eff }} \boldsymbol{\nabla} \phi_{\mathrm{e}^{-}}$is the electronic flux directed from low to high electronic potentials. 
10) Ionic or protonic transport: PEM and CLs $\left(\phi_{\mathrm{H}^{+}}\right)$. As for electron transport, the governing equation for ionic transport can be written as:

$$
-\boldsymbol{\nabla} \cdot\left(\overline{\overline{\boldsymbol{\sigma}}}_{\mathrm{H}^{+}}^{\text {eff }} \boldsymbol{\nabla} \phi_{\mathrm{H}^{+}}\right)=S_{\mathrm{H}^{+}}
$$

where $\phi_{\mathrm{H}^{+}}$is the ionic potential in the electrolyte phase, and $\overline{\overline{\boldsymbol{\sigma}}}_{\mathrm{H}^{+}}^{\text {eff }}$ is the effective ionic conductivity tensor, which depends on the dissolved water content, $\lambda$, the temperature, $T$, and the electrolyte volume fraction, $\omega_{\mathrm{e}}[101]$. An isotropic Bruggeman correlation $\left(\omega_{\mathrm{e}}^{1.5}\right)$ is used to correct the ionic conductivity in the catalyst layers [128]. The protonic flux, directed from high to low ionic potentials, is equal to $\boldsymbol{j}_{\mathrm{H}^{+}}=-\overline{\overline{\boldsymbol{\sigma}}}_{\mathrm{H}^{+}}^{\text {eff }} \boldsymbol{\nabla} \phi_{\mathrm{H}^{+}}$.

11) Water content per sulfonic acid group: PEM and CLs ( $\lambda)$. According to Springer et al. [13], the conservation equation for the water content per sulfonic acid group in the electrolyte, $\lambda$, is given by

$$
\boldsymbol{\nabla} \cdot\left(\frac{\mathrm{n}_{\mathrm{d}}^{\mathrm{w}}}{F} \boldsymbol{j}_{\mathrm{H}^{+}}\right)-\boldsymbol{\nabla} \cdot\left[\left(\frac{\rho_{\mathrm{e}}}{E W_{\mathrm{e}}}\right) \overline{\overline{\boldsymbol{D}}}_{\mathrm{w}, \mathrm{e}}^{\mathrm{eff}} \boldsymbol{\nabla} \lambda\right]=S_{\lambda}
$$

where $V_{\mathrm{m}, \mathrm{e}}=E W_{\mathrm{e}} / \rho_{\mathrm{e}}$ is the molar volume of the electrolyte. The first term on the left hand side accounts for electro-osmotic drag of water due to ionic transport from anode to cathode, while the second term represents diffusion of dissolved water. $\mathrm{n}_{\mathrm{d}}^{\mathrm{w}}$ and $\overline{\overline{\boldsymbol{D}}_{\mathbf{w}, \mathrm{e}}}$ eff are the electroosmotic drag coefficient and the effective diffusivity tensor of dissolved water in the electrolyte phase, respectively. According to Kulikovsky [118] and Zhao et al. [23], $\overline{\bar{D}}_{\mathbf{w}, \mathbf{e}}^{\text {eff }}$ increases nonlinearly with the water content $\lambda$. In addition, $\overline{\bar{D}}_{\mathbf{w}, \mathbf{e}}^{\text {eff }}$ is corrected in the catalyst layers as a function of the electrolyte volume fraction by a Bruggeman correlation $\left(\omega_{\mathrm{e}}^{1.5}\right)[128]$. $\mathrm{n}_{\mathrm{d}}^{\mathrm{W}}$ is modeled by a continuous piece-wise function based on the works of Weber and Newman [12] and Springer et al. [13] 


$$
\mathrm{n}_{\mathrm{d}}^{\mathrm{w}}= \begin{cases}\lambda, & \lambda<1 \\ 1, & 1 \leq \lambda<\left.\lambda_{\mathrm{eq}}\right|_{a_{\mathrm{H}_{2} \mathrm{O}}=1} \\ 1+\frac{1}{4}\left(\lambda-\left.\lambda_{\mathrm{eq}}\right|_{a_{\mathrm{H}_{2} \mathrm{O}}=1}\right), & \lambda \geq\left.\lambda_{\mathrm{eq}}\right|_{a_{\mathrm{H}_{2} \mathrm{O}}=1}\end{cases}
$$

where $\lambda_{\text {eq }}$ is the equilibrium water content in the electrolyte and $a_{\mathrm{H}_{2} \mathrm{O}}=p_{\mathrm{H}_{2} \mathrm{O}} / p_{\mathrm{H}_{2} \mathrm{O}}^{\mathrm{sat}}$ is the water activity. The linear increase of $n_{d}^{w}$ for $\lambda \geq \lambda$ eq $\left.\right|_{a_{\mathrm{H}_{2} \mathrm{O}}=1}$ accounts for the raise of $\mathrm{n}_{\mathrm{d}}^{\mathrm{w}}$ observed in membranes equilibrated with liquid water $[12,13]$.

12-13) Liquid-phase flow: CLs, MPLs, GDLs and channels ( $s_{\text {mea }}$ and $\left.s_{\mathrm{ch}}\right)$. Ignoring any effect of gas-phase convection (and gravity), capillary transport of liquid water in the MEA is described through a non-homogeneous Richard's equation $[106,114]$. In addition, the liquid water flow in the channels is modeled through a non-homogeneous diffusive Burger's-type equation, i.e.,

$$
\begin{aligned}
& -\boldsymbol{\nabla} \cdot\left(\overline{\overline{\boldsymbol{D}}}_{\mathrm{lw}, \text { mea }}^{\text {eff }} \boldsymbol{\nabla} s_{\text {mea }}\right) \quad=S_{\mathrm{ml}} \quad \text { in CL, MPL and GDL } \\
& \boldsymbol{\nabla} \cdot\left(\rho_{\mathrm{lw}} \boldsymbol{u}_{\mathrm{lw}, \mathbf{c h}} S_{\mathrm{ch}}\right)-\boldsymbol{\nabla} \cdot\left(\overline{\overline{\boldsymbol{D}}}_{\mathbf{l w}, \mathbf{c h}}^{\text {eff }} \boldsymbol{\nabla} s_{\mathrm{ch}}\right)=S_{\mathrm{ml}} \quad \text { in channels }
\end{aligned}
$$

where $\overline{\overline{\boldsymbol{D}}}_{\mathbf{l w} \text {,mea }}^{\text {eff }}$ is the capillary diffusivity tensor, and $\overline{\overline{\boldsymbol{D}}}_{\mathbf{l w}, \mathbf{c h}}^{\text {eff }}$ and $\boldsymbol{u}_{\mathbf{l w}, \mathbf{c h}}$ are the effective diffusivity tensor and velocity of liquid water in the channel, respectively. According to Darcy's law, the capillary diffusivity tensor is given by

$$
\overline{\overline{\boldsymbol{D}}}_{\text {lw,mea }}^{\text {eff }}=-\frac{\rho_{\mathrm{lw}}}{\mu_{\mathrm{lw}}} \frac{\mathrm{d} p_{\mathrm{c}}}{\mathrm{d} s_{\text {mea }}} \overline{\overline{\boldsymbol{K}}} \circ \overline{\overline{\boldsymbol{k}}}_{\mathrm{rlw}}
$$

where $\rho_{\mathrm{lw}}$ and $\mu_{\mathrm{lw}}$ are the density and dynamic viscosity of liquid water, and $\overline{\overline{\boldsymbol{K}}}$ and $\overline{\boldsymbol{k}}_{\text {rlw }}$ are the absolute and liquid-phase relative permeability tensors, respectively. The capillary pressure, $p_{c}$, is expressed as a function of liquid saturation, $s_{\text {mea }}$, using the semi-empirical correlation proposed by Leverett [129], $p_{\mathrm{c}}=p_{\mathrm{g}}-p_{\mathrm{l}}=\left(\sigma \cos \theta_{\mathrm{c}} \varepsilon /\|\boldsymbol{K}\|\right) J\left(s_{\text {mea }}\right)$, where $\sigma$ is the surface tension of the immiscible liquid-gas pair, $\theta_{\text {c }}$ is the contact angle, $\|\overline{\overline{\boldsymbol{K}}}\|=\left(\overline{\overline{\boldsymbol{K}}}: \overline{\overline{\boldsymbol{K}}}^{\mathbf{T}}\right)^{1 / 2}$ 
is the magnitude of the absolute permeability tensor [130], and $J\left(s_{\text {mea }}\right)$ is the so-called Leverett J-function, which is equal to $J\left(s_{\text {mea }}\right)=1.4 s_{\text {mea }}-2.1 s_{\text {mea }}^{2}+1.3 s_{\text {mea }}^{3}$ for $\theta_{c} \geq 90^{\circ}$.

The liquid-phase velocity in the flow channel, $\boldsymbol{u}_{\mathbf{l w}, \mathbf{c h}}$, is assumed to have the same direction and orientation of the gas-phase velocity, $\boldsymbol{u}_{\mathbf{g}}$, and a dispersion linearly proportional to $s_{\mathrm{ch}}$, i.e.,

$$
\boldsymbol{u}_{\mathrm{lw}, \mathrm{ch}}=\left.u_{\mathrm{lw}, \mathrm{ch}}\right|_{\mathrm{s}=1} s_{\mathrm{ch}} \frac{\boldsymbol{u}_{\mathrm{g}}}{\left\|\boldsymbol{u}_{\mathrm{g}}\right\|}
$$

where $\left.u_{\mathrm{lw}, \mathrm{ch}}\right|_{\mathrm{s}=1}$ is the liquid-phase velocity under fully-saturated conditions, and $\left\|\boldsymbol{u}_{\mathrm{g}}\right\|$ is the magnitude of the superficial gas-phase velocity. This modeling approach provides a good approximation to the flow patterns observed in the neutron experiments.

\section{A.3. Source terms}

The source terms include the electrochemical reaction rates, the mass transfer rates between the different phases of water, the Darcy's viscous resistance, and the release and absorption rates of heat in the various cell components. Table 4 summarizes the regions where the different source terms are applied. 


\begin{tabular}{|c|c|c|c|c|c|c|c|}
\hline $\begin{array}{l}\text { Domain } \rightarrow \\
\downarrow \text { Source }\end{array}$ & PEM & $\begin{array}{c}\text { Anode } \\
\text { catalyst layer }\end{array}$ & $\begin{array}{c}\text { Cathode } \\
\text { catalyst layer }\end{array}$ & MPL & GDL & Channel & BPP \\
\hline$S_{\mathrm{mg}}$ & - & $-M_{\mathrm{H}_{2} \mathrm{O}}\left(S_{\mathrm{v} \lambda}+S_{\mathrm{vl}}\right)-M_{\mathrm{H}_{2}} \frac{R R_{\mathrm{a}}}{2 F}$ & $-M_{\mathrm{H}_{2} \mathrm{O}}\left(S_{\mathrm{v} \lambda}+S_{\mathrm{vl}}\right)-M_{\mathrm{O}_{2}} \frac{R R_{\mathrm{c}}}{4 F}$ & $-M_{\mathrm{H}_{2} \mathrm{O}} S_{\mathrm{vl}}$ & $-M_{\mathrm{H}_{2} \mathrm{O}} S_{\mathrm{vl}}$ & $-M_{\mathrm{H}_{2} \mathrm{O}} S_{\mathrm{vl}}$ & - \\
\hline$S_{\text {ug }}$ & - & $-\mu_{\mathrm{g}}\left(\overline{\overline{\mathbf{1} / \boldsymbol{K}}} \circ \overline{\overline{\mathbf{1}} / \boldsymbol{k}}_{\mathrm{rg}}\right) \boldsymbol{u}_{\mathrm{g}}$ & $-\mu_{\mathrm{g}}\left(\overline{\overline{\mathbf{1} / \boldsymbol{K}}} \circ{\overline{\overline{\mathbf{1}} / \overline{\boldsymbol{k}}_{\mathrm{rg}}}}\right) \boldsymbol{u}_{\mathrm{g}}$ & $-\mu_{\mathrm{g}}\left(\overline{\overline{\mathbf{1} / \boldsymbol{K}}} \circ \overline{\overline{\mathbf{1}} / \boldsymbol{k}}_{\mathrm{rg}}\right) \boldsymbol{u}_{\mathrm{g}}$ & $-\mu_{\mathrm{g}}\left(\overline{\overline{\mathbf{1} / \boldsymbol{K}}} \circ \overline{\overline{\mathbf{1}} / \boldsymbol{k}}_{\mathrm{rg}}\right) \boldsymbol{u}_{\mathrm{g}}$ & $-\mu_{\mathrm{g}}\left(\overline{\overline{\mathbf{1} / \boldsymbol{K}}} \circ \overline{\overline{\mathbf{1}} / \boldsymbol{k}}_{\mathrm{rg}}\right) \boldsymbol{u}_{\mathrm{g}}$ & - \\
\hline$S_{\mathrm{O}_{2}}$ & - & - & $-M_{\mathrm{O}_{2}} \frac{R R_{\mathrm{c}}}{4 F}$ & 0 & 0 & 0 & - \\
\hline$S_{\mathrm{H}_{2}}$ & - & $-M_{\mathrm{H}_{2}} \frac{R R_{\mathrm{a}}}{2 F}$ & 0 & 0 & 0 & 0 & - \\
\hline$S_{\mathrm{H}_{2} \mathrm{O}}$ & - & $-M_{\mathrm{H}_{2} \mathrm{O}}\left(S_{\mathrm{v} \lambda}+S_{\mathrm{vl}}\right)$ & $-M_{\mathrm{H}_{2} \mathrm{O}}\left(S_{\mathrm{v} \lambda}+S_{\mathrm{vl}}\right)$ & $-M_{\mathrm{H}_{2} \mathrm{O}} S_{\mathrm{vl}}$ & $-M_{\mathrm{H}_{2} \mathrm{O}} S_{\mathrm{vl}}$ & $-M_{\mathrm{H}_{2} \mathrm{O}} S_{\mathrm{vl}}$ & - \\
\hline$S_{\mathrm{T}}$ & $S_{\mathrm{T}, \mathrm{H}^{+}}$ & $\begin{aligned} & S_{\mathrm{T}, \mathrm{act}}+S_{\mathrm{T}, \mathrm{ohm}}+M_{\mathrm{H}_{2} \mathrm{O}}\left(S_{\mathrm{T}, \mathrm{vl}}\right. \\
+ & \left.S_{\mathrm{T}, \mathrm{v} \lambda}\right)\end{aligned}$ & $S_{\mathrm{T}, \mathrm{rev}}+S_{\mathrm{T}, \mathrm{act}}+S_{\mathrm{T}, \mathrm{ohm}}+M_{\mathrm{H}_{2} \mathrm{O}}\left(S_{\mathrm{T}, \mathrm{vl}}+S_{\mathrm{T}, \mathrm{v} \lambda}\right)$ & $S_{\mathrm{T}, \mathrm{e}^{-}}+M_{\mathrm{H}_{2} \mathrm{O}} S_{\mathrm{T}, \mathrm{vl}}$ & $S_{\mathrm{T}, \mathrm{e}^{-}}+M_{\mathrm{H}_{2} \mathrm{O}} S_{\mathrm{T}, \mathrm{vl}}$ & $M_{\mathrm{H}_{2} \mathrm{O}} S_{\mathrm{T}, \mathrm{vl}}$ & $S_{\mathrm{T}, \mathrm{e}^{-}}$ \\
\hline$S_{\mathrm{e}^{-}}$ & 0 & $R R_{\mathrm{a}}$ & $-R R_{\mathrm{c}}$ & 0 & 0 & 0 & 0 \\
\hline$S_{\mathrm{H}^{+}}$ & 0 & $R R_{\mathrm{a}}$ & $-R R_{\mathrm{c}}$ & 0 & 0 & 0 & 0 \\
\hline$S_{\lambda}$ & 0 & $S_{\mathrm{v} \lambda}$ & $S_{\mathrm{v} \lambda}+\frac{R R_{\mathrm{c}}}{2 F}$ & 0 & 0 & 0 & 0 \\
\hline$S_{\mathrm{ml}}$ & 0 & $M_{\mathrm{H}_{2} \mathrm{O}} S_{\mathrm{vl}}$ & $M_{\mathrm{H}_{2} \mathrm{O}} S_{\mathrm{vl}}$ & $M_{\mathrm{H}_{2} \mathrm{O}} S_{\mathrm{vl}}$ & $M_{\mathrm{H}_{2} \mathrm{O}} S_{\mathrm{vl}}$ & $M_{\mathrm{H}_{2} \mathrm{O}} S_{\mathrm{vl}}$ & 0 \\
\hline
\end{tabular}

Table 4: Source terms appearing in the conservation equations of the numerical model. The gas flow and species mass fractions are not defined in the solid membrane (PEM) and bipolar plates (BPPs).

- Reaction rates (charge/mass electrochemical consumption and production). The half-cell reactions corresponding to the fast hydrogen oxidation reaction in the anode catalyst layer and the sluggish oxygen reduction reaction in the cathode catalyst layer are $\mathrm{H}_{2} \rightarrow 2 \mathrm{H}^{+}+2 \mathrm{e}^{-}$ and $(1 / 2) \mathrm{O}_{2}+2 \mathrm{H}^{+}+2 \mathrm{e}^{-} \rightarrow \mathrm{H}_{2} \mathrm{O}$, respectively. The volumetric current densities of both reactions are modeled through Butler-Volmer equations [2,94]:

$$
\begin{gathered}
R R_{\mathrm{a}}=\left(1-s_{\text {mea }}\right)\left(\frac{C_{\mathrm{H}_{2}}}{C_{\mathrm{H}_{2}}^{\text {ref }}}\right)^{\gamma_{\mathrm{a}}} i_{0, \mathrm{a}}\left[\exp \left(\frac{\alpha_{\mathrm{a}} F}{R T} \eta_{\mathrm{a}}\right)-\exp \left(-\frac{\left(1-\alpha_{\mathrm{a}}\right) F}{R T} \eta_{\mathrm{a}}\right)\right] \\
R R_{\mathrm{c}}=\left(1-s_{\text {mea }}\right) a_{+}\left(\frac{C_{\mathrm{O}_{2}}}{C_{\mathrm{O}_{2}}^{\mathrm{ref}}}\right)^{\gamma_{\mathrm{c}}} i_{0, \mathrm{c}}\left[\exp \left(-\frac{\alpha_{\mathrm{c}} F}{R T} \eta_{\mathrm{c}}\right)-\exp \left(\frac{\left(1-\alpha_{\mathrm{c}}\right) F}{R T} \eta_{\mathrm{c}}\right)\right]
\end{gathered}
$$

where $i_{0}$ is the volumetric exchange current density, $\alpha$ is the transfer coefficient describing the symmetry of the reactions, $\gamma$ is the reaction order, $C^{\text {ref }}$ and $C=Y_{i} \rho_{\mathrm{g}} / M_{\mathrm{i}}$ are the reference and actual molar concentrations, and $\eta$ is the overpotential, defined as $\eta=\phi_{\mathrm{e}^{-}}-\phi_{\mathrm{H}^{+}}$in both electrodes [105]. The pre-factor $\left(1-s_{\text {mea }}\right)$ takes into account the reduction of the reaction active area due to liquid water blockage, while the parameter $a_{+}$represents the electrochemical activity of solvated protons (hiydronium). According to Bao and Bessler [94], $a_{+}$is modeled by the following ramp function depending on the dissolved water content: 
$a_{+}=\lambda / 2.5$ if $\lambda<2.5, a_{+}=1$ if $\lambda \geq 2.5$. The decrease of $a_{+}$affects the cathode reaction rate when the membrane is significantly dry, further reducing the output current density $[25,94]$.

The source terms for the electronic and ionic potentials due to generation/consumption of electrons are given by $S_{\mathrm{e}^{-}}=S_{\mathrm{H}^{+}}=R R_{\mathrm{a}}$ and $S_{\mathrm{e}^{-}}=S_{\mathrm{H}^{+}}=-R R_{\mathrm{c}}$ in the anode and cathode catalyst layers, respectively. According to Faraday's law and the reaction stoichiometry, the production/consumption rates of hydrogen, oxygen and dissolved water are $S_{\mathrm{H}_{2}}=-R R_{\mathrm{a}} / 2 F$, $S_{\mathrm{O}_{2}}=-R R_{\mathrm{c}} / 4 F$ and $S_{\lambda, \text { prod }}=R R_{\mathrm{c}} / 2 F$, where the minus sign denotes consumption.

- Water evaporation and condensation. The evaporation/condensation rate of water is modeled by the following expression $[2,54]$ :

$$
S_{\mathrm{vl}}= \begin{cases}\frac{k_{\mathrm{evp}} \varepsilon s \rho_{\mathrm{lw}}}{M_{\mathrm{H}_{2} \mathrm{O}}}\left(p_{\mathrm{H}_{2} \mathrm{O}}-p_{\mathrm{H}_{2} \mathrm{O}}^{\mathrm{sat}}\right), & p_{\mathrm{H}_{2} \mathrm{O}}<p_{\mathrm{H}_{2} \mathrm{O}, \mathrm{sat}} \\ \frac{k_{\mathrm{con}} \varepsilon(1-s) X_{\mathrm{H}_{2} \mathrm{O}}}{R T}\left(p_{\mathrm{H}_{2} \mathrm{O}}-p_{\mathrm{H}_{2} \mathrm{O}}^{\mathrm{sat}}\right), & p_{\mathrm{H}_{2} \mathrm{O}} \geq p_{\mathrm{H}_{2} \mathrm{O}, \text { sat }}\end{cases}
$$

where $k_{\text {evp }}$ and $k_{\text {con }}$ are the evaporation and condensation rate constants, $V_{\mathrm{m}, \mathrm{lw}}=M_{\mathrm{H}_{2} \mathrm{O}} / \rho_{\mathrm{lw}}$ is the molar volume of liquid water, $X_{\mathrm{H}_{2} \mathrm{O}}=C_{\mathrm{H}_{2} \mathrm{O}} R T / p_{\mathrm{g}}$ is the mole fraction of water vapor, and the driving force is the difference between the partial and saturation vapor pressures of water, $p_{\mathrm{H}_{2} \mathrm{O}}=C_{\mathrm{H}_{2} \mathrm{O}} R T$ and $p_{\mathrm{H}_{2} \mathrm{O}}^{\text {sat }}(T)$, respectively.

- Water sorption and desorption. The sorption/desorption rate between water vapor and dissolved water in the catalyst layers has the following form:

$$
S_{\mathrm{v} \lambda}= \begin{cases}\frac{k_{\mathrm{sor}} \rho_{\mathrm{e}}}{E W_{\mathrm{e}}}\left(\lambda_{\mathrm{eq}}-\lambda\right), & \lambda<\lambda_{\mathrm{eq}} \\ \frac{k_{\mathrm{des}} \rho_{\mathrm{e}}}{E W_{\mathrm{e}}}\left(\lambda_{\mathrm{eq}}-\lambda\right), & \lambda \geq \lambda_{\mathrm{eq}}\end{cases}
$$


where $k_{\text {sor }}$ and $k_{\text {des }}$ are the sorption and desorption rate constants, and the driving force is the difference between the equilibrium $\left(\lambda_{\text {eq }}\right)$ and actual $(\lambda)$ water contents in the electrolyte. The sorption and desorption rate constants are modeled using the empirical data of Ge et al. [26]:

$$
k_{\mathrm{des}}=\frac{4.59 \times 10^{-5} f_{\mathrm{V}}}{\delta_{\mathrm{cl}}} \exp \left[2416\left(\frac{1}{303}-\frac{1}{T}\right)\right], k_{\mathrm{sor}}=\frac{1.14 \times 10^{-5} f_{\mathrm{V}}}{\delta_{\mathrm{cl}}} \exp \left[2416\left(\frac{1}{303}-\frac{1}{T}\right)\right]
$$

where $f_{\mathrm{V}}=\lambda V_{\mathrm{m}, \mathrm{lw}} /\left(V_{\mathrm{m}, \mathrm{e}}+\lambda V_{\mathrm{m}, \mathrm{lw}}\right)$ is the water volume fraction in the electrolyte. The equilibrium water content is determined through the family of sorption isotherms reported by Liu et al. [102]:

$$
\lambda_{\text {eq }}= \begin{cases}{\left[1+0.2 a_{\mathrm{H}_{2} \mathrm{O}}^{2}\left(\frac{T-303.1}{30}\right)\right]\left(14.2 a_{\mathrm{H}_{2} \mathrm{O}}^{3}-18.9 a_{\mathrm{H}_{2} \mathrm{O}}^{2}+13.4 a_{\mathrm{H}_{2} \mathrm{O}}\right),} & a_{\mathrm{H}_{2} \mathrm{O}}<1 \\ \left.\lambda_{\text {eq }}\right|_{a_{\mathrm{H}_{2} \mathrm{O}} \mathrm{O}}+6\left(a_{\mathrm{H}_{2} \mathrm{O}}+2 s_{\text {mea }}-1\right), & a_{\mathrm{H}_{2} \mathrm{O}} \geq 1\end{cases}
$$

where the term $6\left(a_{\mathrm{H}_{2} \mathrm{O}}+2 s_{\text {mea }}-1\right)$ accounts for the raise of the equilibrium water content when the electrolyte is in contact with liquid water rather than with water vapor $[12,13]$.

- Darcy's viscous resistance. The momentum sink term of the gas flow due to Darcy's viscous resistance can be written as:

$$
S_{\text {ug }}=-\mu_{\mathrm{g}}\left(\overline{\overline{\mathbf{1} / \boldsymbol{K}}} \circ \overline{\overline{\mathbf{1}} / \boldsymbol{k}}_{\mathrm{rg}}\right) \boldsymbol{u}_{\mathrm{g}}
$$

where $\overline{\overline{\mathbf{1}} \overline{\mathbf{K}}}$ and $\overline{\overline{\mathbf{1}} \mathbf{k}}_{\text {rg }}$ are the element-wise inverse gas-phase absolute permeability and relative permeability tensors, the latter accounting for the resistance of liquid water saturation on gas convection. An isotropic third-order correlation is used to model $\overline{\boldsymbol{k}}_{\mathrm{rg}}$ in the porous media of the MEA, $k_{\mathrm{rg}}^{\mathrm{ip} / \mathrm{tp}}=\left(1-s_{\text {mea }}\right)^{3}$. The absolute permeability of the channel is calculated based on the hydraulic conductance of a Hagen-Poiseuille flow in a square cross- 
section channel $[95,96], K_{\mathrm{ch}}^{\mathrm{ip} / \mathrm{tp}}=c\left(d_{\mathrm{h}}^{2} / 32\right)$, where $c=1.127$ is the flow shape factor and $d_{\mathrm{h}}=H_{\mathrm{ch}}=w_{\mathrm{ch}}$ is the square channel hydraulic diameter. This expression yields a channel absolute permeability $K_{\mathrm{ch}}^{\mathrm{ip} / \mathrm{tp}}=3.52 \times 10^{-8} \mathrm{~m}^{2}$, which is three orders of magnitude larger than the through-plane permeability of SIGRACET $^{\oplus}$ substrates subjected to moderate compressive loads, $K_{\mathrm{gdl}} \sim \mathcal{O}\left(10^{-11}\right) \mathrm{m}^{2}[103,125,126]$. The channel relative permeability is modeled through a fourth-order power law, $k_{\mathrm{rg}}^{\mathrm{ip} / \mathrm{tp}}=\left(1-s_{\mathrm{ch}}\right)^{4}$, according to the expressions adopted by Wang et al. [95] to improve the pressure drop predictions of their model under two-phase conditions.

- Heat release and absorption. Five heat sources can be distinguished in PEFCs, namely: i) heat release by the electrochemical reactions at the reversible cell voltage, $S_{\mathrm{T}, \mathrm{rev}}$; ii) activation or irreversible electrochemical heat generation due to cell operation at a voltage different from equilibrium, $S_{\mathrm{T} \text {,act }}$; iii) ohmic (Joule) heating due to electronic and ionic transport, $S_{\mathrm{T}, \mathrm{ohm}}$; iv) latent heat due to water condensation and evaporation, $S_{\mathrm{T}, \mathrm{vl}}$; and v) latent heat due to water sorption/desorption into/from the electrolyte, $S_{\mathrm{T}, \mathrm{v} \lambda}$. The expressions of each term are as follows:

$$
\begin{aligned}
& S_{\mathrm{T}, \mathrm{rev}}=\frac{R R_{\mathrm{c}}}{4 F}(T \Delta S), S_{\mathrm{T}, \mathrm{act}}=\left|\eta_{\mathrm{i}} R R_{\mathrm{i}}\right|, S_{\mathrm{T}, \mathrm{ohm}}=S_{\mathrm{T}, \mathrm{e}^{-}}+S_{\mathrm{T}, \mathrm{H}^{+}}=\frac{\left\|\boldsymbol{j}_{\mathrm{e}^{-}}\right\|^{2}}{\left\|\overline{\overline{\boldsymbol{\sigma}}}_{\mathrm{e}} \mathbf{e f f}\right\|}+\frac{\left\|\boldsymbol{j}_{\mathrm{H}^{+}}\right\|^{2}}{\left\|\overline{\overline{\boldsymbol{\sigma}}}_{\mathrm{H}^{+}}^{\text {eff }}\right\|}, \\
& S_{\mathrm{T}, \mathrm{vl}}=h_{\mathrm{gl}} S_{\mathrm{vl}}, S_{\mathrm{T}, \mathrm{v} \lambda}=h_{\mathrm{gl}, \mathrm{e}} S_{\mathrm{v} \lambda}
\end{aligned}
$$

where $\Delta S$ is the entropy change of the oxygen reduction reaction for liquid water production (assumed here as water dissolved in the electrolyte), $\left\|\boldsymbol{j}_{\mathrm{e}^{-}}\right\|^{2}$ and $\left\|\boldsymbol{j}_{\mathbf{H}^{+}}\right\|^{2}$ are the squared

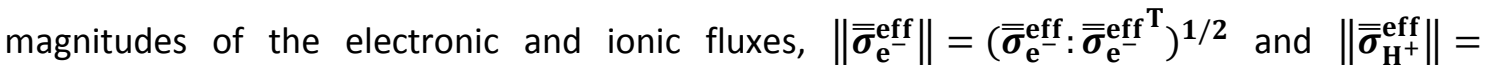
$\left(\overline{\bar{\sigma}}_{\mathbf{H}^{+}}^{\text {eff }}: \overline{\overline{\boldsymbol{\sigma}}}_{\mathbf{H}^{+}}^{\text {eff }^{\mathbf{T}}}\right)^{\mathbf{1 / 2}}$ are the magnitudes of the electrical and ionic conductivity tensors [130], $h_{\mathrm{gl}}$ is the latent heat of water evaporation/condensation, and $h_{\mathrm{gl}, \mathrm{e}}$ is the latent heat of water 
sorption/desorption, which is assumed equal to $h_{\mathrm{gl}}$ in this work. The absolute value in the expression for $S_{\mathrm{T} \text {,act }}$ takes into account the negative overpotentials present in the cathode catalyst layer $(\mathrm{i}=\mathrm{c})$.

\section{A.4. Boundary conditions}

The boundary conditions prescribed at the internal and external surfaces of the computational domain are presented below. The set of internal boundaries includes the fluid-fluid and fluidsolid interfaces between components, whereas the set of external boundaries includes the sidewalls of the cell, the anode and cathode channel inlets/outlets, and the bipolar plate terminals (see Figure 2).

- Internal interfaces. A continuity boundary condition is prescribed at all internal interfaces between fluid regions (catalyst layers, MPLs, GDLs and channels). In contrast, at the walls between fluid and solid regions (i.e., channel/BPP, GDL/BPP and CL/PEM interfaces) different boundary conditions are used depending on the variable of interest. For user-defined scalars $\left(\phi_{\mathrm{e}^{-}}, \phi_{\mathrm{H}^{+}}, \lambda, s_{\text {mea }}\right.$ and $\left.s_{\mathrm{ch}}\right)$, we impose a continuity boundary condition according to the single-domain approach adopted here (see Section A.5). For temperature, we also prescribe a continuity boundary condition since the energy equation holds for all cell components. For species, we set a zero-gradient boundary condition $\left(\nabla Y_{\mathrm{i}} \cdot \mathbf{n}=0\right)$. Finally, for the gas flow we consider an impermeable no-slip boundary condition $\left(\boldsymbol{u}_{\mathrm{g}}=\mathbf{0}\right)$ at all interfaces except the channel/BPP wall. There, we impose an impermeable free-slip boundary condition $\left(\boldsymbol{u}_{\mathbf{g}} \cdot \mathbf{n}=\mathbf{0}\right.$, $\tau^{\mathrm{ip} / \mathrm{tp}}=0$ ) according to the porous media assumption used to model the gas flow in the channels [96]. The symbol $\mathbf{n}$ stands for the outward unit normal vector.

- Sidewalls. The sidewalls of the fluid regions are considered isolated impermeable nonconducting surfaces, so that impermeable no-slip $\left(\boldsymbol{u}_{\mathbf{g}}=\mathbf{0}\right)$ and zero-gradient $(\nabla \Phi \cdot \mathbf{n}=0)$ 
boundary conditions are imposed for the gas flow and the remaining variables $(\Phi=$ $Y_{\mathrm{H}_{2}}, Y_{\mathrm{O}_{2}}, Y_{\mathrm{H}_{2} \mathrm{O}}, T, \phi_{\mathrm{e}^{-}}, \phi_{\mathrm{H}^{+}}, \lambda$ and $\left.s_{\mathrm{mea}}\right)$, respectively. At the sidewalls of the solid membrane and bipolar plates where the gas phase is not defined, a zero-gradient boundary condition is set for $\Phi=T, \phi_{\mathrm{e}^{-}}, \phi_{\mathrm{H}^{+}}, \lambda$ and $s_{\text {mea }}$.

- Anode and cathode channel inlets/outlets. At the anode channel inlet, the gas mass flux, hydrogen and water vapor mass fractions, gas temperature and liquid water convective flux are specified, while a zero-gradient boundary condition is set for the remaining variables (i.e., $\phi_{\mathrm{e}^{-}}, \phi_{\mathrm{H}^{+}}$and $\left.\lambda\right)$

$$
\begin{aligned}
& \left(\rho_{\mathrm{g}} \boldsymbol{u}_{\mathbf{g}}\right) \cdot \mathbf{n}=-\dot{m}_{\mathrm{H}_{2}}^{\text {in }} /\left[A_{\mathrm{ch}}\left(1-Y_{\mathrm{H}_{2} \mathrm{O}, \mathrm{a}}^{\text {in }}\right)\right], Y_{\mathrm{H}_{2}}=Y_{\mathrm{H}_{2}}^{\text {in }}, Y_{\mathrm{H}_{2} \mathrm{O}}=Y_{\mathrm{H}_{2} \mathrm{O}, \mathrm{a}}^{\text {in }}, T=T_{\mathrm{a}}^{\text {in }}, \\
& \left(\rho_{\mathrm{lw}} \boldsymbol{u}_{\mathbf{l w}, \mathbf{c h}} S_{\mathrm{ch}}\right) \cdot \mathbf{n}=-\rho_{\mathrm{lw}}^{\text {in }}\left\|\boldsymbol{u}_{\mathbf{l w}, \mathbf{c h}, \mathbf{a}}^{\text {in }}\right\| s_{\mathrm{ch}, \mathbf{a}}^{\mathrm{in}}, \nabla \Phi \cdot \mathbf{n}=0
\end{aligned}
$$

where $\dot{m}_{\mathrm{H}_{2}}^{\text {in }}=\rho_{\mathrm{H}_{2}}^{\text {std }} Q_{\mathrm{H}_{2}}$ is the inlet hydrogen mass flow rate, $A_{\mathrm{ch}}$ is the channel cross-sectional area, $T_{\mathrm{a}}^{\mathrm{in}}$ is the inlet gas temperature, $\rho_{\mathrm{lw}}^{\mathrm{in}}$ is the density of liquid water at the channel inlet, $\left\|\boldsymbol{u}_{\mathrm{lw}, \mathbf{c h}, \mathbf{a}}^{\mathrm{in}}\right\|=\left.u_{\mathrm{lw}, \mathrm{ch}}\right|_{\mathrm{s}=1} s_{\mathrm{ch}, \mathrm{a}}^{\mathrm{in}}$ is the magnitude of the inlet velocity of liquid water, and $s_{\mathrm{ch}, \mathrm{a}}^{\mathrm{in}}$ is the inlet saturation. According to the ideal gas law, the inlet mass fractions of hydrogen and water vapor are given by $Y_{\mathrm{H}_{2}}^{\text {in }}=C_{\mathrm{H}_{2}}^{\text {in }} M_{\mathrm{H}_{2}} /\left(C_{\mathrm{H}_{2} \mathrm{O}, \mathrm{a}}^{\text {in }} M_{\mathrm{H}_{2} \mathrm{O}}+C_{\mathrm{H}_{2}}^{\text {in }} M_{\mathrm{H}_{2}}\right)$ and $Y_{\mathrm{H}_{2} \mathrm{O}, \mathrm{a}}^{\text {in }}=1-Y_{\mathrm{H}_{2}}^{\text {in }}$, being the molar concentrations: $C_{\mathrm{H}_{2}}^{\text {in }}=\left[p_{\mathrm{g}, \mathrm{a}}^{\text {in }}-\mathrm{RH}_{\mathrm{a}}^{\mathrm{in}} p_{\mathrm{H}_{2} \mathrm{O}}^{\text {sat }}\left(T_{\mathrm{a}}^{\mathrm{in}}\right)\right] /\left(R T_{\mathrm{a}}^{\mathrm{in}}\right)$ and $C_{\mathrm{H}_{2} \mathrm{O}, \mathrm{a}}^{\text {in }}=$ $\mathrm{RH}_{\mathrm{a}}^{\mathrm{in}} p_{\mathrm{H}_{2} \mathrm{O}}^{\mathrm{sat}}\left(T_{\mathrm{a}}^{\mathrm{in}}\right) /\left(R T_{\mathrm{a}}^{\mathrm{in}}\right)$. Here, $\mathrm{RH}_{\mathrm{a}}^{\mathrm{in}}$ is the anode inlet relative humidity and $p_{\mathrm{g}, \mathrm{a}}^{\mathrm{in}}$ is the inlet gas pressure, which is assumed equal to the back-pressure, $p_{\mathrm{g}, \mathrm{a}}^{\text {in }} \cong p_{\mathrm{g}, \mathrm{a}}^{\text {out }}$, for the calculation of the inlet gas composition.

Similarly, the gas mass flux, humid air mass fractions, inlet temperature and liquid water convective flux are prescribed at the cathode channel inlet 


$$
\begin{aligned}
& \left(\rho_{\mathrm{g}} \boldsymbol{u}_{\mathrm{g}}\right) \cdot \mathbf{n}=-\dot{m}_{\mathrm{air}}^{\text {in }} /\left[A_{\mathrm{ch}}\left(1-Y_{\mathrm{H}_{2} \mathrm{O}, \mathrm{c}}^{\mathrm{in}}\right)\right], Y_{\mathrm{O}_{2}}=Y_{\mathrm{O}_{2}}^{\text {in }}, Y_{\mathrm{H}_{2} \mathrm{O}}=Y_{\mathrm{H}_{2} \mathrm{O}, \mathrm{c}}^{\text {in }}, T=T_{\mathrm{c}}^{\text {in }}, \\
& \left(\rho_{\mathrm{lw}} \boldsymbol{u}_{\mathrm{lw}, \mathbf{c h}} S_{\mathrm{ch}}\right) \cdot \mathbf{n}=0, \nabla \Phi \cdot \mathbf{n}=0
\end{aligned}
$$

where $\dot{m}_{\text {air }}^{\text {in }}=\rho_{\text {air }}^{\text {std }} Q_{\text {air }}$ is the inlet air mass flow rate. The inlet mass fractions of oxygen and water vapor are given by $Y_{\mathrm{O}_{2}}^{\text {in }}=C_{\mathrm{O}_{2}}^{\text {in }} M_{\mathrm{O}_{2}} /\left(C_{\mathrm{O}_{2}}^{\mathrm{in}} M_{\mathrm{O}_{2}}+C_{\mathrm{H}_{2} \mathrm{O}, \mathrm{c}}^{\mathrm{in}} M_{\mathrm{H}_{2} \mathrm{O}}+C_{\mathrm{N}_{2}}^{\text {in }} M_{\mathrm{N}_{2}}\right)$ and $Y_{\mathrm{H}_{2} \mathrm{O}, \mathrm{c}}^{\text {in }}=$ $C_{\mathrm{H}_{2} \mathrm{O}, \mathrm{c}}^{\text {in }} M_{\mathrm{H}_{2} \mathrm{O}} /\left(C_{\mathrm{O}_{2}}^{\text {in }} M_{\mathrm{O}_{2}}+C_{\mathrm{H}_{2} \mathrm{O}, \mathrm{c}}^{\text {in }} M_{\mathrm{H}_{2} \mathrm{O}}+C_{\mathrm{N}_{2}}^{\text {in }} M_{\mathrm{N}_{2}}\right)$, being the inlet molar concentrations: $C_{\mathrm{O}_{2}}^{\text {in }}=X_{\mathrm{O}_{2, \text { air }}}\left[p_{\mathrm{g}, \mathrm{c}}^{\text {in }}-\mathrm{RH}_{\mathrm{c}}^{\mathrm{in}} p_{\mathrm{H}_{2} \mathrm{O}}^{\mathrm{sat}}\left(T_{\mathrm{c}}^{\mathrm{in}}\right)\right] /\left(R T_{\mathrm{c}}^{\mathrm{in}}\right), \quad C_{\mathrm{H}_{2} \mathrm{O}, \mathrm{c}}^{\mathrm{in}}=\mathrm{RH}_{\mathrm{c}}^{\mathrm{in}} p_{\mathrm{H}_{2} \mathrm{O}}^{\mathrm{sat}}\left(T_{\mathrm{c}}^{\mathrm{in}}\right) /\left(R T_{\mathrm{c}}^{\mathrm{in}}\right) \quad$ and $C_{\mathrm{N}_{2}}^{\text {in }}=\left[\left(1-X_{\mathrm{O}_{2, \text { air }}}\right) / X_{\mathrm{O}_{2, \text { air }}}\right] C_{\mathrm{O}_{2}}^{\mathrm{in}}$.

At the channel outlets, the back-pressure is imposed on the anode $(i=a)$ and cathode $(i=c)$ gas streams, $p_{\mathrm{g}}=p_{\mathrm{g}, \mathrm{i}}^{\text {out }}$, while a zero-gradient boundary condition is set for other variables $\left(\Phi=Y_{\mathrm{H}_{2}}, Y_{\mathrm{O}_{2}}, Y_{\mathrm{H}_{2} \mathrm{O}}, T, \phi_{\mathrm{e}^{-}}, \phi_{\mathrm{H}^{+}}, \lambda\right.$ and $\left.s_{\mathrm{ch}}\right), \nabla \Phi \cdot \mathbf{n}=0$.

- Anode and cathode terminals. At the anode terminal (the bottom surface of the anode bipolar plate), the electronic potential is set equal to the electronic potential loss across the cell [105], i.e., $\phi_{\mathrm{e}^{-}}=\mathrm{OCV}-V_{\text {cell }}$, where OCV is the Open-Circuit Voltage. In addition, the temperature is fixed to the cell operating temperature, $T=T_{\text {cell, }}$ and a zero-gradient boundary condition, $\nabla \Phi \cdot \mathbf{n}=0$, is set for other variables $\left(\Phi=\phi_{\mathrm{H}^{+}}\right.$and $\left.\lambda\right)$. At the cathode terminal (the top surface of the cathode bipolar plate), the boundary conditions are the same as those in the anode side, except that the electronic potential is equal to zero $\left(\phi_{\mathrm{e}^{-}}=0\right)$.

\section{A.5. Numerical implementation and solution}

The computational domain was meshed with a structured hexahedral grid of about 1.2 millions of cells. 10 cells were used in the through-plane direction (z-axis) to discretize the membrane, catalyst layers, MPLs and GDLs, and 8 cells for the channels; a through-plane bias factor of 1.5 
was applied in the mesh of each MEA component [108]. In the in-plane direction ( $x$-axis) the number of cells between rib/channel mid-planes was set to 6 , while in the along-the-channel direction (y-axis) it was set to 25 for each unit segment of length $L_{\mathrm{ch}}=4.8 \mathrm{~cm}$ (see Figure 2). The solution computed with this mesh for the baseline case showed a deviation in the average current density lower than 5\% compared to a mesh with 1.6 millions of cells. Therefore, the level of accuracy achieved with the coarser mesh was considered appropriate for this work. Meshes with a similar number of elements and distribution among the three $x, y, z$ directions were used in previous numerical works (see, e.g., $[104,109,110,114,131])$.

The set of coupled partial differential equations was solved in ANSYS ${ }^{\circledR}$ FLUENT with the pressure-based segregated solver, using the SIMPLE algorithm to handle the pressure-velocity coupling, a linear pressure interpolation scheme, a least square cell-based discretization for gradients, and a second-order upwind spatial discretization. The convergence criterion for the residuals was set to $10^{-7}$. User Defined Functions (UDFs) were employed to customize different aspects of the model, including convective terms, source terms, effective transport properties, etc. Furthermore, only one gas mixture was defined in the computational domain, so that nitrogen was considered to be the most abundant species and its mass fraction calculated as $Y_{\mathrm{N}_{2}}=1-\sum_{\mathrm{i}} Y_{\mathrm{i}}$. The hydrogen and oxygen concentrations were fixed to zero in the cathode and anode compartments, respectively, using the standard built-in capabilities of ANSYS ${ }^{\circledR}$ FLUENT, while the nitrogen concentration was kept equal to zero in the anode through "Adjust" and "Execute-at-end" UDFs. This workaround (also adopted by others [110]) slightly increases the computational cost because the equations for both hydrogen and water vapor have to be solved in the anode, but leads to a correct implementation provided that hydrogen and water vapor are treated as a binary mixture (i.e., $D_{\mathrm{H}_{2} \mathrm{O}, \mathrm{H}_{2}}=D_{\mathrm{H}_{2}, \mathrm{H}_{2} \mathrm{O}}$, so that $Y_{\mathrm{H}_{2}}+Y_{\mathrm{H}_{2} \mathrm{O}}=$ 1). The governing equations for the electronic and ionic potentials, $\phi_{\mathrm{e}^{-}}$and $\phi_{\mathrm{H}^{+}}$, dissolved water, $\lambda$, and water saturation in the MEA and the channels, $s_{\text {mea }}$ and $s_{\mathrm{ch}}$, were solved via 
User Define Scalars (UDSs). To simplify the model setup, a single-domain approach was considered. Accordingly, each UDS equation was solved in the entire computational domain, and a small diffusivity of $10^{-16}$ was imposed on the regions where the equations have no physical meaning [132]. This allowed us to simulate no-flux boundary conditions in the interior surfaces delimiting the regions of interest of each UDS (see Section A.2), while specifying a continuity boundary condition in ANSYS ${ }^{\circledR}$ FLUENT (see Section A.4). The minimum ionic

conductivity was limited to $\sigma_{\mathrm{H}^{+}}^{\text {effip/tp }}=10^{-2} \mathrm{~S} \mathrm{~m}^{-1}$ to avoid divergence of the numerical scheme.

\section{References}

[1] M. Ji, Z. Wei, Energies 2 (2009) 1057-1106.

[2] K. Jiao, X. Li, Prog. Energy Combust. Sci. 37 (2011) 221-291.

[3] S.G. Kandlikar, M.L. Garofalo, Z. Lu, Fuel Cells 11 (2011) 814-823.

[4] S.G. Kandlikar, Z. Lu, J. Fuel Cell Sci. Technol. 6 (2009) 044001-044009.

[5] C.-Y. Wang, Chem. Rev. 104 (2004) 4727-65.

[6] A.Z. Weber, R.L. Borup, R.M. Darling, P.K. Das, T.J. Dursch, W. Gu, D. Harvey, A. Kusoglu, S. Litster, M.M. Mench, R. Mukundan, J.P. Owejan, J.G. Pharoah, M. Secanell, I.V. Zenyuk, J. Electrochem. Soc. 161 (2014) F1254-F1299.

[7] A.Z. Weber, J. Newman, Chem. Rev. 104 (2004) 4679-4726.

[8] D.H. Ye, Z.G. Zhan, J. Power Sources 231 (2013) 285-292.

[9] N. Yousfi-Steiner, P. Moçotéguy, D. Candusso, D. Hissel, A. Hernandez, A. Aslanides, J. Power Sources 183 (2008) 260-274.

[10] J. St-Pierre, D.P. Wilkinson, S. Knights, M.L. Bos, J. New Mater. Electrochem. Syst. 3 (2000) 99-106.

[11] J.T. Gostick, A.Z. Weber, Electrochim. Acta 179 (2015) 137-145. 
[12] A.Z. Weber, J. Newman, J. Electrochem. Soc. 150 (2003).

[13] T.E. Springer, T.A. Zawodzinski, S. Gottesfeld, J. Electrochem. Soc. 138 (1991) 23342342.

[14] C. Yang, S. Srinivasan, A.B. Bocarsly, S. Tulyani, J.B. Benziger, J. Memb. Sci. 237 (2004).

[15] P.A. García-Salaberri, G. Hwang, M. Vera, A.Z. Weber, J.T. Gostick, Int. J. Heat Mass Transf. 86 (2015) 319-333.

[16] P.A. García-Salaberri, J.T. Gostick, G. Hwang, A.Z. Weber, M. Vera, J. Power Sources 296 (2015) 440-453.

[17] T. Rosén, J. Eller, J. Kang, N.I. Prasianakis, J. Mantzaras, F.N. Buchi, J. Electrochem. Soc. 159 (2012) F536-F544.

[18] D.G. Sanchez, D.G. Diaz, R. Hiesgen, I. Wehl, K.A. Friedrich, J. Electroanal. Chem. 649 (2010) 219-231.

[19] D.G. Sanchez, A. Ortiz, K.A. Friedrich, J. Electrochem. Soc. 160 (2013) F636-F644.

[20] D.G. Sanchez, T. Ruiu, K.A. Friedrich, J. Sanchez-Monreal, M. Vera, J. Electrochem. Soc. 163 (2015) F150-F159.

[21] Q. Duan, H. Wang, J. Benziger, J. Memb. Sci. 392-393 (2012) 88-94.

[22] S. Kim, M.M. Mench, J. Memb. Sci. 328 (2009) 113-120.

[23] Q. Zhao, P. Majsztrik, J. Benziger, J. Phys. Chem. B 115 (2011) 2717-2727.

[24] I.V. Zenyuk, P.K. Das, A.Z. Weber, J. Electrochem. Soc. 163 (2016) F691-F703.

[25] K.C. Neyerlin, H.A. Gasteiger, C.K. Mittelsteadt, J. Jorne, W. Gu, J. Electrochem. Soc. 152 (2005) A1073-A1080.

[26] S. Ge, X. Li, B. Yi, I.-M. Hsing, J. Electrochem. Soc. 152 (2005) A1149-A1157.

[27] B. Kientiz, H. Yamada, N. Nonoyama, A.Z. Weber, J. Fuel Cell Sci. Technol. 8 (2011) 011013-011019.

[28] M. Grimm, E.J. See, S.G. Kandlikar, Int. J. Hydrogen Energy 37 (2012) 12489-12503.

[29] B. Straubhaar, J. Pauchet, M. Prat, Int. J. Heat Mass Transf. 102 (2016) 891-901. 
[30] J.T. Gostick, M.A. Ioannidis, M.W. Fowler, M.D. Pritzker, J. Power Sources 194 (2009).

[31] I.V. Zenyuk, D.Y. Parkinson, G. Hwang, A.Z. Weber, Electrochem. Commun. 53 (2015) $24-28$.

[32] C. Quesnel, R. Cao, J. Lehr, A.-M. Kietzig, A.Z. Weber, J.T. Gostick, J. Phys. Chem. C 119 (2015) 22934-22944.

[33] A.D. Santamaria, P.K. Das, J.C. MacDonald, A.Z. Weber, J. Electrochem. Soc. 161 (2014) F1184-F1193.

[34] J.M. Sergi, S.G. Kandlikar, Int. J. Hydrogen Energy 36 (2011) 12381-12392.

[35] M. Koz, S.G. Kandlikar, J. Power Sources 243 (2013) 946-957.

[36] C. Chan, N. Zamel, X. Li, J. Shen, Electrochim. Acta 65 (2012) 13-21.

[37] R. Koresawa, Y. Utaka, Int. J. Heat Mass Transf. 76 (2014) 549-558.

[38] L.M. Pant, S.K. Mitra, M. Secanell, J. Power Sources 206 (2012) 153-160.

[39] J. Yuan, B. Sundén, Int. J. Heat Mass Transf. 69 (2014) 358-374.

[40] G.S. Hwang, A.Z. Weber, J. Electrochem. Soc. 159 (2012) F683-F692.

[41] Y. Wang, K.S. Chen, J. Mishler, S.C. Cho, X.C. Adroher, Appl. Energy 88 (2011) 981-1007.

[42] J. Wu, X.Z. Yuan, H. Wang, M. Blanco, J.J. Martin, J. Zhang, Int. J. Hydrogen Energy 33 (2008) 1735-1746.

[43] J. Wu, X. Zi Yuan, H. Wang, M. Blanco, J.J. Martin, J. Zhang, Int. J. Hydrogen Energy 33 (2008) 1747-1757.

[44] W. Mérida, D.A. Harrington, J.M. Le Canut, G. McLean, J. Power Sources 161 (2006) $264-274$.

[45] P. Oberholzer, P. Boillat, J. Electrochem. Soc. 161 (2013) F139-F152.

[46] M. Schulze, E. Gülzow, S. Schönbauer, T. Knöri, R. Reissner, J. Power Sources 173 (2007).

[47] T. Vidaković, M. Christov, K. Sundmacher, Electrochim. Acta 52 (2007) 5606-5613.

[48] J. Kleemann, F. Finsterwalder, W. Tillmetz, J. Power Sources 190 (2009) 92-102. 
[49] N. Zamel, X. Li, Prog. Energy Combust. Sci. 39 (2013) 111-146.

[50] M. Aghighi, M.A. Hoeh, W. Lehnert, G. Merle, J. Gostick, J. Electrochem. Soc. 163 (2016).

[51] P.A. García-Salaberri, M. Vera, Energy 113 (2016) 1265-1287.

[52] P.A. García-Salaberri, M. Vera, J. Power Sources 285 (2015) 543-558.

[53] P.A. García-Salaberri, M. Vera, R. Zaera, Int. J. Hydrogen Energy 36 (2011) 1185611870.

[54] P.A. García-Salaberri, M. Vera, I. Iglesias, J. Power Sources 246 (2014) 239-252.

[55] T. Jahnke, G. Futter, A. Latz, T. Malkow, G. Papakonstantinou, G. Tsotridis, P. Schott, M. Gérard, M. Quinaud, M. Quiroga, A.A. Franco, K. Malek, F. Calle-Vallejo, R. Ferreira de Morais, T. Kerber, P. Sautet, D. Loffreda, S. Strahl, M. Serra, P. Polverino, C. Pianese, M. Mayur, W.G. Bessler, C. Kompis, J. Power Sources 304 (2016) 207-233.

[56] M. Secanell, B. Carnes, A. Suleman, N. Djilali, Electrochim. Acta 52 (2007) 2668-2682.

[57] F.N. Büchi, S. Srinivasan, J. Electrochem. Soc. 144 (1997) 2767-2772.

[58] M. Watanabe, H. Uchida, M. Emori, J. Electrochem. Soc. 145 (1998) 1137-1141.

[59] J. Benziger, E. Chia, E. Karnas, J. Moxley, C. Teuscher, I.G. Kevrekidis, AIChE J. 50 (2004) 1889-1900.

[60] H.-T. Kim, K.-Y. Song, T.V. Reshetenko, S.-I. Han, T.-Y. Kim, S.-Y. Cho, M.-K. Min, G.-S. Chai, S.-C. Shin, J. Power Sources 193 (2009) 515-522.

[61] M. Adachi, T. Navessin, Z. Xie, B. Frisken, S. Holdcroft, J. Electrochem. Soc. 156 (2009) B782-B790.

[62] D.G. Sanchez, P.L. Garcia-Ybarra, Int. J. Hydrogen Energy 37 (2012) 7279-7288.

[63] R. Hanke-Rauschenbach, M. Mangold, K. Sundmacher, Rev. Chem. Eng. 27 (2011) 2352.

[64] J.R. Atkins, S.C. Savett, S.E. Creager, J. Power Sources 128 (2004) 201-207.

[65] M. Grötsch, R. Hanke-Rauschenbach, M. Mangold, J. Fuel Cell Sci. Technol. 5 (2008) 
0210011-0210019.

[66] M. Grötsch, M. Mangold, Chem. Eng. Sci. 63 (2008) 434-447.

[67] R. Hanke-Rauschenbach, M. Mangold, K. Sundmacher, J. Electrochem Soc. 155 (2008).

[68] A. Katsaounis, S.P. Balomenou, D. Tsiplakides, M. Tsampas, C.G. Vayenas, Electrochim. Acta 50 (2005) 5132-5143.

[69] A. Katsaounis, S. Balomenou, D. Tsiplakides, S. Brosda, S. Neophytides, C.G. Vayenas, Appl. Catal. B Environ. 56 (2005) 251-258.

[70] A. Katsaounis, M. Tsampas, S.P. Balomenou, D. Tsiplakides, C.G. Vayenas, Solid State Ionics 177 (2006) 2397-2401.

[71] S. Kirsch, R. Hanke-Rauschenbach, K. Sundmacher, J. Electrochem. Soc. 158 (2011) B44B53.

[72] A.A. Kulikovsky, H. Scharmann, K. Wippermann, Electrochem. Commun. 6 (2004) 729736.

[73] R. Lemoine-Nava, R. Hanke-Rauschenbach, M. Mangold, K. Sundmacher, Int. J. Hydrogen Energy 36 (2011) 1637-1653.

[74] J. Zhang, R. Datta, Electrochem. Solid-State Lett. 7 (2004) A37-A40.

[75] J. Zhang, J.D. Fehribach, R. Datta, J. Electrochem. Soc. 151 (2004) A689- A697.

[76] J.F. Moxley, S. Tulyani, J.B. Benziger, Chem. Eng. Sci. 58 (2003) 4705-4708.

[77] A. Liñán, F.A. Williams, Fundamental Aspects of Combustion, Oxford Univ. Press, New York, 1993.

[78] J. Benziger, E. Chia, J.F. Moxley, I.G. Kevrekidis, Chem. Eng. Sci. 60 (2005) 1743-1759.

[79] T. Mennola, M. Noponen, T. Kallio, M. Mikkola, T. Hottinen, J. Appl. Electrochem. 34 (2004) 31-36.

[80] I. Nazarov, K. Promislow, Chem. Eng. Sci. 61 (2006) 3198-3209.

[81] A.Z. Weber, R.M. Darling, J. Newman, J. Electrochem. Soc. 151 (2004) A1715-A1727.

[82] A.Z. Weber, J. Newman, J. Electrochem. Soc. 153 (2006) A2205-A2214. 
[83] SIGRACET ${ }^{\oplus}$ GDL Specification Sheet, SGL CARBON GmbH, Meitingen, Germany, 2015.

[84] A.P. Kaestner, S. Hartmann, G. Kühne, G. Frei, C. Grünzweig, L. Josic, F. Schmid, E.H. Lehmann, Nucl. Instrum. Meth. A 659 (2011) 387-393.

[85] P. Boillat, D. Kramer, B.C. Seyfang, G. Frei, E. Lehmann, G.G. Scherer, A. Wokaun, Y. Ichikawa, Y. Tasaki, K. Shinohara, Electrochem. Commun. 10 (2008) 546-550.

[86] P. Boillat, G. Frei, E.H. Lehmann, G.G. Scherer, A. Wokaun, Electrochem. Solid-State Lett. 13 (2010) B25-B27.

[87] O.S. Burheim, G.A. Crymble, R. Bock, N. Hussain, S. Pasupathi, A. Du Plessis, S. Le Roux, F. Seland, H. Su, B.G. Pollet, Int. J. Hydrogen Energy 40 (2015) 16775-16785.

[88] H. Meng, Int. J. Hydrogen Energy 34 (2009) 5488-5497.

[89] G. Luo, H. Ju, C.-Y. Wang, J. Electrochem. Soc. 154 (2007) B316-B321.

[90] Y. Wang, C.-Y. Wang, K.S. Chen, Electrochim. Acta 52 (2007) 3965-3975.

[91] Y. Wang, C.-Y. Wang, J. Electrochem. Soc. 154 (2007) B636-B643.

[92] S. Gamburzev, A.J. Appleby, J. Power Sources 107 (2002) 5-12.

[93] M. Bhaiya, A. Putz, M. Secanell, Electrochim. Acta 147 (2014) 294-309.

[94] C. Bao, W.G. Bessler, J. Power Sources 275 (2015) 922-934.

[95] Y. Wang, S. Basu, C.Y. Wang, J. Power Sources 179 (2008) 603-617.

[96] F. Jiang, C.-Y. Wang, Int. J. Hydrogen Energy 39 (2014) 942-950.

[97] P.O. Olapade, J.P. Meyers, R. Mukundan, J.R. Davey, R.L. Borup, J. Electrochem. Soc. 158 (2011) B536-B549.

[98] F. Liu, G. Lu, C.Y. Wang, J. Memb. Sci. 287 (2007) 126-131.

[99] H. Lin, T.-F. Cao, L. Chen, Y.-L. He, W.-Q. Tao, Int. J. Hydrogen Energy 37 (2012) 1187111886.

[100] U.N. Shrivastava, K. Tajiri, J. Electrochem. Soc. 163 (2016) F1072-F1083.

[101] P. Dobson, C. Lei, T. Navessin, M. Secanell, J. Electrochem. Soc. 159 (2012) B514-B523.

[102] Y. Liu, M.W. Murphy, D.R. Baker, W. Gu, C. Ji, J. Jorne, H.A. Gasteiger, J. Electrochem. 
Soc. 156 (2009) B970-B980.

[103] J.T. Gostick, M.W. Fowler, M.D. Pritzker, M.A. Ioannidis, L.M. Behra, J. Power Sources 162 (2006) 228-238.

[104] K. Jiao, X. Li, Electrochim. Acta 54 (2009) 6876-6891.

[105] H. Wu, X. Li, P. Berg, Electrochim. Acta 54 (2009) 6913-6927.

[106] I.V. Zenyuk, R. Taspinar, A.R. Kalidindi, E.C. Kumbur, S. Litster, J. Electrochem. Soc. 161 (2014) F3091-F3103.

[107] D. Gerteisen, T. Heilmann, C. Ziegler, J. Power Sources 187 (2009) 165-181

[108] H. Wu, Doctoral dissertation, University of Waterloo, Ontario, Canada, 2009.

[109] H. Wu, P. Berg, X. Li, Appl. Energy 87 (2010) 2778-2784.

[110] K. Jiao, Doctoral dissertation, University of Waterloo, Ontario, Canada, 2011.

[111] F.M. White, Fluid Mechanics, fifth ed., McGraw-Hill, 2003.

[112] Q. Ye, T. Van Nguyen, J. Electrochem. Soc. 154 (2007) B1242-B1251.

[113] F.D. Incropera, D.P. DeWitt, Fundamentals of Heat and Mass Transfer, John Wiley \& Sons, New York, 1995.

[114] A. Iranzo, M. Muñoz, F. Rosa, J. Pino, Int. J. Hydrogen Energy 35 (2010) 11533-11550.

[115] H. Sadeghifar, N. Djilali, M. Bahrami, J. Power Sources 248 (2014) 632-641.

[116] M.L.V. Ramires, C.A. Nieto de Castro, Y. Nagasaka, A. Nagashima, M.J. Assael, W.A. Wakeham, J. Phys. Chem. Ref. Data 24 (1995) 1377-1381.

[117] H. Meng, J. Power Sources 168 (2007) 218-228.

[118] A.A. Kulikovsky, J. Electrochem. Soc. 150 (2003) A1432-A1439.

[119] Z. Fishman, A. Bazylak, J. Electrochem. Soc. 158 (2011) B846-B851.

[120] R.R. Rashapov, J.T. Gostick, Transp. Porous Media (2016) 1-23.

[121] R. Rashapov, F. Imami, J.T. Gostick, Int. J. Heat Mass Transf. 85 (2015) 367-374.

[122] J.M. LaManna, S.G. Kandlikar, Int. J. Hydrogen Energy 36 (2011) 5021-5029.

[123] R. Flückiger, S.A. Freunberger, D. Kramer, A. Wokaun, G.G. Scherer, F.N. Büchi, 
Electrochim. Acta 54 (2008) 551-559.

[124] M. Andisheh-Tadbir, M. El Hannach, E. Kjeang, M. Bahrami, Int. J. Hydrogen Energy 40 (2015) 10242-10250.

[125] M.S. Ismail, D. Borman, T. Damjanovic, D.B. Ingham, M. Pourkashanian, Int. J. Hydrogen Energy 36 (2011) 10392-10402.

[126] A. El-Kharouf, T.J. Mason, D.J.L. Brett, B.G. Pollet, J. Power Sources 218 (2012) 393-404.

[127] D.R. Lide, Handbook of Chemistry and Physics, 88th ed., CRC Press, 2007.

[128] D.A.G. Bruggeman, Ann. Phys. 5 (1935) 636-664.

[129] M.C. Leverett, Trans. AIME 142 (1941) 152-69.

[130] S. Hess, Tensors for Physics, Springer, Berlin 2015.

[131] L. Valiño, R. Mustata, L. Dueñas, Int. J. Hydrogen Energy 39 (2014) 4030-4036.

[132] Q. Ye, X.-G. Yang, P. Cheng, Electrochim. Acta 69 (2012) 230-238.

\section{Nomenclature}

\section{Symbols}

$A$

cross-sectional area $\left[\mathrm{m}^{2}\right]$

$a_{\mathrm{H}_{2} \mathrm{O}}$

water activity [-]

$a_{+}$

electrochemical activity of solvated protons [-]

C

molar concentration $\left[\mathrm{mol} \mathrm{m}^{-3}\right]$

C

flow shape factor $[-]$

$c_{\mathrm{p}}$

specific heat at constant pressure $\left[\mathrm{Jg}^{-1} \mathrm{~K}^{-1}\right]$

$\overline{\bar{D}}_{\mathbf{i}, \mathbf{j}}^{\text {eff }}$

effective diffusivity tensor of species i in species $j\left[\mathrm{~m}^{2} \mathrm{~s}^{-1}\right]$

$d_{\mathrm{h}} \quad$ hydraulic diameter [m] 
total energy $[\mathrm{J}]$

EW

equivalent weight $\left[\mathrm{kg} \mathrm{mol}^{-1}\right]$

F

Faraday's constant $\left[\mathrm{C} \mathrm{mol}^{-1}\right]$

$f(\varepsilon)$

normalized dry effective diffusivity [-]

$f_{\mathrm{V}}$

water volume fraction in the electrolyte [-]

$g(s)$

relative effective diffusivity [-]

$H$

height $[\mathrm{m}]$

$h$

enthalpy [J]

$h_{\mathrm{gl}}$

evaporation/condensation latent heat $\left[\mathrm{J} \mathrm{kg}^{-1}\right]$

I

current density $\left[\mathrm{A} \mathrm{m}^{-2}\right]$; pixel intensity [-]

$I_{0}$

reference pixel intensity [-]

$\overline{\bar{I}}$

unit tensor [-]

$i_{0}$

exchange current density $\left[\mathrm{A} \mathrm{m}^{-3}\right]$

$J\left(s_{\text {mea }}\right)$

Leverett J-function [-]

$j_{\mathrm{e}^{-}}$

electronic flux $\left[\mathrm{A} \mathrm{m}^{-2}\right]$

$\boldsymbol{j}_{\mathrm{H}^{+}}$

ionic or protonic flux $\left[\mathrm{A} \mathrm{m}^{-2}\right]$

$j_{\text {lw }}$

liquid water mass flux $\left[\mathrm{kg} \mathrm{m}^{-2} \mathrm{~s}^{-1}\right]$

$\overline{\overline{\boldsymbol{K}}}$

absolute permeability tensor $\left[\mathrm{m}^{2}\right]$

$k_{\text {con }}$

condensation rate constant $\left[\mathrm{s}^{-1}\right]$

$k_{\mathrm{des}}$

desorption rate constant $\left[s^{-1}\right]$

$k_{\text {evp }}$

evaporation rate constant $\left[\mathrm{Pa} \mathrm{s}^{-1}\right]$

$k_{\text {sor }}$

sorption rate constant $\left[\mathrm{s}^{-1}\right]$

$\overline{\overline{\boldsymbol{k}}}_{\mathbf{r}}$

relative permeability tensor [-]

$\overline{\bar{k}}^{\text {eff }}$

effective thermal conductivity tensor $\left[\mathrm{W} \mathrm{m}^{-1} \mathrm{~K}^{-1}\right]$

$L$

longitudinal length in $y$-direction [m] 
molecular weight $\left[\mathrm{kg} \mathrm{mol}^{-1}\right]$

mass [kg]

$\dot{m}$

mass flow rate $\left[\mathrm{kg} \mathrm{s}^{-1}\right]$

$N$

molar flux $\left[\mathrm{mol} \mathrm{m}^{-2} \mathrm{~s}^{-1}\right]$

$\dot{N}$

molar flow rate $\left[\mathrm{mol} \mathrm{s}^{-1}\right]$

$n$

number of molecules [-]

n

outward unit normal vector [-]

$n_{d}^{W}$

OCV

$p$

$p_{\mathrm{c}}$

$Q$

$R$

$\mathrm{RH}$

$R R$

S

$\Delta S$

$S$

$T$

$t$

$\boldsymbol{u}$

V

$V_{\mathrm{m}}$

$X_{\mathrm{i}}$

$x$

$Y_{\mathrm{i}}$

electro-osmotic drag coefficient of water [-]

open-circuit voltage [V]

pressure $[\mathrm{Pa}]$

capillary pressure, defined as $p_{\mathrm{c}}=p_{\mathrm{g}}-p_{\mathrm{l}}[\mathrm{Pa}]$

volumetric flow rate $\left[\mathrm{m}^{3} \mathrm{~s}^{-1}\right]$

universal gas constant $\left[\mathrm{J} \mathrm{mol}^{-1} \mathrm{~K}^{-1}\right]$; ohmic resistance $\left[\Omega \mathrm{m}^{2}\right]$

relative humidity [-]

volumetric reaction rate $\left[\mathrm{mol} \mathrm{m}^{-3}\right]$

source term; see Appendix A

entropy change $\left[\mathrm{J} \mathrm{mol}^{-1} \mathrm{~K}^{-1}\right]$

liquid saturation (ratio of water volume to void volume) [-]

temperature $[\mathrm{K}]$

time $[s]$

velocity vector $\left[\mathrm{m} \mathrm{s}^{-1}\right]$

voltage $[\mathrm{V}]$; volume $\left[\mathrm{m}^{3}\right]$

molar volume $\left[\mathrm{m}^{3} \mathrm{~mol}^{-1}\right]$

mole fraction of species i [-]

in-plane $x$-coordinate $[\mathrm{m}]$

mass fraction of species i [-] 


\section{Greek letters}

$\alpha$

$\beta_{\mathrm{i}, \mathrm{j}}$

$\Gamma$

$\gamma$

$\Delta$

$\delta$

$\varepsilon$

$\eta$

$\theta_{\mathrm{c}}$

$\lambda$

$\mu$

$\xi$

$\rho$

$\Sigma$

$\sigma$

$\overline{\bar{\sigma}}_{\mathbf{e}^{-}}^{\text {eff }}$

$\overline{\bar{\sigma}}_{\mathbf{H}^{+}}^{\text {eff }}$

$\overline{\overline{\boldsymbol{\tau}}}$

$\Phi$

$\phi_{\mathrm{e}^{-}}$

$\phi_{\mathrm{H}^{+}}$ secondary in-plane $y$-coordinate [m]

width $[\mathrm{m}]$

through-plane $z$-coordinate [m]

transfer coefficient [-]

parameter in Eq. (A.4) [-]

mute variable; see Eq. (3)

reaction order [-]

increment

thickness [m]

dry porosity [-]

overpotential [V]

contact angle [-]

water content per sulfonic acid group [-]

dynamic viscosity $\left[\mathrm{kg} \mathrm{m}^{-1} \mathrm{~s}^{-1}\right]$

stoichiometric flow ratio [-]

density $\left[\mathrm{kg} \mathrm{m}^{-3}\right]$

attenuation coefficient of neutrons in liquid water $\left[\mathrm{m}^{-1}\right]$

surface tension coefficient $\left[\mathrm{N} \mathrm{m}^{-1}\right]$

effective electrical conductivity tensor $\left[\mathrm{S} \mathrm{m}^{-1}\right]$

effective ionic or protonic conductivity tensor $\left[\mathrm{S} \mathrm{m}^{-1}\right]$

viscous stress tensor $[\mathrm{Pa}]$

mute variable; see Section A.4

electronic potential [V]

ionic or protonic potential [V] 


\section{Subscripts}

a

abpp

ach

$\mathrm{acl}$

act

agdl

ampl

bpp

cbpp

cch

$\mathrm{ccl}$

cgdl

ch

$\mathrm{cmpl}$

diff

e

$\mathrm{e}^{-}$

eod

eq

$\mathrm{fr}$

g

gdl

$\mathrm{H}_{2}$ anode

anode bipolar plate

anode channel

anode catalyst layer

activation

anode gas diffusion layer

anode microporous layer

bipolar plate

cathode

cathode bipolar plate

cathode channel

cathode catalyst layer

cathode gas diffusion layer

channel

cathode microporous layer

diffusion

electrolyte

electron

electro-osmotic drag

equilibrium

outer frame

gas phase

gas diffusion layer

hydrogen 


$\begin{array}{ll}\mathrm{H}_{2} \mathrm{O} & \text { water vapor } \\ \mathrm{H}^{+} & \text {proton } \\ \text { hps } & \text { high-performance state } \\ \mathrm{Iw} & \text { low-performance state } \\ \text { mea } & \text { liquid water or liquid phase } \\ \text { mem } & \text { membrane electrode assembly } \\ \text { mpl } & \text { membrane } \\ \mathrm{N}_{2} & \text { microporous layer } \\ \mathrm{O}_{2} & \text { nitrogen } \\ \text { prod } & \text { oxygen } \\ \text { rev } & \text { production } \\ \text { rib } & \text { reversible } \\ \end{array}$

\section{Superscripts}

$\begin{array}{ll}\text { avg } & \text { average } \\ \text { bulk } & \text { bulk property } \\ \text { dry } & \text { dry conditions } \\ \text { eff } & \text { effective } \\ \text { in } & \text { inlet channel condition } \\ \text { ip } & \text { in-plane direction } \\ \text { out } & \text { outlet channel condition } \\ \text { ref } & \text { reference } \\ \text { rc } & \text { removal capacity } \\ \text { sat } & \text { saturated conditions } \\ \text { std } & \text { standard conditions }\left(T=0{ }^{\circ} \mathrm{C}, p=1 \mathrm{~atm}\right) \\ \text { th } & \text { threshold }\end{array}$




\section{Abbreviations and Acronyms}

2D

$3 D$

BPP

$\mathrm{CL}$

EOD

GDL

HFR

HP

LP

MEA

MPL

OCV

PEFC

PEM

$\mathrm{RH}$ two-dimensional

three-dimensional

bipolar plate

catalyst layer

electro-osmotic drag

gas diffusion layer

high-frequency resistance

high performance

low performance

membrane electrode assembly

microporous layer

open-circuit voltage

proton exchange fuel cell

proton exchange membrane

relative humidity 